medRxiv preprint doi: https://doi.org/10.1101/2020.08.11.20172569; this version posted August 11, 2020. The copyright holder for this preprint (which was not certified by peer review) is the author/funder, who has granted medRxiv a license to display the preprint in It is made available under a CC-BY-NC-ND 4.0 International license .

\title{
Metabolomics dissection of depression heterogeneity and related cardiometabolic risk
}

Tahani Alshehri ${ }^{1}$, Dennis O Mook- Kanamori ${ }^{1,2}$, Ko Willems van Dijk ${ }^{3,4}$, Richard Dinga ${ }^{5}$, Brenda WJH Penninx ${ }^{6}$, Frits R Rosendaal ${ }^{1}$, Saskia le Cessie ${ }^{1,7}$, Yuri Milaneschi ${ }^{6,8}$

Authors information

1 Department of Clinical Epidemiology, Leiden University Medical Center, Leiden, The

Netherlands.

2 Department of Public Health and Primary Care, Leiden University Medical Center, Leiden, The Netherlands.

3 Department of Human Genetics, Leiden University Medical Center, Leiden, The

Netherlands.

4 Department of Internal Medicine, Division of Endocrinology, Leiden University Medical

Center, Leiden, The Netherlands.

5. Donders Institute for Brain, Cognition and Behaviour, Radboud University, Nijmegen, The

Netherlands.

6 Department of Psychiatry, Amsterdam Public Health Research Institute, Amsterdam

Neuroscience, Amsterdam UMC, Vrije Universiteit, The Netherlands.

7 Department of Biomedical Data sciences, Leiden University Medical Center, Leiden, The Netherlands.

8 GGZ inGeest, Research \& Innovation, Amsterdam, The Netherlands.

Key words:

Metabolomics, Depression, Metabolic Syndrome, Body Fat Distribution, Body Mass Index.

Running title:

Disentangle depression by cardiometabolic risk

Disclosures of conflicts of interest

Dennis Mook-Kanamori reports personal fees from Metabolon, Inc, outside the submitted work, and Brenda Penninx reports grants from Jansen Research and Development, LLC, and grants from Boehringer Ingelheim, outside the submitted work. All other co-authors declared no conflict of interest.

Corresponding author

Tahani Alshehri

Correspondence address: Leiden University Medical center (LUMC), Albinusdreef 2,

Postzone C7-P, Postbus 9600, 2300 RC Leiden, the Netherlands

Email address: t.m.alshehri@lumc.nl

Telephone: +31(0)71526206

Word count: 4125

NOTE: This preprint reports new research that has not been certified by peer review and should not be used to guide clinical practice. 
medRxiv preprint doi: https://doi.org/10.1101/2020.08.11.20172569; this version posted August 11, 2020. The copyright holder for this preprint (which was not certified by peer review) is the author/funder, who has granted medRxiv a license to display the preprint in It is made available under a CC-BY-NC-ND 4.0 International license.

\section{$\underline{\text { Abstract }}$}

Background: A recent hypothesis postulates the existence of an "immune-metabolic depression" (IMD) dimension characterized by metabolic dysregulations. Combining data on metabolomics and depressive symptoms, we aimed to identify depressions associated with an increased risk of adverse metabolic alterations.

\section{Method:}

Clustering data were from 1094 individuals with current major depressive disorder and measures of 149 metabolites from a ${ }^{1} \mathrm{H}-\mathrm{NMR}$ platform and 30 depressive symptoms (IDSSR30). Canonical correlation analyses (CCA) were used to identify main independent metabolite-symptom axes of variance. Then, for the replication, we examined the association of the identified dimensions with metabolites from the same platform and cardiometabolic endpoints in an independent population-based cohort $(\mathrm{n}=6572)$.

Results: CCA identified an overall depression dimension and a dimension resembling IMD, in which symptoms such as sleeping too much, increased appetite, and low energy level had higher relative loading. In the independent sample, the overall depression dimension was associated with lower levels of metabolites linked to cardiometabolic risk, such as HOMA1B -0.09 (95\% CI:-0.13--0.06), and visceral adipose tissue $-0.15 \mathrm{~cm}^{2}$ (95\% CI:-0.20--0.10). In contrast, the IMD dimension was associated with well-known adverse cardiometabolic metabolites such as higher visceral adipose tissue $0.11 \mathrm{~cm}^{2}$ (95\% CI:0.06-0.16), HOMA-1B 0.08 (95\% CI: 0.05-0.12), and lower HDL levels -0.04 mmol/L (95\% CI:-0.07--0.01).

Conclusions: Combining metabolomics and clinical symptoms we identified a replicable depression dimension associated with adverse metabolic alterations, in line with the IMD hypothesis. Patients with IMD may be at higher cardiometabolic risk and may benefit from specific treatment targeting underlying metabolic dysregulations. 
medRxiv preprint doi: https://doi.org/10.1101/2020.08.11.20172569; this version posted August 11, 2020. The copyright holder for this preprint (which was not certified by peer review) is the author/funder, who has granted medRxiv a license to display the preprint in It is made available under a CC-BY-NC-ND 4.0 International license.

\section{Introduction}

Cardiovascular disease (CVD) together with major depressive disorder (MDD) are leading causes of mortality and disease burden worldwide (Dhar \& Barton, 2016; Mathers \& Loncar, 2006). Each of these conditions may predispose for the other, and the presence of one condition worsens the prognosis of the other (Penninx, Milaneschi, Lamers, \& Vogelzangs, 2013). Although the mechanism of this comorbidity is still not fully understood, adverse metabolic alterations may serve as the element that connects the two conditions (Dhar \& Barton, 2016; Khandaker et al., 2019; Penninx et al., 2013). A recent large scale epidemiological study in >15,000 individuals analyzing the association between depression and more than 200 lipid related metabolites (Bot et al., 2020) found that depression is associated with a metabolic signature that is also found in CVD patients (Holmes et al., 2018). This metabolic signature was characterized by a shift in the lipids levels encompassing less HDL cholesterol and more very low density lipoproteins (VLDL) and triglycerides, in line with a higher metabolic syndrome profile in depression (Bot et al., 2020). This metabolic signature may represent a substrate linking depression to cardiometabolic diseases (Schwabe et al., 2019). Another large population-based study in >350,000 individuals (Khandaker et al., 2019) concluded that the risk factors of CVD (i.e., inflammatory markers (CRP, IL-6) and biomarker (triglycerides)) are likely causal for the development of depression. MDD is a highly heterogeneous disorder: patients with the same MDD diagnoses according to DSM-V (Diagnostic and Statistical Manual of Mental Disorders) (American Psychiatric Association, 2013) may experience very different symptom profiles (Lux \& Kendler, 2010). These different clinical expressions may be, in turn, differentially related to underlying biological dysregulations. Recent evidence suggests that the MDD link with adverse metabolic alterations and inflammatory dysregulation (i.e., immuno-metabolic dysregulation (Milaneschi, Lamers, Berk, \& Penninx, 2020) seems stronger in patients reporting depressive 
medRxiv preprint doi: https://doi.org/10.1101/2020.08.11.20172569; this version posted August 11, 2020. The copyright holder for this preprint (which was not certified by peer review) is the author/funder, who has granted medRxiv a license to display the preprint in It is made available under a CC-BY-NC-ND 4.0 International license.

symptoms characterized by altered energy intake/expenditure balance, such as excessive sleepiness, hyperphagia, weight gain, and fatigue (Lamers et al., 2010; Lasserre et al., 2017; Sullivan, Prescott, \& Kendler, 2002). Building on this evidence, a recent hypothesis (Milaneschi et al., 2020) postulated the existence of an "immune-metabolic depression" (IMD) dimension emerging from the clustering of energy related clinical symptoms with inflammatory and metabolic dysregulations. Nonetheless, further empirical evidence is needed to fully characterize the clustering between specific symptom profiles and immunometabolic biological dysregulations (Fried \& Nesse, 2015). The identification of depression dimensions characterized by this clustering of clinical and biological features could give us a better understanding of the shared biological mechanisms between depression and cardiometabolic conditions and potential opening for interventions aimed at avoiding their reciprocal influence (Baune et al., 2012; Fried \& Nesse, 2015; Lamers, Milaneschi, de Jonge, Giltay, \& Penninx, 2018). Furthermore, the identification of individuals with this specific form of depression may create awareness amongst healthcare providers and the need to perform more rigorous cardiometabolic health checks and interventions.

The main aim of the present study was to identify depression dimensions associated with increased risk of adverse metabolic profile by combining data on metabolomics and depressive symptoms. First, we applied a data-driven method to identify patterns of correlations between depressive symptoms and metabolites from a lipid-focused metabolomic platform in >1,000 MDD patients. Then, for the replication, we examined the association between the identified dimensions and 51 metabolites from the same panel, and clinical cardiometabolic biomarkers such as fasting glucose, insulin resistance, total and abdominal adiposity in an independent population-based cohort $(n=6572)$. 
medRxiv preprint doi: https://doi.org/10.1101/2020.08.11.20172569; this version posted August 11, 2020. The copyright holder for this preprint (which was not certified by peer review) is the author/funder, who has granted medRxiv a license to display the preprint in It is made available under a CC-BY-NC-ND 4.0 International license .

\section{$\underline{\text { Method }}$}

\section{Study design}

The current analysis consists of two parts: the metabolite-symptom clustering and the replication (Figure 1). In the first part, we used a data-driven approach to dissect the heterogeneity of depression and to identify main independent metabolite-symptom dimension of variance in 1094 individuals with current (i.e., within the past 6 months) depression from the Netherlands Study of Depression and Anxiety cohort (NESDA). Then, in the replication, we examined the association between the dimensions identified and the cardiometabolic metabolites (51 lipids, fatty acids, and low-molecular-weight metabolites) and endpoints in an independent dataset of 6572 participants from the general population enrolled in the Netherlands Epidemiology of Obesity (NEO) study. The research protocol of NESDA was approved by the medical ethical committees of the following participating universities: Leiden University Medical Center (LUMC), Vrije University Medical Center (VUMC), and University Medical Center Groningen (UMCG). The NEO study was approved by medical ethics committee of Leiden University Medical Center (LUMC). All participants gave written informed consent.

\section{Part 1: Metabolite-symptom clustering}

We performed this analysis on 1094 participants diagnosed with current (i.e., within the past 6 months) MDD via the structured Composite Interview Diagnostic Instrument (CIDI, version 2.1) (Robins et al., 1988) from NESDA (Penninx et al., 2008). After an overnight fast, EDTA plasma was collected and stored in aliquots at $-80{ }^{\circ} \mathrm{C}$ until further analysis by ${ }^{1} \mathrm{H}-$ NMR Nightingale Health Ltd, Helsinki, Finland (Soininen, Kangas, Wurtz, Suna, \& AlaKorpela, 2015) metabolomics platform. This metabolomics platform consists of 230 metabolites or metabolite ratios and can be classified into 3 clusters (Wurtz et al., 2017) as 
medRxiv preprint doi: https://doi.org/10.1101/2020.08.11.20172569; this version posted August 11, 2020. The copyright holder for this preprint (which was not certified by peer review) is the author/funder, who has granted medRxiv a license to display the preprint in It is made available under a CC-BY-NC-ND 4.0 International license.

follow: 1) lipids, fatty acids, and low-molecular-weight metabolites $(\mathrm{n}=51) ; 2)$ lipid composition and particle concentration measures of lipoprotein subclasses ( $n=98)$; and 3) metabolite ratios $(n=81)$. In this analysis, we focused on the first two classes $(n=149)$. Metabolite ratios were not used due to redundancy. Values of metabolites that could not be quantified were set as missing for all individuals. Furthermore, metabolite values with outlying concentrations ( $\pm 5 \mathrm{SD}$ ) were additionally set as missing. A value of 1 was added to all metabolite values, which were subsequently natural log-transformed to approximate normality. The obtained values were scaled to standard deviation units to enable comparison. This protocol for processing the metabolomic data was suggested by the manufacturer of the platform and has been consistently applied in several large-scale epidemiological studies (Bot et al., 2020; Onderwater et al., 2019). Blood samples were analyzed in two batches (April 2014 and December 2014) by ${ }^{1}$ H-NMR Nightingale Health Ltd, Helsinki, Finland) (Soininen et al., 2015). A variable indexing batches was added as covariate in the analysis in order to account for potential batch effect. We regressed the metabolites on age and batch effect in order to remove their confounding effect.

During the baseline assessment, the presence of major depressive disorder was determined with the Diagnostic and Statistical Manual of Mental Disorders, Fourth Edition (DSM-IV)based Composite Interview Diagnostic Instrument (CIDI, version 2.1, World Health Organization, 1997) by specially trained research staff. The CIDI has a high reliability and validity for assessment of depressive disorders (Wittchen, 1994). In addition, participants were asked to complete a Dutch translation of the Inventory of Depressive Symptomatology (IDS-SR30), which assesses (via a 4-level response system) the presence of 30 depressive symptoms during the last week and their severity (Rush, Gullion, Basco, Jarrett, \& Trivedi, 1996). 
medRxiv preprint doi: https://doi.org/10.1101/2020.08.11.20172569; this version posted August 11, 2020. The copyright holder for this preprint (which was not certified by peer review) is the author/funder, who has granted medRxiv a license to display the preprint in It is made available under a CC-BY-NC-ND 4.0 International license.

Body mass index (BMI), waist circumference and fasting glucose level were also used in the analysis to examine the relationship between CCA output and cardiometabolic health. Height and weight were measured to calculate BMI in $\mathrm{kg} / \mathrm{m}^{2}$ as an index of general adiposity. Waist circumference $(\mathrm{cm})$, defined as the minimal abdominal circumference between the lower edge of the rib cage and the iliac crests, was measured by trained clinical staff according to a standardized procedure as index of abdominal adiposity. Glucose was measured from fasting plasma samples by using standard laboratory technique.

\section{Statistical analysis for metabolite-symptom clustering}

Our goal was to identify independent dimensions emerging from patterns of correlations between depressive symptoms and metabolites. To do this, we used canonical correlation analysis (CCA, (Hotelling, 1936)). CCA is a method that given two sets of variables X and Y (in this case, metabolites and depressive symptoms), find a linear combination of $\mathrm{X}$ that is maximally correlated with a linear combination of $\mathrm{Y}$ (i.e., a weighted sum of each variable). The linear transformation weights were chosen such that the correlation between resulting linear combinations is maximized. These linear combinations are called canonical variates (i.e., $\mathrm{mCV}$ (metabolites canonical variates), $\mathrm{sCV}$ (symptoms canonical variates)). Together $\mathrm{mCV}$ and $\mathrm{sCV}$ are called a canonical pair and the correlation between this canonical pair is called the canonical correlation. In a specific dataset, it is possible to find multiple canonical pairs such that canonical pairs are uncorrelated to each other and equal to the number of variables in the smallest dataset. In our analysis we chose to proceed with the first two canonical pairs that provided more information about the two sets of variables. The relationship between the created canonical variables of depressive symptoms and metabolites from the same panel and cardiometabolic endpoints was validated in an independent sample (see replication section). 
medRxiv preprint doi: https://doi.org/10.1101/2020.08.11.20172569; this version posted August 11, 2020. The copyright holder for this preprint (which was not certified by peer review) is the author/funder, who has granted medRxiv a license to display the preprint in It is made available under a CC-BY-NC-ND 4.0 International license.

Because metabolites are highly correlated to each other, we first reduced the 149 metabolites residuals into 3 variables that explained $75 \%$ of variance in the data using principal component analysis (PCA). PCA is a method that transforms the variables so they maximize the variance in the data, from which we selected components with the highest variance (David \& Jacobs, 2014). Therefore, the next analysis was performed on metabolic variables explained the highest variance (principal components (PC)) and 30 depressive symptoms. In order to explore how the first two metabolic canonical variates (mCVI and mCVII) classify individuals in terms of conventional cardiometabolic biomarkers (i.e., BMI, waist circumference, fasting glucose) we plotted the predicted level of the biomarkers as a function of the two metabolic canonical variates (i.e., smoothing function was used for the prediction). After that, to evaluate the symptoms contribution to the two canonical correlation, for each symptom we calculated the symptoms loadings, expressed in Pearson's correlation coefficient, with the first two symptoms canonical variates (sCVI and sCVII).

\section{Part 2: Replication}

To replicate the results of previous step, we investigated the association between the dimensions identified in the previous step via CCA and metabolomics and clinical endpoints in the Netherlands Epidemiology of Obesity (NEO) study (de Mutsert et al., 2013). The depressive symptoms in NEO study were assessed by IDS-SR30 (Rush et al., 1996), the same instrument used in the NESDA study. For the purpose of replication, we included only the first class from the ${ }^{1} \mathrm{H}-\mathrm{NMR}$ platform (i.e., 51 lipids, fatty acids, and low-molecular-weight metabolites) in the main results. For completeness of data, we showed the result of the entire metabolomic platform in the supplementary results since they have large overlap with the standard clinical lipid profile. We used the same protocol for processing this metabolomic data in the clustering step. The cardiometabolic endpoints are described in detail elsewhere 
medRxiv preprint doi: https://doi.org/10.1101/2020.08.11.20172569; this version posted August 11, 2020. The copyright holder for this preprint (which was not certified by peer review) is the author/funder, who has granted medRxiv a license to display the preprint in It is made available under a CC-BY-NC-ND 4.0 International license.

(de Mutsert et al., 2013). From fasting glucose and insulin concentrations, we calculated the Homeostasis Model Assessment for Insulin Resistance (HOMA-IR) and HOMA of beta-cell function (HOMA-1B) as markers of hepatic insulin resistance and steady-state insulin secretion (Matthews et al., 1985). HOMA-IR was calculated as fasting insulin $(\mu \mathrm{U} / \mathrm{mL}) \mathrm{x}$ fasting glucose (mmol/L)/22.5 and HOMA-1B\% as $20 \mathrm{x}$ fasting glucose (mmol/l)-3.5 (Matthews et al., 1985; Wallace, Levy, \& Matthews, 2004).

\section{Statistical analysis for replication}

To index the two dimensions identified in the clustering step, we created two weighted depressive symptom scores. We weighted each individual item of the IDS-SR30 based on extracted CCA weights from the previous step. Then, we summed the weighted depressive symptoms to create two weighted IDS scores. We used linear regression to examine the relationship between the two weighted IDS scores as the independent variable and $51{ }^{1} \mathrm{H}$ NMR metabolites and cardiometabolic endpoints (BMI, total body fat, waist circumference, visceral adipose tissue, HbA1c, fasting glucose, HOMA-IR, HOMA-1B, total cholesterol, LDL-cholesterol, HDL-cholesterol, and triglycerides) as dependent variables. We fitted four linear regression models, the crude model, model 1, model 2 and, model 3. Model 1 was adjusted for age, sex, and educational level. Model 2 was adjusted for age, sex, educational level, smoking, alcohol consumption, physical activity, and ethnicity. Model 3 was model 2 with additional adjustment for lipid-lowering drugs, and antidepressants. In the investigation of the association between weighted depressive symptoms score and the $51{ }^{1} \mathrm{H}-\mathrm{NMR}$ metabolites, the false discovery rate (FDR) method was applied to correct for the multiple testing. As the NEO study is a population-based study with oversampling of individuals with a BMI $>27 \mathrm{~kg} / \mathrm{m}^{2}$, all results are based on weighted analysis toward BMI distribution in the general Dutch population. 
medRxiv preprint doi: https://doi.org/10.1101/2020.08.11.20172569; this version posted August 11, 2020. The copyright holder for this preprint (which was not certified by peer review) is the author/funder, who has granted medRxiv a license to display the preprint in It is made available under a CC-BY-NC-ND 4.0 International license.

\section{$\underline{\text { Results }}$}

\section{Metabolite-Symptom clustering}

Table 1 shows the main demographic, health- and depression-related characteristic, in the NESDA sample of individuals with current MDD. Data reduction of metabolomics was performed using PCA, identifying three principle components that explained together $75 \%$ of the variance. The resulting 3 principle components were used in the CCA analysis and were correlated to the 30 depressive symptoms, to identify the main independent metabolitesymptom dimensions of variance based on their correlation. The correlation between the linear transformation (weights) of metabolites principal components (metabolic canonical variate I, mCVI) and depressive symptoms (symptom canonical variate I, sCVI) was 0.30 explaining $54 \%$ of the metabolite-symptom covariance, for the second pair of canonical variates the correlation between $\mathrm{mCVII}$ and sCVII was 0.24 explaining $32 \%$ of the metabolite-symptom covariance (Supplemental figure 2).

In order to explore how the first two metabolic canonical variates (mCVI and mCVII) classify individuals in terms of conventional cardiometabolic biomarkers (i.e., BMI, waist circumference, fasting glucose) we plotted the predicted level of the biomarkers as a function of the two metabolic canonical variates. Level plots depicted in Figure 2 show that high values in BMI, waist circumference, and fasting glucose tended to cluster at high level of mCVII and low levels for mCVI. Figure 3 shows the loading, expressed as Pearson's correlation coefficient, of IDS-SR item on the two symptoms canonical variates (sCVI and sCVII). In the first variate, correlation coefficients were substantially consistent across the entire spectrum of items, including mood, cognitive and somatic symptoms. In the second variate, the loading of specific items such as difficulties falling asleep, sleeping too much, increase weight and appetite, low energy level and gastrointestinal problems were relatively higher as compared to the other symptoms. 
medRxiv preprint doi: https://doi.org/10.1101/2020.08.11.20172569; this version posted August 11, 2020. The copyright holder for this preprint (which was not certified by peer review) is the author/funder, who has granted medRxiv a license to display the preprint in It is made available under a CC-BY-NC-ND 4.0 International license.

We interpreted the first canonical variate CVI, explaining a larger proportion of symptommetabolite covariance (54\%), as an overall depression dimension characterized by a wide array of symptoms (sCVI, Figure 3) and lower levels of cardiometabolic biomarkers (mCVI, Figure 2). The second variate, explaining $32 \%$ of the symptom-metabolite covariance, partially resembled the postulated IMD construct (Milaneschi et al., 2020), with relevance for energy-related behavioral symptoms and higher cardiometabolic biomarkers. Thus, for interpretability we labelled the two canonical variates, respectively, "overall depression" and "IMD".

\section{Replication}

The baseline characteristics for all 6572 participants of the NEO cohort included in the replication step are shown in Supplemental table 1. The mean age in the NEO population was 55.7 years (standard deviation (SD)): 6 years, and the median of the IDS-SR30 questionnaire was 8.0 points $(4,13)$. We created two weighted depressive symptoms scores labelled "overall depression" and "IMD" with the weights derived in CCA for, respectively, the first and second canonical variate. We examined the association of these weighted scores with 51 metabolites and cardiometabolic endpoints (BMI, total body fat, waist circumference, visceral adipose tissue, HbA1c, fasting glucose, HOMA-IR, HOMA-1B, total cholesterol, LDL-cholesterol, HDL-cholesterol and triglycerides). Figures 4A and 4B depict the linear regression effect estimates and $95 \%$ confidence intervals for the association between the weighted symptom sum score and the 51 lipids, fatty acids, and low-molecular-weight metabolites, and cardiometabolic endpoints adjusted for age, sex, and educational level (model 1). Results of all crude and adjusted models can be found in Supplemental table 2 and 3. In general the two weighted symptoms scores showed divergent pattern of results: IMD showed metabolic alterations linked to increased cardiometabolic risk, while overall depression score showed opposite associations. IMD was associated with (per standard 
medRxiv preprint doi: https://doi.org/10.1101/2020.08.11.20172569; this version posted August 11, 2020. The copyright holder for this preprint (which was not certified by peer review) is the author/funder, who has granted medRxiv a license to display the preprint in It is made available under a CC-BY-NC-ND 4.0 International license .

deviation) higher glycoprotein acetylase $0.12 \mathrm{mmol} / \mathrm{L}$ (95\% CI: 0.08-0.15), apolipoprotein B 0.08 g/L (95\% CI:-0.05-0.12), triglyceride levels 0.12 mmol/L (95\% CI: 0.09-0.15), total body fat $0.09 \%$ (95\% CI:0.06-0.11), visceral adipose tissue $0.11 \mathrm{~cm}^{2}$ (95\% CI:0.06-0.16), HOMA-1B 0.08 (95\% CI: 0.05-0.12), and lower HDL levels -0.04 mmol/L (95\% CI: -0.07-0.01). In contrast, the overall depression was associated with (per standard deviation) glycoprotein acetylase $-0.16 \mathrm{mmol} / \mathrm{L}$ (95\% CI: -0.20--0.13), apolipoprotein B -0.06 g/L (95\% CI:-0.09--0.02), triglyceride levels -0.12 mmol/L (95\% CI: -0.16--0.09), total body fat 0.11\% (95\% CI:-0.13--0.09), visceral adipose tissue $-0.15 \mathrm{~cm}^{2}$ (95\% CI:-0.20-0.10), HOMA-1B -0.09 (95\% CI:-0.13--0.06), and HDL levels 0.10 mmol/L (95\% CI: 0.07-0.13) (Figure 4A, 4B). We repeated the analysis of the linear regression with additional adjustment for lipid lowering drugs (model 3) and results did not notably change (Supplement table 2,3). 
medRxiv preprint doi: https://doi.org/10.1101/2020.08.11.20172569; this version posted August 11, 2020. The copyright holder for this preprint (which was not certified by peer review) is the author/funder, who has granted medRxiv a license to display the preprint in It is made available under a CC-BY-NC-ND 4.0 International license.

\section{$\underline{\text { Discussion }}$}

Using a data-driven method, we combined metabolomics and clinical symptoms data to dissect depression heterogeneity and identify independent underlying dimensions in participants diagnosed with current MDD from NESDA cohort $(n=1094)$. Then, we replicated our results by examining the association between the identified dimensions and $51^{1}$ metabolites from the same lipidomic panel, and cardiometabolic endpoints in an independent dataset of 6572 participants from the general population enrolled in the Netherlands Epidemiology of Obesity (NEO) study.

We identified a major dimension reflecting overall depression explaining a large proportion (54\%) of symptom-metabolite covariance, and characterized by a wide array of symptoms and reduced levels of cardiometabolic biomarkers. A second dimension explaining $34 \%$ of symptom-metabolite covariance emerged as characterized by higher cardiometabolic biomarkers and higher relative relevance for symptoms such as difficulties falling asleep, sleeping too much, increase weight and appetite, low energy level and gastrointestinal problems. This second dimension partially resemble the recently pustulated (Milaneschi et al., 2020) construct of IMD, defined by the clustering of inflammatory and metabolic dysregulations with behavioral energy-related symptom. We labelled therefore the first and second dimensions "overall depression " and "IMD”. In the replication step, we found that the IMD dimension was associated with a metabolic profile similar to the metabolic profile reported in individuals with high cardiometabolic risk profile such as higher triglyceride levels, lower HDL-cholesterol levels, higher visceral adipose tissue, higher branched chain amino acids, and higher glycoprotein acetylase and insulin resistance. In contrast, the associations between these metabolites and the overall depression dimension were in the opposite direction, indicating a lower cardiometabolic risk. 
medRxiv preprint doi: https://doi.org/10.1101/2020.08.11.20172569; this version posted August 11, 2020. The copyright holder for this preprint (which was not certified by peer review) is the author/funder, who has granted medRxiv a license to display the preprint in It is made available under a CC-BY-NC-ND 4.0 International license .

The present finding confirm the presence of partially divergent correlation structures between specific depressive symptom profiles and metabolic dysregulations. This is in line with the previous research in this field that confirmed that the presence of homeostatic shift toward increase energy (increased appetite) intake and decrease energy expenditure (sleeping too much, difficulty falling asleep (Markwald et al., 2013) and low energy level) were more strongly associated with inflammatory and metabolic biomarkers considered as risk factors for CVD. In earlier work based on NESDA data, among participants with active depression episode, increased a neuroendocrine energy homeostasis marker (leptin) (Zakrzewska, Cusin, Sainsbury, Rohner-Jeanrenaud, \& Jeanrenaud, 1997) was associated (independently from BMI) with a depressive symptoms profile defined by increase the intake (increase appetite/weight) and decrease the expenditure (fatigue, low energy) (Milaneschi, Lamers, Bot, Drent, \& Penninx, 2017). Likewise, in the same population, another study confirmed the relationship between cardiometabolic conditions, such as abdominal adiposity, inflammation markers, and metabolic syndrome, and increased appetite during the active depressive episode (Lamers et al., 2018). In agreement with above-mentioned well characterized clinical cohort studies, similar results were obtained from two large population-based studies (Alshehri et al., 2019; Jokela, Virtanen, Batty, \& Kivimaki, 2016) that confirmed the association between this cluster of symptoms and higher CRP and adiposity. Also, in a small study that combined neuroimaging and biochemical approaches, hyperphagia during depression was strongly associated with endocrine dysregulation and inflammation (Simmons et al., 2016). Interestingly, earlier (Yuri Milaneschi et al., 2017) and recent (Badini et al., 2020) genomic studies in $>25,000$ and $>30,000$ found that the genetic overlap between BMI, CRP and leptin with depression is symptom specific; this overlap was only found in depressed patients with increased weight and appetite. Another study (Adams et al., 2019) that used neuroticism as genetic specifier to stratify depression patients showed that the 
medRxiv preprint doi: https://doi.org/10.1101/2020.08.11.20172569; this version posted August 11, 2020. The copyright holder for this preprint (which was not certified by peer review) is the author/funder, who has granted medRxiv a license to display the preprint in It is made available under a CC-BY-NC-ND 4.0 International license.

portion of the common genetic liability between depression and neuroticism was also share with other psychiatric disorders; interestingly, the genetic liability not shared with neuroticism was positively correlated with metabolic phenotypes and cardiovascular disease. These results confirm the existence of different dimension within the construct of depression rooted in underlying biological and genetic mechanisms. Based on evidence along this line of research, the existence of an "immuno-metabolic depression (IMD)" dimension of depression was hypothesized (Milaneschi et al., 2020). This dimension is characterized by the clustering of immuno-metabolic biological alterations and behavioral symptom related to homeostasis dysregulation, which in turn can be the link between depression and cardiovascular disease (Milaneschi et al., 2020).

Many plausible mechanisms can directly or indirectly lead to or result from this homeostatic shift as maintaining energy homeostasis is governed by biological, behavioral and environmental factors (Chapelot \& Charlot, 2019). For example (Milaneschi et al., 2020), low-grade inflammation which associated with adiposity and depression (Woelfer, Kasties, Kahlfuss, \& Walter, 2019), favor -as proposed previously (Lacourt, Vichaya, Chiu, Dantzer, \& Heijnen, 2018)- the fast aerobic glycolysis in the immune cells over other efficient but yet slower energy production pathways (e.g., lipid oxidation). This appropriation of the available cellular fuel done by immune cells results in low energy available to any other activities. When the body has low energy level, the circadian rhythm and sleep cycle disturb as well (i.e., feeling tired and sleeping during the day which affect sleeping time and quality during the night) (Lacourt et al., 2018). Moreover, dysregulation of neuroendocrinological signaling such as leptin, and insulin (which have crucial metabolic roles) may diminish their function as satiety inducers hormones which lead to the development of increased appetite and decreased energy level symptoms (Chapelot \& Charlot, 2019). These biological processes also interact with behavioral/environmental factors that contribute in regulating of the energy 
medRxiv preprint doi: https://doi.org/10.1101/2020.08.11.20172569; this version posted August 11, 2020. The copyright holder for this preprint (which was not certified by peer review) is the author/funder, who has granted medRxiv a license to display the preprint in It is made available under a CC-BY-NC-ND 4.0 International license.

homeostasis. Obesogenic environment (e.g., low physical activity demand, and availability of palatable food) could shift the energy balance toward energy accumulation which in turn can result in low grade inflammation and neuroendocrinal dysregulation (Church \& Martin, 2018; Thyfault, Du, Kraus, Levine, \& Booth, 2015). Putting it together, this symptoms profile (difficulty falling asleep, sleeping too much, increased appetite, low energy level) may reflects a prolonged homeostatic failure that closely interconnected with neuroendocrinal and metabolic dysregulation that also reported in patients with CVD from metabolic dysregulation (Naisberg, 1996).

Fully characterizing the IMD dimension identified in the present study, in terms of its clinical manifestation and underlying biological mechanisms is the first step in the path to a personalized approach for patients with depression (Simon \& Perlis, 2010). This full characterization may help in guiding the choice of the most suitable intervention to alleviate the symptoms burden or to prevent its adverse prognosis. Moreover, understanding the clinical, and biological characteristics of this depression dimension will increase the precision of the genetic studies that aim to comprehend depression genetic architecture (Schwabe et al., 2019). Future research is needed to help us understand to what extent treating underlaying metabolic dysregulation (i.e., lipids and glucose) will contribute to mitigate this symptoms profile adversity. On the other hand, we also need to know to what degree will behavioral intervein that target this symptoms profile such as exercising, dieting and sleep hygiene will play a role in achieving better cardiometabolic health profile. Moreover, future genetics studies using techniques such as Mendelian Randomization are needed to test the causal direction between metabolic dysregulation (i.e., triglycerides (Khandaker et al., 2019)) and specific depressive symptom profile.

To the best of our knowledge, this study is the largest study that exploits jointly metabolomic data to dissect the dimensionality of depressive symptoms in a large, well-defined clinical 
medRxiv preprint doi: https://doi.org/10.1101/2020.08.11.20172569; this version posted August 11, 2020. The copyright holder for this preprint (which was not certified by peer review) is the author/funder, who has granted medRxiv a license to display the preprint in It is made available under a CC-BY-NC-ND 4.0 International license .

cohort (NESDA). Moreover, we replicate our findings from the clustering set in a population based large cohort (NEO). However, some methodological issues should be considered. First, we should acknowledge the limitation of the NMR metabolite platform, which mainly is a lipidomic metabolomic platform. For that reason, the term metabolic dysregulation should be interpreted based on the used metabolomic platform (i.e., metabolic dysregulation in this lipid focus metabolomic platform). Clustering based on different metabolomic platform could results on divergent results. However, the metabolomic platform used in this study is sufficient for inspecting the association between depression symptomatology and cardiometabolic endpoints (Holmes et al., 2018). Third, based on the cross-sectional study design, we are unable to infer the directionality of the relationship between depressive symptoms and adverse metabolic alterations.

In the present study, using a data-driven method we identified two independent depression dimension differentially related with cardiometabolic risk markers, such as higher triglycerides, higher visceral fat content, lower HDL-cholesterol levels and insulin resistance in the replication step. Our findings confirm that depression is associated with metabolic alterations that could represent the mechanism linking depression with cardiometabolic disorders. However, these metabolic alteration are not present in all forms of depression. Depressed patients with IMD may be at higher cardiometabolic risk and may require specific additional treatment targeting underlying metabolic dysregulations. 
medRxiv preprint doi: https://doi.org/10.1101/2020.08.11.20172569; this version posted August 11, 2020. The copyright holder for this preprint (which was not certified by peer review) is the author/funder, who has granted medRxiv a license to display the preprint in It is made available under a CC-BY-NC-ND 4.0 International license .

\section{Acknowledgement}

\section{NESDA}

The infrastructure for the NESDA study (www.nesda.nl) is funded through the Geestkracht program of the Netherlands Organization for Health Research and Development (ZonMw, grant number: 10-000-1002) and financial contributions by participating universities and mental health care organizations (VU University Medical Center, GGZ inGeest, Leiden University Medical Center, Leiden University, GGZ Rivierduinen, University Medical Center Groningen, University of Groningen, Lentis, GGZ Friesland, GGZ Drenthe, Rob Giel Onderzoekscentrum).

\section{NEO study}

The NEO study is supported by the participating Departments, Division, and Board of Directors of the Leiden University Medical Center, and by the Leiden University, Research Profile Area Vascular and Regenerative Medicine. DOM-K is supported by Dutch Science Organization (ZonMW-VENI Grant No. 916.14.023).We express our gratitude to all participants of the Netherlands Epidemiology of Obesity (NEO) study, in addition to all participating general practitioners. We furthermore thank P.R. van Beelen and all research nurses for collecting the data, P.J. Noordijk and her team for sample handling and storage, and I. de Jonge for data management of the NEO study. 
medRxiv preprint doi: https://doi.org/10.1101/2020.08.11.20172569; this version posted August 11, 2020. The copyright holder for this preprint (which was not certified by peer review) is the author/funder, who has granted medRxiv a license to display the preprint in It is made available under a CC-BY-NC-ND 4.0 International license .

\section{References}

Adams, M. J., Howard, D. M., Luciano, M., Clarke, T.-K., Davies, G., Hill, W. D., . . McIntosh, A. M. (2019). Genetic stratification of depression by neuroticism: revisiting a diagnostic tradition. Psychol Med, 1-10. doi:10.1017/S0033291719002629

Alshehri, T., Boone, S., de Mutsert, R., Penninx, B., Rosendaal, F., le Cessie, S., . . Mook-Kanamori, D. (2019). The association between overall and abdominal adiposity and depressive mood: A cross-sectional analysis in 6459 participants. Psychoneuroendocrinology, 110, 104429. doi:10.1016/j.psyneuen.2019.104429

American Psychiatric Association. (2013). Diagnostic and statistical manual of mental disorders (DSM-5 ${ }^{\circledR}$ ): American Psychiatric Association, Washington, DC2013.

Badini, I., Coleman, J. R. I., Hagenaars, S. P., Hotopf, M., Breen, G., Lewis, C. M., \& Fabbri, C. (2020). Atypical depression shares genetic predisposition with immuno-metabolic traits: a population-based study. medRxiv, 2020.2002.2018.20024091. doi:10.1101/2020.02.18.20024091

Baune, B. T., Stuart, M., Gilmour, A., Wersching, H., Heindel, W., Arolt, V., \& Berger, K. (2012). The relationship between subtypes of depression and cardiovascular disease: a systematic review of biological models. Transl Psychiatry, 2, e92. doi:10.1038/tp.2012.18

Bot, M., Milaneschi, Y., Al-Shehri, T., Amin, N., Garmaeva, S., Onderwater, G. L. J., . . Penninx, B. (2020). Metabolomics Profile in Depression: A Pooled Analysis of 230 Metabolic Markers in 5283 Cases With Depression and 10,145 Controls. Biol Psychiatry, 87(5), 409-418. doi:10.1016/j.biopsych.2019.08.016

Chapelot, D., \& Charlot, K. (2019). Physiology of energy homeostasis: Models, actors, challenges and the glucoadipostatic loop. Metabolism, 92, 11-25. doi:10.1016/j.metabol.2018.11.012

Church, T., \& Martin, C. K. (2018). The Obesity Epidemic: A Consequence of Reduced Energy Expenditure and the Uncoupling of Energy Intake? Obesity (Silver Spring, Md.), 26(1), 14-16. doi:10.1002/oby. 22072

David, C. C., \& Jacobs, D. J. (2014). Principal component analysis: a method for determining the essential dynamics of proteins. Methods Mol Biol, 1084, 193-226. doi:10.1007/978-1-62703658-0_11

de Mutsert, R., den Heijer, M., Rabelink, T. J., Smit, J. W., Romijn, J. A., Jukema, J. W., . . Rosendaal, F. R. (2013). The Netherlands Epidemiology of Obesity (NEO) study: study design and data collection. Eur J Epidemiol, 28(6), 513-523. doi:10.1007/s10654-013-9801-3

Dhar, A. K., \& Barton, D. A. (2016). Depression and the Link with Cardiovascular Disease. Front Psychiatry, 7, 33. doi:10.3389/fpsyt.2016.00033

Fried, E. I., \& Nesse, R. M. (2015). Depression sum-scores don't add up: why analyzing specific depression symptoms is essential. BMC Med, 13, 72. doi:10.1186/s12916-015-0325-4

Holmes, M. V., Millwood, I. Y., Kartsonaki, C., Hill, M. R., Bennett, D. A., Boxall, R., . . Chen, Z. (2018). Lipids, Lipoproteins, and Metabolites and Risk of Myocardial Infarction and Stroke. J Am Coll Cardiol, 71(6), 620-632. doi:10.1016/j.jacc.2017.12.006

Hotelling, H. (1936). Relations Between Two Sets of Variates. Biometrika, 28(3/4), 321-377. doi:10.2307/2333955

Jokela, M., Virtanen, M., Batty, G. D., \& Kivimaki, M. (2016). Inflammation and Specific Symptoms of Depression. JAMA Psychiatry, 73(1), 87-88. doi:10.1001/jamapsychiatry.2015.1977

Khandaker, G. M., Zuber, V., Rees, J. M. B., Carvalho, L., Mason, A. M., Foley, C. N., . . Burgess, S. (2019). Shared mechanisms between coronary heart disease and depression: findings from a large UK general population-based cohort. Mol Psychiatry. doi:10.1038/s41380-019-0395-3

Lacourt, T. E., Vichaya, E. G., Chiu, G. S., Dantzer, R., \& Heijnen, C. J. (2018). The High Costs of LowGrade Inflammation: Persistent Fatigue as a Consequence of Reduced Cellular-Energy Availability and Non-adaptive Energy Expenditure. 12(78). doi:10.3389/fnbeh.2018.00078 
medRxiv preprint doi: https://doi.org/10.1101/2020.08.11.20172569; this version posted August 11, 2020. The copyright holder for this preprint (which was not certified by peer review) is the author/funder, who has granted medRxiv a license to display the preprint in It is made available under a CC-BY-NC-ND 4.0 International license.

Lamers, F., de Jonge, P., Nolen, W. A., Smit, J. H., Zitman, F. G., Beekman, A. T., \& Penninx, B. W. (2010). Identifying depressive subtypes in a large cohort study: results from the Netherlands Study of Depression and Anxiety (NESDA). J Clin Psychiatry, 71(12), 1582-1589. doi:10.4088/JCP.09m05398blu

Lamers, F., Milaneschi, Y., de Jonge, P., Giltay, E. J., \& Penninx, B. (2018). Metabolic and inflammatory markers: associations with individual depressive symptoms. Psychol Med, 48(7), 1102-1110. doi:10.1017/s0033291717002483

Lasserre, A. M., Strippoli, M. F., Glaus, J., Gholam-Rezaee, M., Vandeleur, C. L., Castelao, E., . . . Preisig, M. (2017). Prospective associations of depression subtypes with cardio-metabolic risk factors in the general population. Mol Psychiatry, 22(7), 1026-1034. doi:10.1038/mp.2016.178

Lux, V., \& Kendler, K. S. (2010). Deconstructing major depression: a validation study of the DSM-IV symptomatic criteria. Psychol Med, 40(10), 1679-1690. doi:10.1017/s0033291709992157

Markwald, R. R., Melanson, E. L., Smith, M. R., Higgins, J., Perreault, L., Eckel, R. H., \& Wright, K. P., Jr. (2013). Impact of insufficient sleep on total daily energy expenditure, food intake, and weight gain. Proceedings of the National Academy of Sciences of the United States of America, 110(14), 5695-5700. doi:10.1073/pnas.1216951110

Mathers, C. D., \& Loncar, D. (2006). Projections of global mortality and burden of disease from 2002 to 2030. PLoS Med, 3(11), e442. doi:10.1371/journal.pmed.0030442

Matthews, D. R., Hosker, J. P., Rudenski, A. S., Naylor, B. A., Treacher, D. F., \& Turner, R. C. (1985). Homeostasis model assessment: insulin resistance and beta-cell function from fasting plasma glucose and insulin concentrations in man. Diabetologia, 28(7), 412-419. doi:10.1007/bf00280883

Milaneschi, Y., Lamers, F., Berk, M., \& Penninx, B. (2020). Depression Heterogeneity and Its Biological Underpinnings: Toward Immunometabolic Depression. Biol Psychiatry. doi:10.1016/j.biopsych.2020.01.014

Milaneschi, Y., Lamers, F., Bot, M., Drent, M. L., \& Penninx, B. W. (2017). Leptin Dysregulation Is Specifically Associated With Major Depression With Atypical Features: Evidence for a Mechanism Connecting Obesity and Depression. Biol Psychiatry, 81(9), 807-814. doi:10.1016/j.biopsych.2015.10.023

Milaneschi, Y., Lamers, F., Peyrot, W. J., Baune, B. T., Breen, G., Dehghan, A., . . Consortium, t. M. D. D. W. G. o. t. P. G. (2017). Genetic Association of Major Depression With Atypical Features and Obesity-Related Immunometabolic Dysregulations. JAMA Psychiatry, 74(12), 1214-1225. doi:10.1001/jamapsychiatry.2017.3016 \%J JAMA Psychiatry

Naisberg, Y. (1996). Homeostatic disruption and depression. Med Hypotheses, 47(6), 415-422. doi:10.1016/s0306-9877(96)90152-8

Onderwater, G. L. J., Ligthart, L., Bot, M., Demirkan, A., Fu, J., van der Kallen, C. J. H., . . van den Maagdenberg, A. (2019). Large-scale plasma metabolome analysis reveals alterations in HDL metabolism in migraine. Neurology, 92(16), e1899-e1911. doi:10.1212/wnl.0000000000007313

Penninx, B. W., Beekman, A. T., Smit, J. H., Zitman, F. G., Nolen, W. A., Spinhoven, P., . . Van Dyck, R. (2008). The Netherlands Study of Depression and Anxiety (NESDA): rationale, objectives and methods. Int J Methods Psychiatr Res, 17(3), 121-140. doi:10.1002/mpr.256

Penninx, B. W., Milaneschi, Y., Lamers, F., \& Vogelzangs, N. (2013). Understanding the somatic consequences of depression: biological mechanisms and the role of depression symptom profile. BMC Med, 11, 129. doi:10.1186/1741-7015-11-129

Robins, L. N., Wing, J., Wittchen, H. U., Helzer, J. E., Babor, T. F., Burke, J., . . et al. (1988). The Composite International Diagnostic Interview. An epidemiologic Instrument suitable for use in conjunction with different diagnostic systems and in different cultures. Arch Gen Psychiatry, 45(12), 1069-1077. doi:10.1001/archpsyc.1988.01800360017003 
medRxiv preprint doi: https://doi.org/10.1101/2020.08.11.20172569; this version posted August 11, 2020. The copyright holder for this preprint (which was not certified by peer review) is the author/funder, who has granted medRxiv a license to display the preprint in It is made available under a CC-BY-NC-ND 4.0 International license.

Rush, A. J., Gullion, C. M., Basco, M. R., Jarrett, R. B., \& Trivedi, M. H. (1996). The Inventory of Depressive Symptomatology (IDS): psychometric properties. Psychol Med, 26(3), 477-486. Retrieved from http://www.ncbi.nlm.nih.gov/pubmed/8733206

Schwabe, I., Milaneschi, Y., Gerring, Z., Sullivan, P. F., Schulte, E., Suppli, N. P., . . Middeldorp, C. M. (2019). Unraveling the genetic architecture of major depressive disorder: merits and pitfalls of the approaches used in genome-wide association studies. Psychol Med, 49(16), 26462656. doi:10.1017/s0033291719002502

Simmons, W. K., Burrows, K., Avery, J. A., Kerr, K. L., Bodurka, J., Savage, C. R., \& Drevets, W. C. (2016). Depression-Related Increases and Decreases in Appetite: Dissociable Patterns of Aberrant Activity in Reward and Interoceptive Neurocircuitry. Am J Psychiatry, 173(4), 418428. doi:10.1176/appi.ajp.2015.15020162

Simon, G. E., \& Perlis, R. H. (2010). Personalized medicine for depression: can we match patients with treatments? Am J Psychiatry, 167(12), 1445-1455. doi:10.1176/appi.ajp.2010.09111680

Soininen, P., Kangas, A. J., Wurtz, P., Suna, T., \& Ala-Korpela, M. (2015). Quantitative serum nuclear magnetic resonance metabolomics in cardiovascular epidemiology and genetics. Circ Cardiovasc Genet, 8(1), 192-206. doi:10.1161/circgenetics.114.000216

Sullivan, P. F., Prescott, C. A., \& Kendler, K. S. (2002). The subtypes of major depression in a twin registry. J Affect Disord, 68(2-3), 273-284. doi:10.1016/s0165-0327(00)00364-5

Thyfault, J. P., Du, M., Kraus, W. E., Levine, J. A., \& Booth, F. W. (2015). Physiology of sedentary behavior and its relationship to health outcomes. Med Sci Sports Exerc, 47(6), 1301-1305. doi:10.1249/mss.0000000000000518

Wallace, T. M., Levy, J. C., \& Matthews, D. R. (2004). Use and abuse of HOMA modeling. Diabetes Care, 27(6), 1487-1495. doi:10.2337/diacare.27.6.1487

Wittchen, H. U. (1994). Reliability and validity studies of the WHO--Composite International Diagnostic Interview (CIDI): a critical review. J Psychiatr Res, 28(1), 57-84.

Woelfer, M., Kasties, V., Kahlfuss, S., \& Walter, M. (2019). The Role of Depressive Subtypes within the Neuroinflammation Hypothesis of Major Depressive Disorder. Neuroscience, 403, 93110. doi:10.1016/j.neuroscience.2018.03.034

Wurtz, P., Kangas, A. J., Soininen, P., Lawlor, D. A., Davey Smith, G., \& Ala-Korpela, M. (2017). Quantitative Serum Nuclear Magnetic Resonance Metabolomics in Large-Scale Epidemiology: A Primer on -Omic Technologies. Am J Epidemiol, 186(9), 1084-1096. doi:10.1093/aje/kwx016

Zakrzewska, K. E., Cusin, I., Sainsbury, A., Rohner-Jeanrenaud, F., \& Jeanrenaud, B. (1997). Glucocorticoids as counterregulatory hormones of leptin: toward an understanding of leptin resistance. Diabetes, 46(4), 717-719. doi:10.2337/diab.46.4.717 
Figure 1. An illustration of the method

\section{A flowchart of the analysis}

STEP 1 METABOLITE-SYMPTOM CLUSTERING

(.) Aim: To extract a cluster of depressive symptoms which associate with the adverse metabolic alteration.

Sample: 1094 participants with current depression (NESDA)

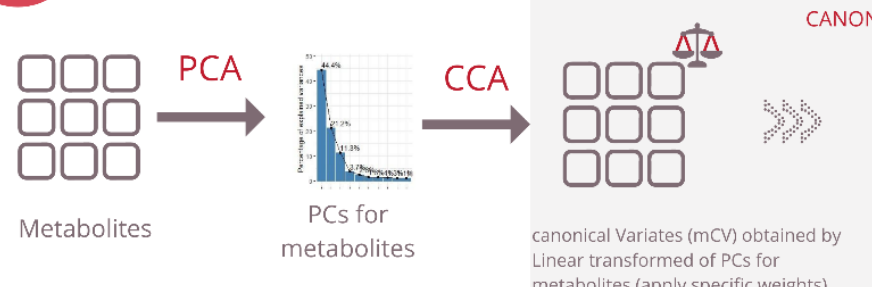

NONICAL CORRELATION ANALYSIS (CCA)

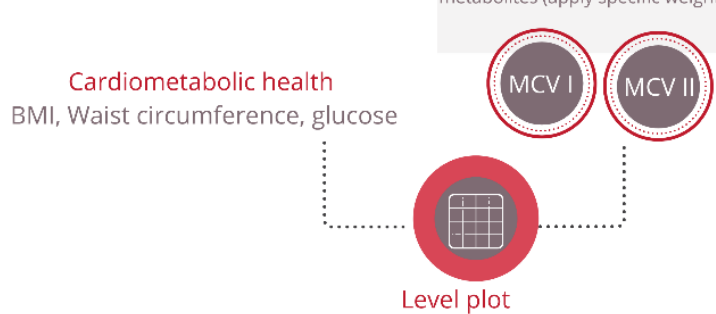

maximum correlation between
canonical Variates $\mathrm{mCV}$ and $\mathrm{sCV}$ (two metabolite-symptom axes)

Classify individuals in terms of cardiometabolic markers

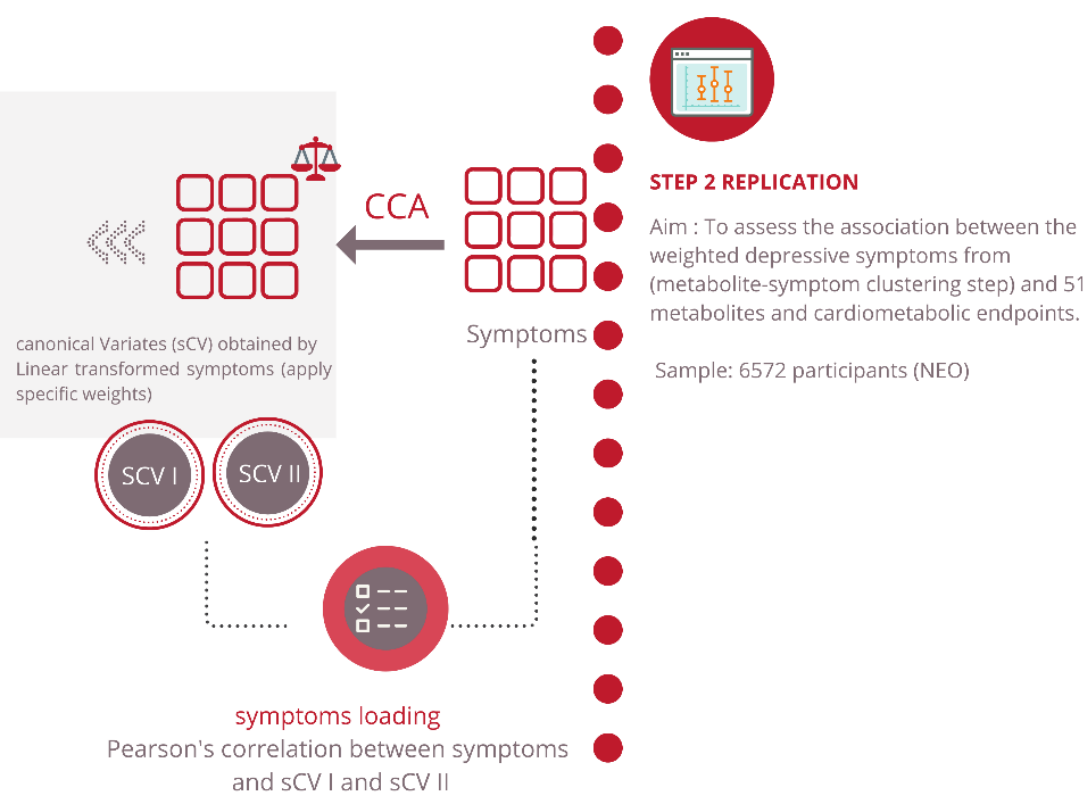


Table 1. Characteristics of the study population for the metabolite-symptom clustering step (NESDA)

\begin{tabular}{|l|l|}
\hline & $\begin{array}{l}\text { Metabolite-symptom clustering } \\
\text { (NESDA n=1094) }\end{array}$ \\
\hline $\mathrm{N}$ & 1094 \\
\hline Women, $\mathrm{n}(\%)$ & $741(67.73)$ \\
\hline Age (years) (mean, sd) & $40.88(12.11)$ \\
\hline High educational level (high) n (\%) & $306(27.97)$ \\
\hline Use of lipid-modifying medications, yes n (\%) & $78(7.13)$ \\
\hline BMI $\left(\mathrm{kg} / \mathrm{m}^{2}\right)($ mean, sd) & $25.90(5.51)$ \\
\hline Waist circumference (cm) & $89.58(14.56)$ \\
\hline Glucose (mmol/L) & $5.20(1.15)$ \\
\hline Use of antidepressant Yes n (\%) & $477(43.60)$ \\
\hline Total IDS-score (0-84) median (25th ,75th percentiles) & $32.50(24.0,41.0)$ \\
\hline
\end{tabular}

Normally distributed data shown as mean and standard deviation (SD), skewed distributed data shown as median (25th, 75th percentiles), and categorical data are shown as percentage. High education level: university or college education, while other education level: none, primary school, or lower vocational education. IDS-SR30: Inventory of Depressive Symptomatology (self-report). BMI: body mass index. NESDA: Netherlands study for depression and anxiety. 
Figure 2. Level plot of the predicted cardiometabolic health conventional biomarker as functions of the first and second metabolic canonical variates.

$\mathrm{BMI}\left(\mathrm{kg} / \mathrm{m}^{\wedge} 2\right)$ as function of metabolic canonical variates

\section{Waist circumference $(\mathrm{cm})$ as function of metabolic canonical variates}
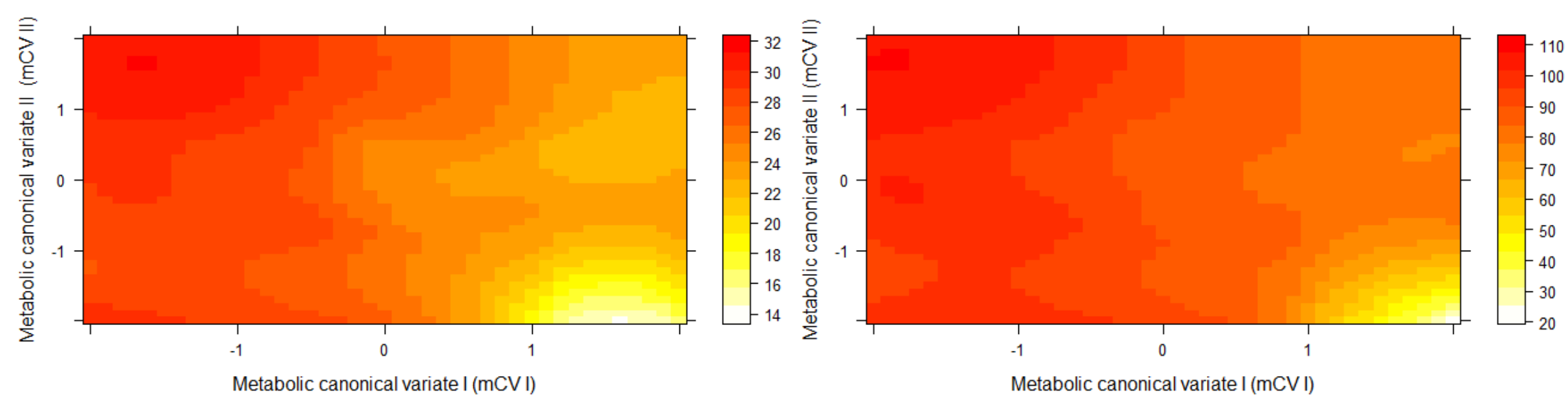

Fasting glucose (mmol/L) as function of metabolic canonical variates

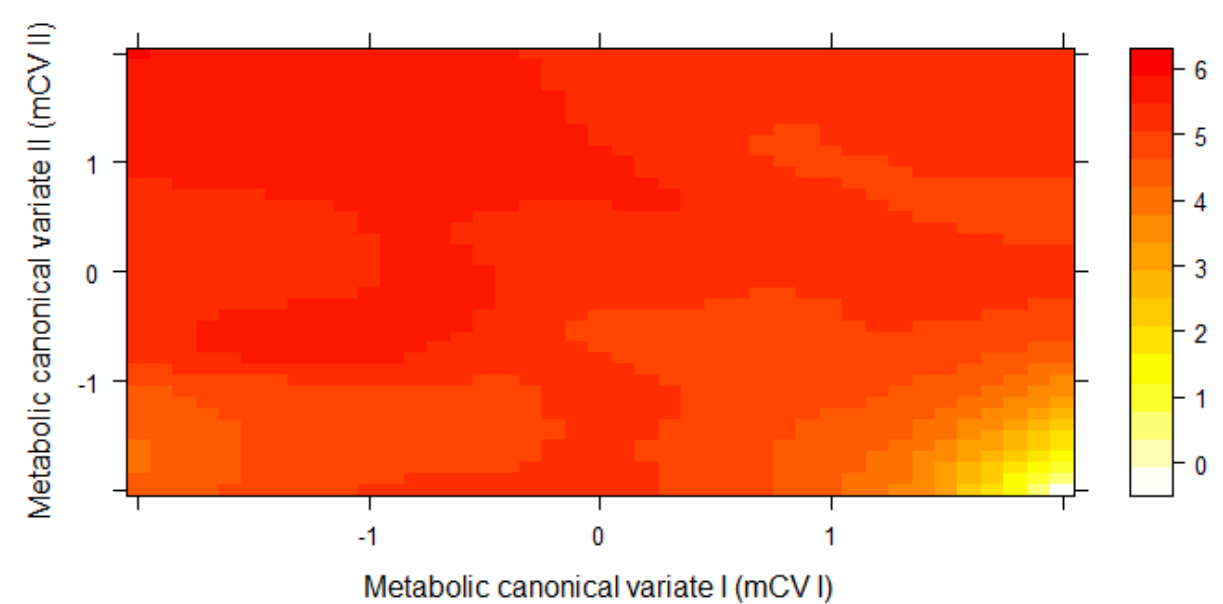

Figure 3. Canonical loading of depressive symptoms on the symptoms canonical variates 


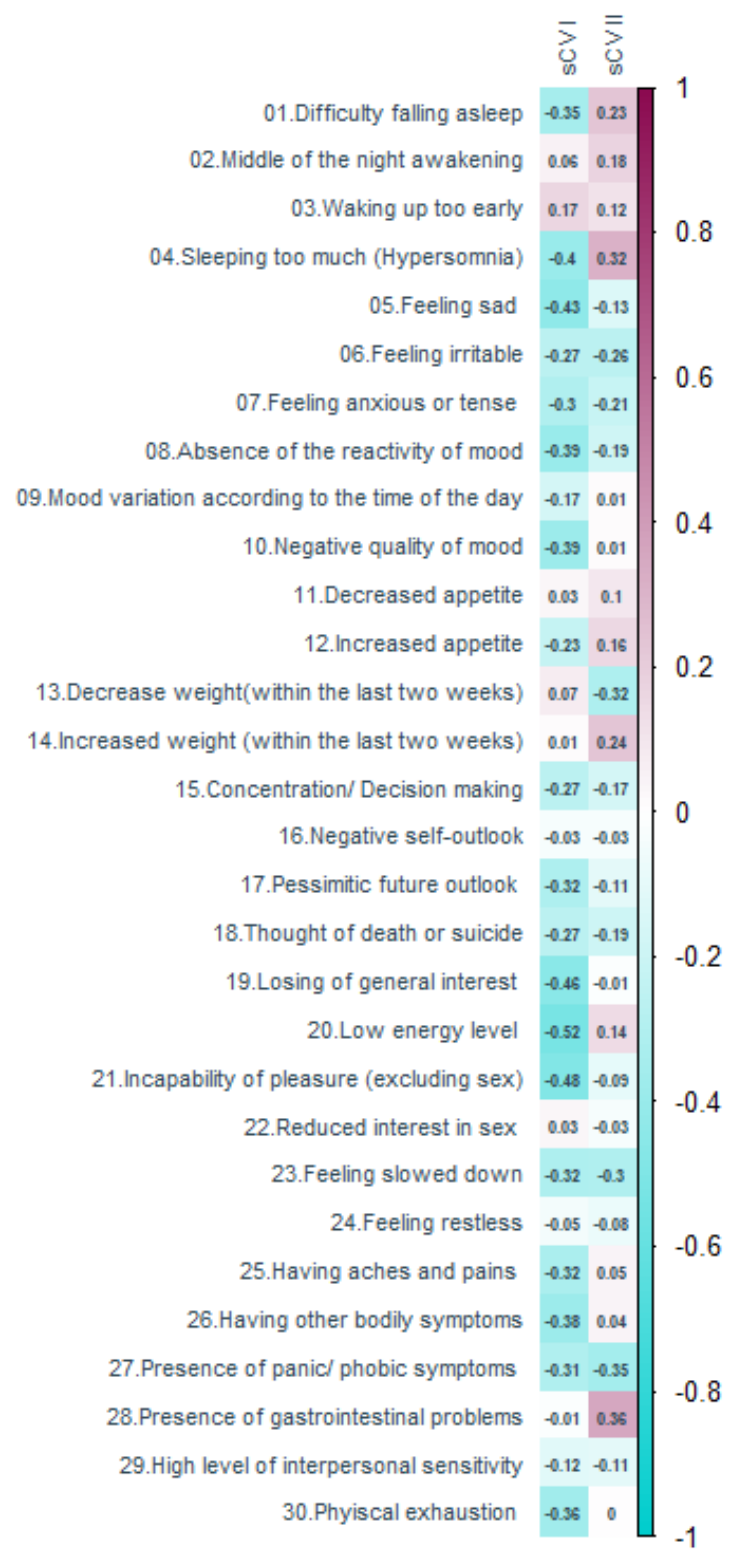


sCV I: First symptoms canonical variates I. sCV II: Second symptoms canonical variates. 
Figure 4. The linear regression analysis of the association between the weighted depressive symptoms score and the cardiometabolic endpoints and metabolites in individuals from NEO study.
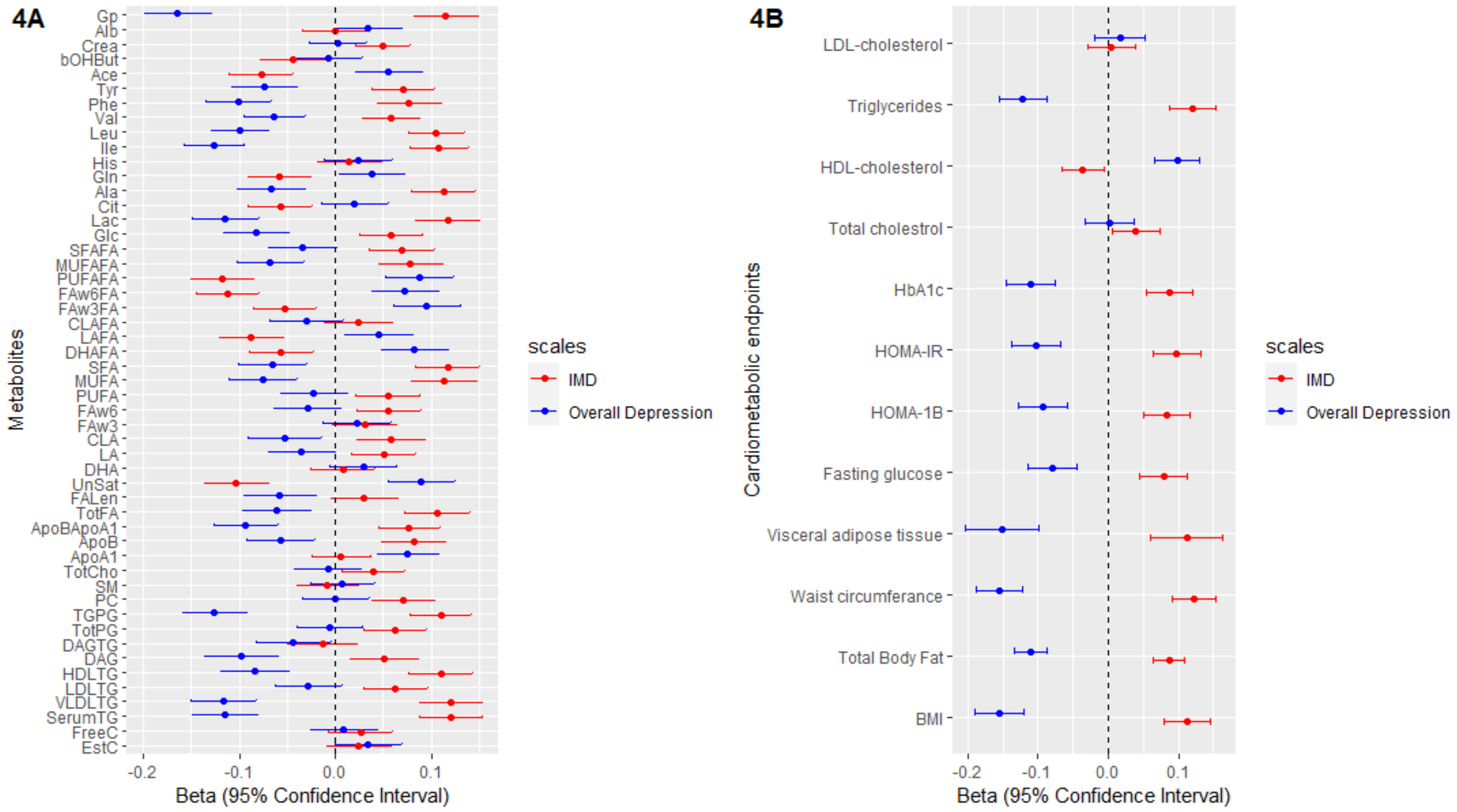
The weights extracted from the metabolite-symptom clustering step. Number of individuals with data for BMI: 6572, Total body fat: 6541, Waist circumference: 6566, Visceral adipose tissue: 1869, Fasting glucose: 6554, HOMA-1B: 6541, HOMA-IR: 6545, HbA1c: 6543, Total cholesterol: 6562, HDL-cholesterol: 6561, Triglycerides: 6561, LDL-cholesterol: 6560. 
medRxiv preprint doi: https://doi.org/10.1101/2020.08.11.20172569; this version posted August 11, 2020. The copyright holder for this preprint (which was not certified by peer review) is the author/funder, who has granted medRxiv a license to display the preprint in It is made available under a CC-BY-NC-ND 4.0 International license .

Supplemental table 1. Characteristics of the replication step, the Netherlands epidemiology of obesity (NEO) study

\begin{tabular}{|c|c|}
\hline & Replication \\
\hline Women (\%) & 56.34 \\
\hline Age (years) (mean, sd) & $55.70(6.0)$ \\
\hline High educational level (high) (\%) & 46.08 \\
\hline \multicolumn{2}{|l|}{ Tobacco smoking $\mathrm{n} \%$} \\
\hline Never $(\%)$ & 38.68 \\
\hline Former $(\%)$ & 45.25 \\
\hline Current (\%) & 16.07 \\
\hline Alcohol consumption (g/day) median & $9.86(2.74,21.41)$ \\
\hline $\begin{array}{l}\text { Use of lipid-modifying medications, yes } \\
(\%)\end{array}$ & 10.31 \\
\hline BMI $\left(\mathrm{kg} / \mathrm{m}^{2}\right)($ mean, $\mathrm{sd})$ & $26.32(4.43)$ \\
\hline Total body fat (\%) & $31.6(24.8,38.2)$ \\
\hline Waist circumference $(\mathrm{cm})$ & $92.15(13.34)$ \\
\hline Visceral adipose tissue $\left(\mathrm{cm}^{2}\right)$ & $90.04(56.04)$ \\
\hline $\begin{array}{l}\text { Serum concentration of total cholesterol } \\
(\mathrm{mmol} / \mathrm{L})\end{array}$ & $5.68(1.05)$ \\
\hline Serum concentration of LDL $(\mathrm{mmol} / \mathrm{L})$ & $3.52(0.96)$ \\
\hline Serum concentration of HDL (mmol/L) & $1.57(0.46)$ \\
\hline $\begin{array}{l}\text { Serum concentration of triglyceride } \\
(\mathrm{mmol} / \mathrm{L})\end{array}$ & $1.23(0.84)$ \\
\hline HBA1C $(\%)$ & $5.36(0.46)$ \\
\hline
\end{tabular}


medRxiv preprint doi: https://doi.org/10.1101/2020.08.11.20172569; this version posted August 11, 2020. The copyright holder for this preprint (which was not certified by peer review) is the author/funder, who has granted medRxiv a license to display the preprint in It is made available under a CC-BY-NC-ND 4.0 International license .

\begin{tabular}{|l|l|}
\hline Glucose (mmol/L) & $5.47(0.96)$ \\
\hline HOMA-IR & $1.86(1.21,2.93)$ \\
\hline HOMA 1B & $86.67(60.0,126.00)$ \\
\hline Use of antidepressant Yes (\%) & 6.59 \\
\hline Total IDS-score (0-84) median (25th & $8(4,13)$ \\
75th percentiles) & \\
\hline
\end{tabular}

Number of individuals with data for BMI: 6572 , Total body fat: 6541, Waist circumference: 6566 , Visceral adipose tissue: 1869, Fasting glucose: 6554, HOMA-1B: 6541, HOMA-IR: 6545, HbA1c: 6543, Total cholesterol: 6562, HDL-cholesterol: 6561, Triglycerides: 6561, LDL-cholesterol: 6560 Normally distributed data shown as mean and standard deviation (SD), skewed distributed data shown as median (25th, 75th percentiles) and categorical data are shown as percentage. High education level: university or college education, while other education level: none, primary school or lower vocational education. IDS-SR30: Inventory of Depressive Symptomatology (self-report). BMI: body mass index. HOMA-IR: (homeostatic model assessment insulin resistance $)=($ glucose $\mathrm{x}$ insulin $) / 22.5$, HOMA-1B: (homeostatic model assessment of beta cells) HOMA 1B=20 x insulin/glucose-3.5 
medRxiv preprint doi: https://doi.org/10.1101/2020.08.11.20172569; this version posted August 11, 2020. The copyright holder for this preprint (which was not certified by peer review) is the author/funder, who has granted medRxiv a license to display the preprint in It is made available under a CC-BY-NC-ND 4.0 International license .

Supplemental figure 1: Scree plot for the principle component analysis of the metabolites dataset.

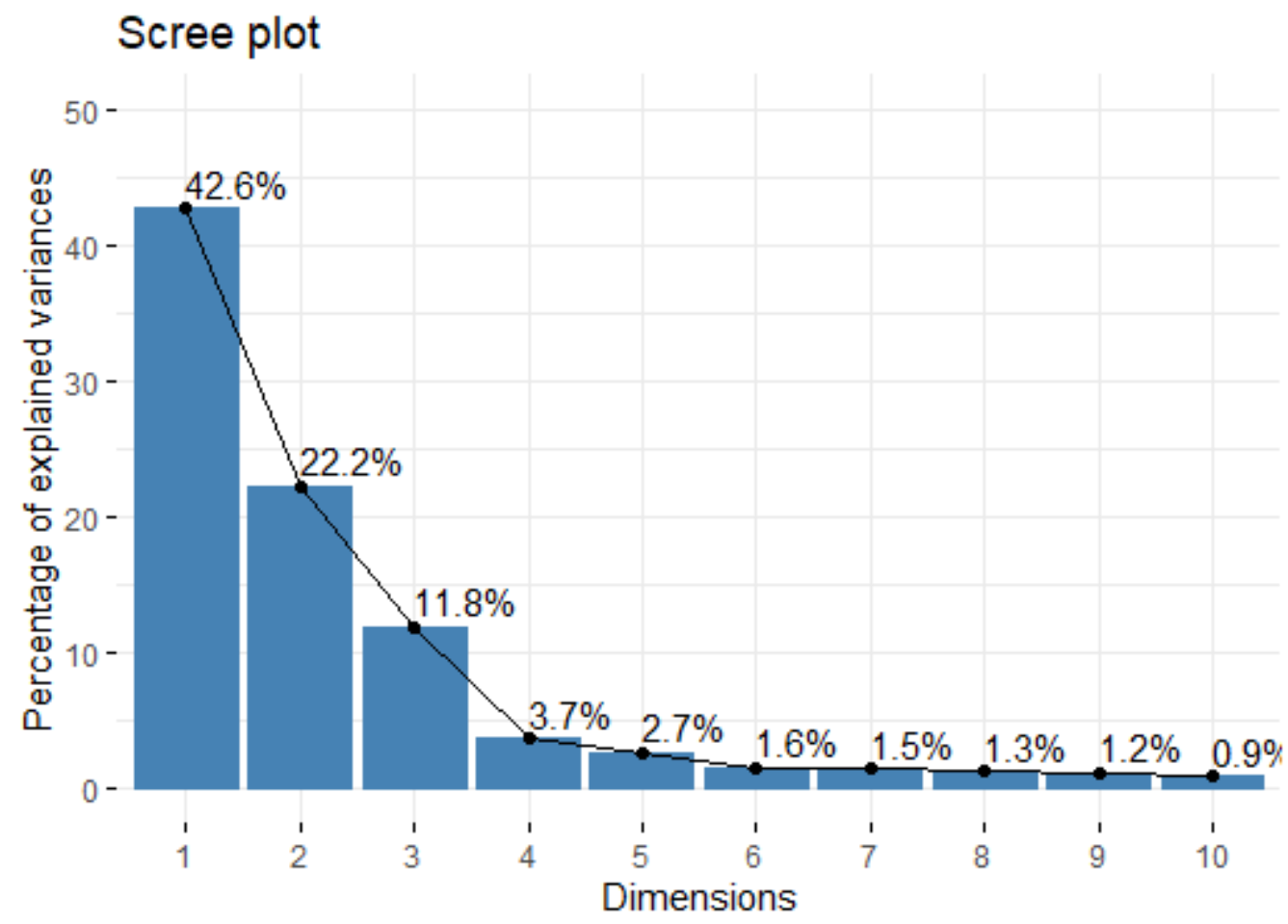


medRxiv preprint doi: https://doi.org/10.1101/2020.08.11.20172569; this version posted August 11, 2020. The copyright holder for this preprint (which was not certified by peer review) is the author/funder, who has granted medRxiv a license to display the preprint in It is made available under a CC-BY-NC-ND 4.0 International license .

Supplemental figure 2: canonical correlation between first and second canonical pairs

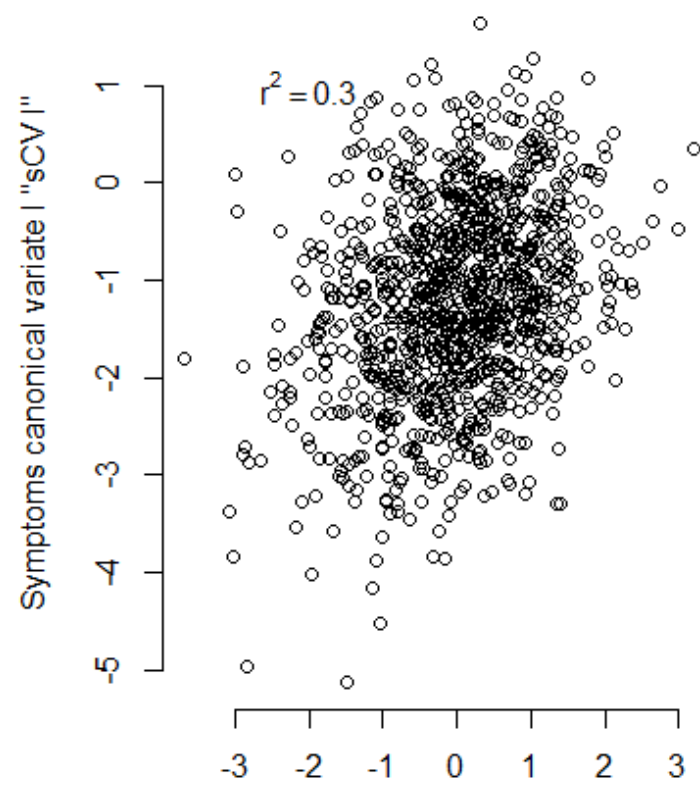

Metabolic canonical variate I "mCV I"

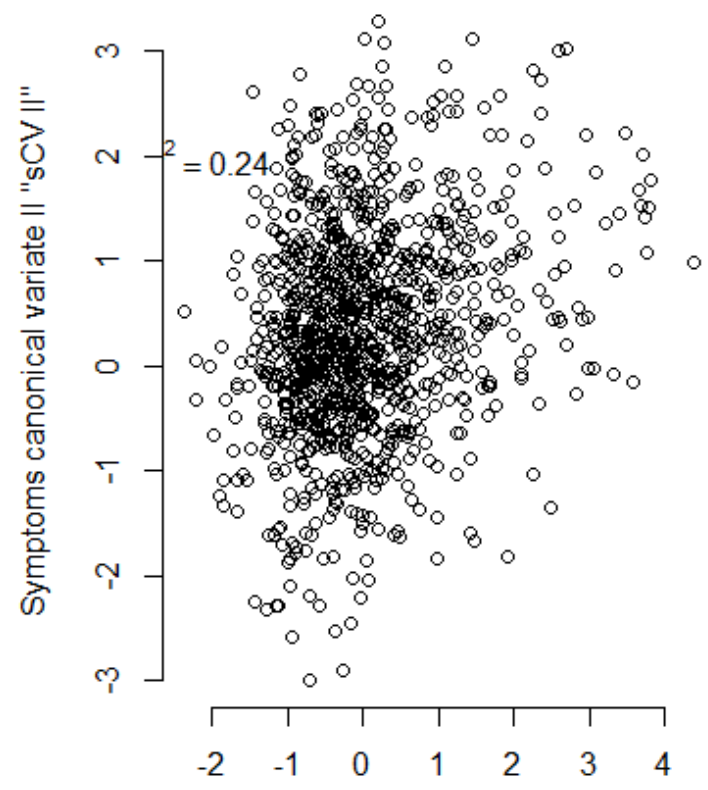

Metabolic canonical variate II "mCV II" 
Supplemental table 2. The linear regression analysis of the association between the sum score of the symptoms extracted from the metabolitesymptom clustering step and the metabolites.

\begin{tabular}{|c|c|c|c|c|c|c|c|c|}
\hline & \multicolumn{4}{|l|}{ Crude } & \multicolumn{4}{|l|}{ Model 1} \\
\hline & \multicolumn{2}{|c|}{ Overall Depression } & \multicolumn{2}{|c|}{ IMD } & \multicolumn{2}{|c|}{ Overall Depression } & \multicolumn{2}{|c|}{ IMD } \\
\hline & $\beta(95 \% \mathrm{CI})$ & FDR q value & $\beta(95 \% \mathrm{CI})$ & FDR q value & $\beta(95 \% \mathrm{CI})$ & FDR q value & $\beta(95 \% \mathrm{CI})$ & FDR q value \\
\hline XXLVLDLL & $-0.12(-0.15--0.08)$ & $1.93 \times 10^{-10}$ & $0.07(0.04-0.10)$ & $1.21 \times 10^{-04}$ & $-0.11(-0.14--0.07)$ & $7.12 \times 10^{-09}$ & $0.13(0.10-0.16)$ & $3.02 \times 10^{-13}$ \\
\hline XXLVLDLPL & $-0.12(-0.15--0.08)$ & $2.21 \times 10^{-10}$ & $0.07(0.04-0.11)$ & $3.79 \times 10^{-05}$ & $-0.11(-0.14--0.07)$ & $7.17 \times 10^{-09}$ & $0.13(0.10-0.16)$ & $2.01 \times 10^{-13}$ \\
\hline XXLVLDLC & $-0.11(-0.15--0.08)$ & $3.11 \times 10^{-09}$ & $0.07(0.03-0.10)$ & $1.87 \times 10^{-04}$ & $-0.10(-0.13--0.06)$ & $1.23 \times 10^{-07}$ & $0.13(0.09-0.16)$ & $1.39 \times 10^{-12}$ \\
\hline XXLVLDLCE & $-0.10(-0.14--0.07)$ & $6.71 \times 10^{-8} 8$ & $0.06(0.02-0.09)$ & $1.59 \times 10^{-03}$ & $-0.09(-0.12--0.05)$ & $1.84 \times 10^{-06}$ & $0.11(0.08-0.15)$ & $2.51 \times 10^{-10}$ \\
\hline XXLVLDLFC & $-0.12(-0.15--0.08)$ & $2.99 \times 10^{-10}$ & $0.07(0.04-0.11)$ & $4.76 \times 10^{-05}$ & $-0.11(-0.14--0.07)$ & $9.68 \times 10^{-09}$ & $0.13(0.10-0.17)$ & $1.87 \times 10^{-13}$ \\
\hline XXLVLDLTG & $-0.12(-0.16--0.09)$ & $1.46 \times 10^{-10}$ & $0.07(0.04-0.10)$ & $1.28 \times 10^{-04}$ & $-0.11(-0.14--0.07)$ & $5.43 \times 10^{-09}$ & $0.13(0.10-0.16)$ & $2.99 \times 10^{-13}$ \\
\hline XLVLDLP & $-0.12(-0.16--0.09)$ & $9.40 \times 10^{-11}$ & $0.07(0.03-0.10)$ & $1.87 \times 10^{-04}$ & $-0.11(-0.15--0.08)$ & $3.39 \times 10^{-09}$ & $0.13(0.10-0.17)$ & $1.87 \times 10^{-13}$ \\
\hline XLVLDLL & $-0.12(-0.16--0.09)$ & $5.67 \times 10^{-11}$ & $0.07(0.03-0.10)$ & $1.87 \times 10^{-04}$ & $-0.11(-0.15--0.08)$ & $1.93 \times 10^{-09}$ & $0.13(0.10-0.17)$ & $1.87 \times 10^{-13}$ \\
\hline XLVLDLPL & $-0.12(-0.15--0.08)$ & $1.85 \times 10^{-10}$ & $0.07(0.04-0.10)$ & $9.08 \times 10^{-05}$ & $-0.11(-0.14--0.07)$ & $6.00 \times 10^{-09}$ & $0.13(0.10-0.17)$ & $1.87 \times 10^{-13}$ \\
\hline XLVLDLC & $-0.12(-0.15--0.08)$ & $1.93 \times 10^{-10}$ & $0.06(0.03-0.10)$ & $4.24 \times 10^{-04}$ & $-0.11(-0.14--0.07)$ & $8.24 \times 10^{-09}$ & $0.13(0.09-0.16)$ & $4.30 \times 10^{-13}$ \\
\hline XLVLDLCE & $-0.12(-0.15--0.08)$ & $2.46 \times 10^{-10}$ & $0.06(0.03-0.09)$ & $7.97 \times 10^{-04}$ & $-0.11(-0.14--0.07)$ & $1.24 \times 10^{-08}$ & $0.13(0.09-0.16)$ & $7.19 \times 10^{-13}$ \\
\hline XLVLDLFC & $-0.12(-0.15--0.08)$ & $1.93 \times 10^{-10}$ & $0.07(0.04-0.10)$ & $1.56 \times 10^{-04}$ & $-0.11(-0.14--0.07)$ & $7.17 \times 10^{-09}$ & $0.13(0.10-0.16)$ & $2.99 \times 10^{-13}$ \\
\hline XLVLDLTG & $-0.13(-0.16--0.09)$ & $2.83 \times 10^{-11}$ & $0.07(0.03-0.10)$ & $2.69 \times 10^{-04}$ & $-0.12(-0.15--0.08)$ & $8.36 \times 10^{-10}$ & $0.13(0.10-0.16)$ & $1.87 \times 10^{-13}$ \\
\hline LVLDLP & $-0.13(-0.16--0.09)$ & $1.73 \times 10^{-11}$ & $0.06(0.02-0.09)$ & $1.33 \times 10^{-03}$ & $-0.12(-0.15--0.08)$ & $6.92 \times 10^{-10}$ & $0.13(0.10-0.16)$ & $3.24 \times 10^{-13}$ \\
\hline LVLDLL & $-0.13(-0.17--0.10)$ & $8.07 \times 10^{-12}$ & $0.06(0.02-0.09)$ & $1.38 \times 10^{-03}$ & $-0.12(-0.15--0.09)$ & $2.73 \times 10^{-10}$ & $0.13(0.10-0.16)$ & $2.99 \times 10^{-13}$ \\
\hline LVLDLPL & $-0.13(-0.16--0.09)$ & $1.73 \times 10^{-11}$ & $0.06(0.03-0.09)$ & $7.69 \times 10^{-04}$ & $-0.12(-0.15--0.08)$ & $6.92 \times 10^{-10}$ & $0.13(0.10-0.16)$ & $3.24 \times 10^{-13}$ \\
\hline LVLDLC & $-0.13(-0.16--0.09)$ & $2.95 \times 10^{-11}$ & $0.06(0.03-0.09)$ & $1.11 \times 10^{-03}$ & $-0.11(-0.15--0.08)$ & $1.24 \times 10^{-09}$ & $0.13(0.09-0.16)$ & $3.88 \times 10^{-13}$ \\
\hline LVLDLCE & $-0.13(-0.16--0.09)$ & $1.12 \times 10^{-11}$ & $0.05(0.02-0.08)$ & $5.35 \times 10^{-03}$ & $-0.12(-0.15--0.08)$ & $7.34 \times 10^{-10}$ & $0.12(0.09-0.15)$ & $4.15 \times 10^{-12}$ \\
\hline LVLDLFC & $-0.12(-0.16--0.09)$ & $5.35 \times 10^{-11}$ & $0.06(0.03-0.10)$ & $3.16 \times 10^{-04}$ & $-0.11(-0.15--0.08)$ & $1.50 \times 10^{-09}$ & $0.13(0.10-0.16)$ & $2.01 \times 10^{-13}$ \\
\hline LVLDLTG & $-0.13(-0.17--0.10)$ & $8.07 \times 10^{-12}$ & $0.06(0.02-0.09)$ & $1.80 \times 10^{-03}$ & $-0.12(-0.15--0.09)$ & $2.73 \times 10^{-10}$ & $0.13(0.10-0.16)$ & $3.01 \times 10^{-13}$ \\
\hline MVLDLP & $-0.13(-0.16--0.09)$ & $1.12 \times 10^{-11}$ & $0.04(0.01-0.08)$ & $1.77 \times 10^{-02}$ & $-0.12(-0.15--0.08)$ & $7.34 \times 10^{-10}$ & $0.12(0.09-0.15)$ & $1.01 \times 10^{-11}$ \\
\hline MVLDLL & $-0.13(-0.17--0.10)$ & $6.87 \times 10^{-12}$ & $0.04(0.01-0.08)$ & $1.79 \times 10^{-02}$ & $-0.12(-0.15--0.08)$ & $3.53 \times 10^{-10}$ & $0.12(0.09-0.15)$ & $5.61 \times 10^{-12}$ \\
\hline MVLDLPL & $-0.13(-0.16--0.09)$ & $1.12 \times 10^{-11}$ & $0.05(0.01-0.08)$ & $9.89 \times 10^{-03}$ & $-0.12(-0.15--0.08)$ & $6.92 \times 10^{-10}$ & $0.12(0.09-0.15)$ & $6.22 \times 10^{-12}$ \\
\hline MVLDLC & $-0.12(-0.16--0.09)$ & $4.71 \times 10^{-11}$ & $0.05(0.02-0.08)$ & $4.78 \times 10^{-03}$ & $-0.11(-0.15--0.08)$ & $2.00 \times 10^{-09}$ & $0.12(0.08-0.15)$ & $2.35 \times 10^{-11}$ \\
\hline MVLDLCE & $-0.11(-0.15--0.08)$ & $6.54 \times 10^{-10}$ & $0.05(0.02-0.08)$ & $5.99 \times 10^{-03}$ & $-0.10(-0.14--0.07)$ & $2.44 \times 10^{-08}$ & $0.11(0.07-0.14)$ & $9.95 \times 10^{-10}$ \\
\hline MVLDLFC & $-0.13(-0.16--0.09)$ & $2.20 \times 10^{-11}$ & $0.05(0.02-0.08)$ & $4.23 \times 10^{-03}$ & $-0.11(-0.15--0.08)$ & $8.56 \times 10^{-10}$ & $0.12(0.09-0.16)$ & $1.39 \times 10^{-12}$ \\
\hline MVLDLTG & $-0.13(-0.17--0.10)$ & $5.86 \times 10^{-12}$ & $0.04(0.01-0.07)$ & $2.70 \times 10^{-02}$ & $-0.12(-0.15--0.08)$ & $2.73 \times 10^{-10}$ & $0.12(0.09-0.15)$ & $2.08 \times 10^{-12}$ \\
\hline SVLDLP & $-0.12(-0.15--0.08)$ & $1.93 \times 10^{-10}$ & $0.03(0.00-0.06)$ & $7.11 \times 10^{-02}$ & $-0.11(-0.14--0.07)$ & $8.24 \times 10^{-09}$ & $0.10(0.07-0.13)$ & $4.94 \times 10^{-09}$ \\
\hline SVLDLL & $-0.12(-0.15--0.08)$ & $2.76 \times 10^{-10}$ & $0.03(0.00-0.06)$ & $7.14 \times 10^{-02}$ & $-0.11(-0.14--0.07)$ & $9.52 \times 10^{-09}$ & $0.10(0.07-0.13)$ & $6.80 \times 10^{-09}$ \\
\hline SVLDLPL & $-0.11(-0.15--0.08)$ & $9.89 \times 10^{-10}$ & $0.04(0.01-0.07)$ & $1.99 \times 10^{-02}$ & $-0.10(-0.14--0.07)$ & $2.01 \times 10^{-08}$ & $0.10(0.07-0.13)$ & $6.80 \times 10^{-09}$ \\
\hline SVLDLC & $-0.09(-0.12--0.05)$ & $1.76 \times 10^{-06}$ & $0.03(0.00-0.07)$ & $5.79 \times 10^{-02}$ & $-0.08(-0.11--0.05)$ & $1.68 \times 10^{-05}$ & $0.08(0.05-0.12)$ & $2.08 \times 10^{-06}$ \\
\hline SVLDLCE & $-0.07(-0.11-0.04)$ & $6.86 \times 10^{-05}$ & $0.03(-0.01-0.06)$ & $1.26 \times 10^{-01}$ & $-0.07(-0.10--0.03)$ & $3.60 \times 10^{-04}$ & $0.07(0.04-0.10)$ & $1.42 \times 10^{-04}$ \\
\hline
\end{tabular}




\begin{tabular}{|c|c|c|c|c|c|c|c|c|}
\hline SVLDLFC & $-0.11(-0.14--0.07)$ & $7.49 \times 10^{-09}$ & $0.04(0.01-0.08)$ & $1.61 \times 10^{-2}$ & $-0.10(-0.13--0.06)$ & $1.33 \times 10^{-07}$ & $0.10(0.07-0.14)$ & $3.95 \times 10^{-09}$ \\
\hline SVLDLTG & $-0.13(-0.16--0.09)$ & $1.52 \times 10^{-11}$ & $0.03(0.00-0.06)$ & $1.03 \times 10^{-01}$ & $-0.11(-0.15--0.08)$ & $8.36 \times 10^{-10}$ & $0.11(0.08-0.14)$ & $4.04 \times 10^{-10}$ \\
\hline XSVLDLP & $-0.05(-0.09--0.02)$ & $4.87 \times 10^{-09}$ & $0.06(0.03-0.09)$ & $1.03 \times 10^{-03}$ & $-0.05(-0.09--0.02)$ & $4.45 \times 10^{-03}$ & $0.07(0.03-0.10)$ & $3.14 \times 10^{-04}$ \\
\hline XSVLDLL & $-0.05(-0.08--0.01)$ & $1.65 \times 10^{-02}$ & $0.06(0.02-0.09)$ & $1.54 \times 10^{-03}$ & $-0.05(-0.08--0.01)$ & $1.35 \times 10^{-02}$ & $0.06(0.03-0.09)$ & $1.23 \times 10^{-03}$ \\
\hline XSVLDLPL & $-0.01(-0.04-0.03)$ & $6.70 \times 10^{-01}$ & $0.07(0.04-0.10)$ & $1.61 \times 10^{-04}$ & $-0.02(-0.05-0.02)$ & $3.93 \times 10^{-01}$ & $0.04(0.01-0.07)$ & $2.93 \times 10^{-02}$ \\
\hline XSVLDLC & $-0.03(-0.06-0.01)$ & $1.47 \times 10^{-01}$ & $0.04(0.01-0.07)$ & $2.06 \times 10^{-2}$ & $-0.03(-0.07-0.01)$ & $1.32 \times 10^{-01}$ & $0.03(0.00-0.07)$ & $6.70 \times 10^{-02}$ \\
\hline XSVLDLCE & $-0.04(-0.07-0.00)$ & $6.77 \times 10^{-2}$ & $0.04(0.00-0.07)$ & $3.42 \times 10^{-2}$ & $-0.04(-0.07-0.00)$ & $6.70 \times 10^{-02}$ & $0.03(0.00-0.07)$ & $7.86 \times 10^{-02}$ \\
\hline XSVLDLFC & $-0.01(-0.05-0.03)$ & $6.17 \times 10^{-01}$ & $0.05(0.02-0.08)$ & $6.60 \times 10^{-03}$ & $-0.01(-0.05-0.02)$ & $4.62 \times 10^{-01}$ & $0.04(0.00-0.07)$ & $4.66 \times 10^{-02}$ \\
\hline XSVLDLTG & $-0.10(-0.14--0.07)$ & $2.32 \times 10^{-08}$ & $0.05(0.02-0.08)$ & $5.90 \times 10^{-03}$ & $-0.10(-0.13--0.06)$ & $1.86 \times 10^{-07}$ & $0.10(0.07-0.13)$ & $1.11 \times 10^{-08}$ \\
\hline IDLP & $0.01(-0.02-0.05)$ & $4.51 \times 10^{-01}$ & $0.07(0.03-0.10)$ & $2.72 \times 10^{-04}$ & $0.00(-0.03-0.04)$ & $8.12 \times 10^{-01}$ & $0.03(-0.01-0.06)$ & $1.40 \times 10^{-01}$ \\
\hline IDLL & $0.02(-0.01-0.06)$ & $2.75 \times 10^{-01}$ & $0.06(0.03-0.09)$ & $6.99 \times 10^{-04}$ & $0.01(-0.02-0.05)$ & $5.87 \times 10^{-01}$ & $0.02(-0.01-0.06)$ & $2.56 \times 10^{-01}$ \\
\hline IDLPL & $0.03(0.00-0.07)$ & $7.30 \times 10^{-2}$ & $0.06(0.03-0.09)$ & $9.42 \times 10^{-04}$ & $0.02(-0.01-0.06)$ & $2.53 \times 10^{-01}$ & $0.01(-0.02-0.05)$ & $5.18 \times 10^{-01}$ \\
\hline IDLC & $0.02(-0.01-0.06)$ & $2.37 \times 10^{-01}$ & $0.06(0.03-0.09)$ & $1.23 \times 10^{-03}$ & $0.01(-0.02-0.05)$ & $4.82 \times 10^{-01}$ & $0.02(-0.01-0.06)$ & $2.53 \times 10^{-01}$ \\
\hline IDLCE & $0.01(-0.03-0.04)$ & $6.21 \times 10^{-01}$ & $0.06(0.03-0.09)$ & $6.93 \times 10^{-04}$ & $0.00(-0.03-0.04)$ & $8.88 \times 10^{-01}$ & $0.03(0.00-0.07)$ & $7.89 \times 10^{-02}$ \\
\hline IDLFC & $0.05(0.02-0.09)$ & $3.99 \times 10^{-03}$ & $0.05(0.02-0.08)$ & $6.98 \times 10^{-03}$ & $0.04(0.01-0.08)$ & $3.04 \times 10^{-02}$ & $-0.01(-0.04-0.03)$ & $7.62 \times 10^{-01}$ \\
\hline IDLTG & $-0.05(-0.08--0.01)$ & $1.01 \times 10^{-2}$ & $0.09(0.06-0.13)$ & $1.20 \times 10^{-07}$ & $-0.06(-0.09--0.02)$ & $3.22 \times 10^{-03}$ & $0.08(0.05-0.11)$ & $1.05 \times 10^{-05}$ \\
\hline LLDLP & $0.02(-0.01-0.06)$ & $2.17 \times 10^{-01}$ & $0.06(0.02-0.09)$ & $1.69 \times 10^{-03}$ & $0.01(-0.02-0.05)$ & $4.69 \times 10^{-1}$ & $0.02(-0.01-0.06)$ & $2.18 \times 10^{-01}$ \\
\hline LLDLL & $0.03(-0.01-0.06)$ & $1.43 \times 10^{-01}$ & $0.05(0.02-0.08)$ & $3.80 \times 10^{-03}$ & $0.02(-0.02-0.05)$ & $3.41 \times 10^{-1}$ & $0.02(-0.01-0.05)$ & $3.14 \times 10^{-01}$ \\
\hline LLDLPL & $0.03(-0.01-0.06)$ & $1.72 \times 10^{-01}$ & $0.06(0.02-0.09)$ & $1.35 \times 10^{-03}$ & $0.02(-0.02-0.05)$ & $4.04 \times 10^{-1}$ & $0.02(-0.01-0.06)$ & $2.52 \times 10^{-01}$ \\
\hline LLDLC & $0.03(0.00-0.07)$ & $1.15 \times 10^{-01}$ & $0.04(0.01-0.08)$ & $1.78 \times 10^{-02}$ & $0.02(-0.01-0.06)$ & $2.67 \times 10^{-01}$ & $0.01(-0.02-0.05)$ & $4.91 \times 10^{-01}$ \\
\hline LLDLCE & $0.02(-0.01-0.06)$ & $2.48 \times 10^{-01}$ & $0.04(0.01-0.08)$ & $1.41 \times 10^{-02}$ & $0.02(-0.02-0.05)$ & $4.58 \times 10^{-1}$ & $0.02(-0.01-0.05)$ & $2.90 \times 10^{-01}$ \\
\hline LLDLFC & $0.05(0.02-0.09)$ & $4.74 \times 10^{-03}$ & $0.04(0.00-0.07)$ & $3.41 \times 10^{-02}$ & $0.04(0.01-0.08)$ & $2.90 \times 10^{-02}$ & $-0.01(-0.04-0.03)$ & $6.97 \times 10^{-01}$ \\
\hline LLDLTG & $-0.01(-0.04-0.03)$ & $6.86 \times 10^{-01}$ & $0.11(0.08-0.14)$ & $3.15 \times 10^{-10}$ & $-0.02(-0.06-0.01)$ & $2.41 \times 10^{-01}$ & $0.06(0.03-0.09)$ & $6.42 \times 10^{-04}$ \\
\hline MLDLP & $0.02(-0.01-0.06)$ & $2.19 \times 10^{-01}$ & $0.04(0.01-0.08)$ & $1.45 \times 10^{-2}$ & $0.02(-0.02-0.05)$ & $4.42 \times 10^{-01}$ & $0.02(-0.01-0.05)$ & $2.81 \times 10^{-01}$ \\
\hline MLDLL & $0.03(-0.01-0.06)$ & $1.82 \times 10^{-01}$ & $0.04(0.01-0.07)$ & $2.15 \times 10^{-2}$ & $0.02(-0.02-0.05)$ & $3.74 \times 10^{-01}$ & $0.02(-0.01-0.05)$ & $3.38 \times 10^{-01}$ \\
\hline MLDLPL & $0.00(-0.03-0.04)$ & $9.00 \times 10^{-01}$ & $0.06(0.03-0.09)$ & $7.94 \times 10^{-04}$ & $0.00(-0.04-0.03)$ & $8.25 \times 10^{-01}$ & $0.04(0.01-0.08)$ & $2.19 \times 10^{-02}$ \\
\hline MLDLC & $0.03(0.00-0.07)$ & $9.45 \times 10^{-2}$ & $0.03(-0.01-0.06)$ & $1.18 \times 10^{-01}$ & $0.03(-0.01-0.06)$ & $2.12 \times 10^{-01}$ & $0.01(-0.03-0.04)$ & $6.82 \times 10^{-01}$ \\
\hline MLDLCE & $0.03(0.00-0.07)$ & $9.98 \times 10^{-2}$ & $0.03(-0.01-0.06)$ & $1.55 \times 10^{-01}$ & $0.02(-0.01-0.06)$ & $2.16 \times 10^{-01}$ & $0.01(-0.03-0.04)$ & $7.26 \times 10^{-01}$ \\
\hline MLDLFC & $0.03(0.00-0.07)$ & $7.41 \times 10^{-2}$ & $0.04(0.00-0.07)$ & $3.83 \times 10^{-02}$ & $0.03(-0.01-0.06)$ & $1.95 \times 10^{-01}$ & $0.01(-0.02-0.05)$ & $5.02 \times 10^{-01}$ \\
\hline MLDLTG & $0.01(-0.03-0.05)$ & $6.21 \times 10^{-1}$ & $0.12(0.08-0.15)$ & $5.63 \times 10^{-11}$ & $-0.01(-0.04-0.03)$ & $6.53 \times 10^{-01}$ & $0.05(0.02-0.09)$ & $3.28 \times 10^{-03}$ \\
\hline SLDLP & $0.03(-0.01-0.06)$ & $1.43 \times 10^{-1}$ & $0.04(0.01-0.08)$ & $1.31 X-10^{-2}$ & $0.02(-0.02-0.06)$ & $3.23 \times 10^{-01}$ & $0.02(-0.01-0.06)$ & $2.61 \times 10^{-01}$ \\
\hline SLDLL & $0.03(0.00-0.07)$ & $1.04 \times 10^{-1}$ & $0.04(0.01-0.07)$ & $1.90 \times 10^{-2}$ & $0.02(-0.01-0.06)$ & $2.53 \times 10^{-01}$ & $0.02(-0.01-0.05)$ & $3.33 \times 10^{-01}$ \\
\hline SLDLPL & $0.02(-0.02-0.05)$ & $3.56 \times 10^{-1}$ & $0.07(0.03-0.10)$ & $2.47 \times 10^{-04}$ & $0.01(-0.03-0.04)$ & $6.63 \times 10^{-01}$ & $0.04(0.01-0.07)$ & $3.04 \times 10^{-02}$ \\
\hline SLDLC & $0.04(0.00-0.08)$ & $3.76 \times 10^{-2}$ & $0.02(-0.01-0.06)$ & $1.58 \times 10^{-01}$ & $0.03(0.00-0.07)$ & $1.04 \times 10^{-01}$ & $0.00(-0.03-0.04)$ & $9.04 \times 10^{-01}$ \\
\hline SLDLCE & $0.04(0.01-0.08)$ & $3.67 \times 10^{-2}$ & $0.02(-0.01-0.05)$ & $2.24 \times 10^{-01}$ & $0.03(0.00-0.07)$ & $1.01 \times 10^{-01}$ & $0.00(-0.03-0.03)$ & $9.92 \times 10^{-01}$ \\
\hline SLDLFC & $0.04(0.00-0.07)$ & $6.28 \times 10^{-2}$ & $0.04(0.00-0.07)$ & $4.46 \times 10^{-02}$ & $0.03(-0.01-0.06)$ & $1.67 \times 10^{-01}$ & $0.01(-0.02-0.05)$ & $4.91 \times 10^{-01}$ \\
\hline SLDLTG & $-0.05(-0.09--0.02)$ & $7.74 \times 10^{-3}$ & $0.11(0.07-0.14)$ & $1.21 \times 10^{-09}$ & $-0.06(-0.09--0.02)$ & $2.80 \times 10^{-03}$ & $0.10(0.06-0.13)$ & $4.52 \times 10^{-08}$ \\
\hline XLHDLP & $0.10(0.07-0.14)$ & $6.19 \times 10^{-8}$ & $0.11(0.08-0.14)$ & $8.67 \times 10^{-10}$ & $0.07(0.04-0.10)$ & $1.50 \times 10^{-05}$ & $-0.02(-0.05-0.01)$ & $2.45 \times 10^{-01}$ \\
\hline
\end{tabular}




\begin{tabular}{|c|c|c|c|c|c|c|c|c|}
\hline XLHDLL & $0.10(0.07-0.14)$ & $6.90-\times 10^{-08}$ & $0.11(0.07-0.14)$ & $1.28 \times 10^{-09}$ & $0.07(0.04-0.10)$ & $1.54 \times 10^{-05}$ & $-0.02(-0.05-0.01)$ & $1.96 \times 10^{-01}$ \\
\hline XLHDLPL & $0.11(0.08-0.15)$ & $1.75 \times 10^{-09}$ & $0.10(0.07-0.13)$ & $7.66 \times 10^{-09}$ & $0.08(0.05-0.11)$ & $5.47 \times 10^{-07}$ & $-0.04(-0.06--0.01)$ & $3.06 \times 10^{-02}$ \\
\hline XLHDLC & $0.09(0.05-0.12)$ & $1.79 \times 10^{-06}$ & $0.10(0.07-0.14)$ & $6.71 \times 10^{-09}$ & $0.06(0.03-0.10)$ & $2.62 \times 10^{-04}$ & $-0.01(-0.04-0.02)$ & $4.31 \times 10^{-01}$ \\
\hline XLHDLCE & $0.09(0.05-0.12)$ & $4.46 \times 10^{-06}$ & $0.10(0.06-0.13)$ & $3.49 \times 10^{-08}$ & $0.06(0.03-0.09)$ & $4.65 \times 10^{-04}$ & $-0.01(-0.04-0.02)$ & $4.99 \times 10^{-01}$ \\
\hline XLHDLFC & $0.10(0.06-0.13)$ & $2.33 \times 10^{-07}$ & $0.12(0.08-0.15)$ & $7.55 \times 10^{-11}$ & $0.07(0.04-0.10)$ & $5.99 \times 10^{-05}$ & $-0.01(-0.04-0.02)$ & $3.96 \times 10^{-01}$ \\
\hline XLHDLTG & $-0.02(-0.06-0.01)$ & $2.46 \times 10^{-01}$ & $0.12(0.08-0.15)$ & $5.63 \times 10-11$ & $-0.03(-0.07-0.00)$ & $1.16 \times 10^{-01}$ & $0.08(0.05-0.12)$ & $4.62 \times 10^{-06}$ \\
\hline LHDLP & $0.12(0.08-0.15)$ & $4.78 \times 10^{-10}$ & $0.11(0.08-0.14)$ & $5.95 \times 10^{-10}$ & $0.09(0.05-0.12)$ & $2.43 \times 10^{-07}$ & $-0.03(-0.06-0.00)$ & $9.52 \times 10^{-02}$ \\
\hline LHDLL & $0.12(0.08-0.15)$ & $4.00 \times 10^{-10}$ & $0.10(0.07-0.14)$ & $4.18 \times 10^{-09}$ & $0.09(0.06-0.12)$ & $2.13 \times 10^{-07}$ & $-0.03(-0.06-0.00)$ & $4.50 \times 10^{-02}$ \\
\hline LHDLPL & $0.11(0.08-0.15)$ & $7.30 \times 10^{-10}$ & $0.11(0.07-0.14)$ & $1.21 \times 10^{-09}$ & $0.08(0.05-0.11)$ & $4.88 \times 10^{-07}$ & $-0.03(-0.06-0.00)$ & $7.53 \times 10^{-02}$ \\
\hline LHDLC & $0.12(0.08-0.15)$ & $1.54 \times 10^{-10}$ & $0.10(0.07-0.13)$ & $8.23 \times 10^{-09}$ & $0.09(0.06-0.12)$ & $5.11 \times 10^{-08}$ & $-0.04(-0.06--0.01)$ & $3.06 \times 10^{-02}$ \\
\hline LHDLCE & $0.12(0.08-0.15)$ & $1.98 \times 10^{-10}$ & $0.10(0.07-0.14)$ & $5.84 \times 10^{-09}$ & $0.09(0.06-0.12)$ & $7.50 \times 10^{-08}$ & $-0.03(-0.06-0.00)$ & $3.91 \times 10^{-02}$ \\
\hline LHDLFC & $0.12(0.09-0.16)$ & $7.50 \times 10^{-11}$ & $0.10(0.07-0.13)$ & $9.97 \times 10^{-09}$ & $0.09(0.06-0.12)$ & $2.66 \times 10^{-08}$ & $-0.04(-0.07--0.01)$ & $3.05 \times 10^{-02}$ \\
\hline LHDLTG & $0.08(0.04-0.11)$ & $4.72 \times 10^{-05}$ & $0.13(0.09-0.16)$ & $1.23 \times 10^{-12}$ & $0.05(0.02-0.08)$ & $2.80 \times 10^{-03}$ & $0.01(-0.02-0.04)$ & $6.08 \times 10^{-01}$ \\
\hline MHDLP & $0.08(0.04-0.11)$ & $2.62 \times 10^{-05}$ & $0.14(0.10-0.17)$ & $3.35 \times 10^{-14}$ & $0.05(0.02-0.08)$ & $4.13 \times 10^{-03}$ & $0.01(-0.02-0.04)$ & $4.88 \times 10^{-01}$ \\
\hline MHDLL & $0.07(0.04-0.11)$ & $1.35 \times 10^{-04}$ & $0.13(0.10-0.17)$ & $6.12 \times 10^{-14}$ & $0.05(0.01-0.08)$ & $1.05 \times 10^{-02}$ & $0.02(-0.01-0.05)$ & $2.41 \times 10^{-01}$ \\
\hline MHDLPL & $0.08(0.04-0.11)$ & $2.24 \times 10^{-05}$ & $0.14(0.11-0.17)$ & $9.98 \times 10^{-15}$ & $0.05(0.02-0.08)$ & $4.30 \times 10^{-03}$ & $0.01(-0.02-0.04)$ & $4.91 \times 10^{-01}$ \\
\hline MHDLC & $0.09(0.05-0.12)$ & $1.61 \times 10^{-06}$ & $0.11(0.08-0.15)$ & $1.02 \times 10^{-10}$ & $0.06(0.03-0.10)$ & $3.15 \times 10^{-04}$ & $0.00(-0.03-0.03)$ & $9.34 \times 10^{-01}$ \\
\hline MHDLCE & $0.09(0.05-0.12)$ & $2.05 \times 10^{-06}$ & $0.11(0.08-0.15)$ & $2.31 \times 10^{-10}$ & $0.06(0.03-0.10)$ & $3.54 \times 10^{-04}$ & $0.00(-0.03-0.03)$ & $9.29 \times 10^{-01}$ \\
\hline MHDLFC & $0.09(0.06-0.13)$ & $8.70 \times 10^{-07}$ & $0.12(0.09-0.15)$ & $9.21 \times 10^{-12}$ & $0.06(0.03-0.10)$ & $2.62 \times 10^{-04}$ & $0.00(-0.03-0.03)$ & $9.92 \times 10^{-01}$ \\
\hline MHDLTG & $-0.09(-0.13--0.06)$ & $5.69 \times 10^{-07}$ & $0.10(0.07-0.13)$ & $8.80 \times 10^{-09}$ & $-0.09(-0.13--0.06)$ & $7.25 \times 10^{-07}$ & $0.11(0.07-0.14)$ & $2.53 \times 10^{-09}$ \\
\hline SHDLP & $0.03(-0.01-0.06)$ & $1.28 \times 10^{-01}$ & $0.08(0.05-0.11)$ & $7.13 \times 10^{-06}$ & $0.01(-0.02-0.05)$ & $5.03 \times 10^{-01}$ & $0.03(0.00-0.06)$ & $1.24 \times 10^{-01}$ \\
\hline SHDLL & $0.04(0.00-0.07)$ & $5.71 \times 10^{-02}$ & $0.08(0.05-0.11)$ & $1.07 \times 10^{-05}$ & $0.02(-0.02-0.05)$ & $3.22 \times 10^{-01}$ & $0.02(-0.01-0.06)$ & $2.15 \times 10^{-01}$ \\
\hline SHDLPL & $0.00(-0.04-0.03)$ & $8.17 \times 10^{-01}$ & $0.11(0.07-0.14)$ & $1.79 \times 10^{-09}$ & $-0.02(-0.05-0.02)$ & $3.68 \times 10^{-01}$ & $0.06(0.03-0.09)$ & $1.15 \times 10^{-03}$ \\
\hline SHDLC & $0.09(0.05-0.12)$ & $4.86 \times 10^{-06}$ & $0.02(-0.01-0.05)$ & $2.19 \times 10^{-01}$ & $0.07(0.03-0.10)$ & $3.91 \times 10^{-04}$ & $-0.04(-0.07--0.01)$ & $3.34 \times 10^{-02}$ \\
\hline SHDLCE & $0.09(0.05-0.12)$ & $2.06 \times 10^{-06}$ & $0.00(-0.03-0.04)$ & $7.91 \times 10-01$ & $0.07(0.04-0.11)$ & $1.27 \times 10^{-04}$ & $-0.05(-0.08--0.01)$ & $8.59 \times 10^{-03}$ \\
\hline SHDLFC & $0.02(-0.01-0.06)$ & $2.24 \times 10^{-01}$ & $0.10(0.07-0.13)$ & $1.98 \times 10^{-08}$ & $0.01(-0.03-0.04)$ & $7.13 \times 10^{-01}$ & $0.05(0.01-0.08)$ & $1.04 \times 10^{-02}$ \\
\hline SHDLTG & $-0.12(-0.15--0.08)$ & $3.88 \times 10^{-10}$ & $0.04(0.01-0.08)$ & $1.20 \times 10^{-02}$ & $-0.11(-0.14--0.07)$ & $6.18 \times 10^{-09}$ & $0.10(0.07-0.13)$ & $5.30 \times 10^{-09}$ \\
\hline XXLVLDLPLp & $-0.06(-0.09--0.02)$ & $1.77 \times 10^{-03}$ & $0.05(0.01-0.08)$ & $8.16 \times 10^{-03}$ & $-0.06(-0.09--0.02)$ & $2.70 \times 10^{-03}$ & $0.07(0.04-0.10)$ & $8.54 \times 10^{-05}$ \\
\hline XXLVLDLCp & $-0.06(-0.10--0.03)$ & $1.41 \times 10^{-03}$ & $0.05(0.01-0.08)$ & $7.92 \times 10^{-03}$ & $-0.06(-0.09--0.02)$ & $3.10 \times 10^{-03}$ & $0.08(0.04-0.11)$ & $1.78 \times 10^{-05}$ \\
\hline XXLVLDLCEp & $-0.05(-0.08--0.01)$ & $9.95 \times 10^{-03}$ & $0.05(0.01-0.08)$ & $8.20 \times 10^{-03}$ & $-0.04(-0.08--0.01)$ & $2.26 \times 10^{-02}$ & $0.08(0.04-0.11)$ & $2.81 \times 10^{-05}$ \\
\hline XXLVLDLFCp & $-0.07(-0.11--0.04)$ & $7.84 \times 10^{-05}$ & $0.05(0.02-0.08)$ & $5.71 \times 10^{-03}$ & $-0.07(-0.11--0.04)$ & $2.04 \times 10^{-04}$ & $0.08(0.05-0.12)$ & $3.76 \times 10^{-06}$ \\
\hline XXLVLDLTGp & $-0.05(-0.09--0.02)$ & $4.09 \times 10^{-03}$ & $0.03(0.00-0.07)$ & $5.32 \times 10^{-02}$ & $-0.05(-0.09--0.02)$ & $6.47 \times 10^{-03}$ & $0.06(0.02-0.09)$ & $1.64 \times 10^{-03}$ \\
\hline XLVLDLPLp & $-0.06(-0.10--0.03)$ & $7.50 \times 10^{-04}$ & $0.06(0.03-0.10)$ & $4.37 \times 10^{-04}$ & $-0.06(-0.10--0.03)$ & $6.92 \times 10^{-04}$ & $0.09(0.05-0.12)$ & $1.40 \times 10^{-06}$ \\
\hline XLVLDLCp & $-0.06(-0.10--0.03)$ & $7.48 \times 10^{-04}$ & $0.05(0.02-0.08)$ & $3.58 \times 10^{-03}$ & $-0.06(-0.10--0.03)$ & $1.36 \times 10^{-03}$ & $0.08(0.05-0.12)$ & $2.19 \times 10^{-06}$ \\
\hline XLVLDLCEp & $-0.06(-0.09--0.02)$ & $1.74 \times 10^{-03}$ & $0.04(0.01-0.08)$ & $1.61 \times 10^{-02}$ & $-0.06(-0.09--0.02)$ & $3.92 \times 10^{-03}$ & $0.08(0.05-0.11)$ & $1.24 \times 10^{-05}$ \\
\hline XLVLDLFCp & $-0.07(-0.11--0.04)$ & $1.20 \times 10^{-04}$ & $0.06(0.03-0.09)$ & $5.91 \times 10^{-04}$ & $-0.07(-0.11-0.04)$ & $1.68 \times 10^{-04}$ & $0.09(0.06-0.13)$ & $1.77 \times 10^{-07}$ \\
\hline XLVLDLTGp & $-0.06(-0.09--0.02)$ & $2.01 \times 10^{-03}$ & $0.05(0.02-0.08)$ & $4.52 \times 10^{-03}$ & $-0.06(-0.09--0.02)$ & $2.39 \times 10^{-03}$ & $0.07(0.04-0.11)$ & $3.14 \times 10^{-05}$ \\
\hline LVLDLPLp & $-0.05(-0.09--0.01)$ & $8.64 \times 10^{-03}$ & $0.04(0.01-0.07)$ & $1.92 \times 10^{-02}$ & $-0.05(-0.09--0.02)$ & $5.83 \times 10^{-03}$ & $0.05(0.02-0.08)$ & $5.34 \times 10^{-03}$ \\
\hline
\end{tabular}




\begin{tabular}{|c|c|c|c|c|c|c|c|c|}
\hline LVLDLCp & $-0.07(-0.11--0.04)$ & $1.95 \times 10^{-04}$ & $0.04(0.01-0.07)$ & $1.85 \times 10^{-02}$ & $-0.07(-0.10--0.03)$ & $2.62 \times 10^{-04}$ & $0.07(0.03-0.10)$ & $2.79 \times 010^{-04}$ \\
\hline LVLDLCEp & $-0.06(-0.09--0.02)$ & $2.05 \times 10^{-03}$ & $0.03(0.00-0.06)$ & $1.10 \times 10^{-01}$ & $-0.06(-0.09--0.02)$ & $3.38 \times 10^{-03}$ & $0.05(0.02-0.08)$ & $6.87 \times 10^{-03}$ \\
\hline LVLDLFCp & $-0.09(-0.12--0.05)$ & $3.37 \times 10^{-06}$ & $0.06(0.02-0.09)$ & $1.54 \times 10^{-03}$ & $-0.09(-0.12--0.05)$ & $3.60 \times 10^{-06}$ & $0.09(0.05-0.12)$ & $1.46 \times 10^{-06}$ \\
\hline LVLDLTGp & $-0.05(-0.09--0.02)$ & $7.58 \times 10^{-03}$ & $0.03(0.00-0.07)$ & $5.32 \times 10^{-02}$ & $-0.05(-0.09--0.02)$ & $6.24 \times 10^{-03}$ & $0.05(0.01-0.08)$ & $1.13 \times 10^{-02}$ \\
\hline MVLDLPLp & $0.12(0.09-0.16)$ & $3.46 \times 10^{-11}$ & $0.02(-0.01-0.05)$ & $2.90 \times 10^{-01}$ & $0.10(0.07-0.14)$ & $8.24 \times 10^{-09}$ & $-0.08(-0.11--0.05)$ & $1.01 \times 10^{-06}$ \\
\hline MVLDLCp & $0.01(-0.03-0.04)$ & $7.44 \times 10^{-01}$ & $0.06(0.02-0.09)$ & $1.40 \times 10^{-03}$ & $0.00(-0.04-0.03)$ & $8.59 \times 10^{-01}$ & $0.02(-0.02-0.05)$ & $3.51 \times 10^{-01}$ \\
\hline MVLDLCEp & $0.00(-0.04-0.03)$ & $8.01 \times 10^{-01}$ & $0.05(0.01-0.08)$ & $9.20 \times 10^{-03}$ & $-0.01(-0.05-0.02)$ & $6.13 \times 10^{-01}$ & $0.02(-0.02-0.05)$ & $4.31 \times 10^{-01}$ \\
\hline MVLDLFCp & $-0.08(-0.11--0.04)$ & $2.47 \times 10^{-05}$ & $0.07(0.04-0.10)$ & $6.30 \times 10^{-05}$ & $-0.08(-0.12--0.05)$ & $1.32 \times 10^{-05}$ & $0.10(0.06-0.13)$ & $3.95 \times 10^{-08}$ \\
\hline MVLDLTGp & $-0.05(-0.08--0.01)$ & $9.18 \times 10^{-03}$ & $-0.06(-0.10--0.03)$ & $2.95 \times 10^{-04}$ & $-0.03(-0.07-0.00)$ & $8.10 \times 10^{-02}$ & $0.00(-0.03-0.04)$ & $9.19 \times 10^{-01}$ \\
\hline SVLDLPLp & $0.10(0.07-0.14)$ & $4.49 \times 10^{-08}$ & $0.01(-0.02-0.04)$ & $5.55 \times 10^{-01}$ & $0.09(0.05-0.12)$ & $2.31 \times 10^{-06}$ & $-0.08(-0.11--0.05)$ & $8.00 \times 10^{-06}$ \\
\hline SVLDLCp & $0.04(0.00-0.07)$ & $5.94 \times 10^{-02}$ & $0.01(-0.02-0.05)$ & $4.72 \times 10^{-01}$ & $0.03(-0.01-0.06)$ & $1.44 \times 10^{-01}$ & $-0.02(-0.05-0.02)$ & $3.71 \times 10^{-01}$ \\
\hline SVLDLCEp & $0.00(-0.04-0.03)$ & $9.17 \times 10^{-01}$ & $0.01(-0.02-0.04)$ & $5.88 \times 10^{-01}$ & $0.00(-0.04-0.03)$ & $8.68 \times 10^{-01}$ & $0.00(-0.03-0.03)$ & $9.92 \times 10^{-01}$ \\
\hline SVLDLFCp & $0.11(0.08-0.15)$ & $1.00 \times 10^{-09}$ & $0.06(0.03-0.10)$ & $2.91 \times 10^{-04}$ & $0.09(0.05-0.12)$ & $8.81 \times 10^{-07}$ & $-0.03(-0.07-0.00)$ & $5.16 \times 10^{-02}$ \\
\hline SVLDLTGp & $-0.10(-0.13--0.06)$ & $1.21 \times 10^{-07}$ & $-0.02(-0.05-0.02)$ & $3.43 \times 10^{-01}$ & $-0.08(-0.12--0.05)$ & $8.20 \times 10^{-06}$ & $0.06(0.03-0.09)$ & $8.43 \times 10^{-04}$ \\
\hline XSVLDLPLp & $0.12(0.09-0.16)$ & $4.61 \times 10-11$ & $0.03(0.00-0.07)$ & $6.22 \times 10^{-02}$ & $0.10(0.07-0.14)$ & $8.24 \times 10^{-09}$ & $-0.06(-0.10--0.03)$ & $1.87 \times 10^{-04}$ \\
\hline XSVLDLCp & $0.02(-0.02-0.05)$ & $3.29 \times 10^{-01}$ & $-0.02(-0.05-0.02)$ & $3.60 \times 10^{-01}$ & $0.02(-0.02-0.05)$ & $3.64 \times 10^{-01}$ & $-0.04(-0.07-0.00)$ & $5.20 \times 10^{-02}$ \\
\hline XSVLDLCEp & $-0.02(-0.06-0.02)$ & $3.03 \times 10^{-01}$ & $0.00(-0.03-0.03)$ & $9.03 \times 10^{-01}$ & $-0.02(-0.05-0.02)$ & $3.68 \times 10^{-01}$ & $-0.01(-0.05-0.02)$ & $5.16 \times 10^{-01}$ \\
\hline XSVLDLFCp & $0.12(0.08-0.15)$ & $1.67 \times 10^{-10}$ & $-0.04(-0.07-0.00)$ & $4.01 \times 10^{-02}$ & $0.11(0.07-0.14)$ & $6.69 \times 10^{-09}$ & $-0.09(-0.12--0.05)$ & $1.71 \times 10^{-06}$ \\
\hline XSVLDLTGp & $-0.08(-0.12--0.05)$ & $1.05 \times 10^{-05}$ & $0.01(-0.03-0.04)$ & $7.51 \times 10^{-01}$ & $-0.07(-0.11--0.04)$ & $1.12 \times 10^{-04}$ & $0.06(0.03-0.09)$ & $6.17 \times 10^{-04}$ \\
\hline IDLPLp & $0.07(0.04-0.11)$ & $1.05 \times 10^{-04}$ & $-0.07(-0.10--0.03)$ & $2.07 \times 10^{-04}$ & $0.07(0.03-0.10)$ & $3.60 \times 10^{-04}$ & $-0.10(-0.13--0.07)$ & $3.22 \times 10^{-08}$ \\
\hline IDLCp & $0.02(-0.02-0.05)$ & $3.34 \times 10^{-01}$ & $0.00(-0.03-0.03)$ & $9.96 \times 10^{-01}$ & $0.02(-0.02-0.05)$ & $3.62 \times 10^{-01}$ & $-0.01(-0.05-0.02)$ & $4.84 \times 10^{-01}$ \\
\hline IDLCEp & $-0.04(-0.07-0.00)$ & $6.96 \times 10^{-02}$ & $0.02(-0.01-0.05)$ & $2.55 \times 10^{-01}$ & $-0.03(-0.07-0.00)$ & $1.28 \times 10^{-01}$ & $0.04(0.01-0.07)$ & $3.43 \times 10^{-02}$ \\
\hline IDLFCp & $0.12(0.08-0.15)$ & $3.91 \times 10^{-10}$ & $-0.04(-0.07--0.01)$ & $2.74 \times 10^{-02}$ & $0.10(0.07-0.14)$ & $1.39 \times 10^{-08}$ & $-0.11(-0.14--0.08)$ & $4.26 \times 10^{-10}$ \\
\hline IDLTGp & $-0.05(-0.09--0.01)$ & $8.83 \times 10^{-03}$ & $0.03(0.00-0.07)$ & $5.32 \times 10^{-02}$ & $-0.05(-0.08--0.01)$ & $1.35 \times 10^{-02}$ & $0.06(0.02-0.09)$ & $1.63 \times 10^{-03}$ \\
\hline LLDLPLp & $-0.03(-0.06-0.01)$ & $1.34 \times 10^{-01}$ & $-0.02(-0.05-0.02)$ & $3.48 \times 10^{-01}$ & $-0.02(-0.06-0.01)$ & $2.90 \times 10^{-01}$ & $0.00(-0.03-0.04)$ & $9.29 \times 10^{-01}$ \\
\hline LLDLCp & $0.04(0.00-0.07)$ & $6.53 \times 10^{-02}$ & $-0.03(-0.07-0.00)$ & $6.56 \times 10^{-02}$ & $0.03(0.00-0.07)$ & $8.16 \times 10^{-02}$ & $-0.04(-0.07-0.00)$ & $5.24 \times 10^{-02}$ \\
\hline LLDLCEp & $-0.01(-0.04-0.03)$ & $6.86 \times 10^{-01}$ & $0.00(-0.03-0.03)$ & $9.03 \times 10^{-01}$ & $-0.01(-0.04-0.03)$ & $7.32 \times 10^{-01}$ & $0.02(-0.02-0.05)$ & $3.96 \times 10^{-01}$ \\
\hline LLDLFCp & $0.09(0.06-0.13)$ & $4.03 \times 10^{-07}$ & $-0.07(-0.11-0.04)$ & $5.05 \times 10^{-05}$ & $0.09(0.05-0.12)$ & $1.95 \times 10^{-06}$ & $-0.12(-0.16--0.09)$ & $1.79 \times 10^{-12}$ \\
\hline LLDLTGp & $-0.03(-0.07-0.00)$ & $7.41 \times 10^{-02}$ & $0.07(0.03-0.10)$ & $2.30 \times 10^{-04}$ & $-0.04(-0.08-0.00)$ & $4.11 \times 10^{-02}$ & $0.05(0.02-0.09)$ & $5.25 \times 10^{-03}$ \\
\hline MLDLPLp & $-0.06(-0.10--0.03)$ & $1.00 \times 10^{-03}$ & $0.01(-0.02-0.04)$ & $5.22 \times 10^{-01}$ & $-0.05(-0.09--0.02)$ & $5.27 \times 10^{-03}$ & $0.04(0.00-0.07)$ & $4.97 \times 10^{-02}$ \\
\hline MLDLCp & $0.04(0.01-0.08)$ & $2.86 \times 10^{-02}$ & $-0.04(-0.07--0.01)$ & $2.73 \times 10^{-02}$ & $0.04(0.00-0.08)$ & $4.39 \times 10^{-02}$ & $-0.04(-0.08--0.01)$ & $2.05 \times 10^{-02}$ \\
\hline MLDLCEp & $0.04(0.00-0.07)$ & $5.15 \times 10^{-02}$ & $-0.02(-0.05-0.01)$ & $2.34 \times 10^{-01}$ & $0.03(0.00-0.07)$ & $8.38 \times 10^{-02}$ & $-0.03(-0.06-0.00)$ & $1.30 \times 10^{-01}$ \\
\hline MLDLFCp & $0.00(-0.04-0.03)$ & $9.82 \times 10^{-01}$ & $-0.04(-0.07-0.00)$ & $4.14 \times 10^{-02}$ & $0.01(-0.03-0.04)$ & $7.92 \times 10^{-01}$ & $-0.02(-0.06-0.01)$ & $2.17 \times 10^{-01}$ \\
\hline MLDLTGp & $-0.02(-0.05-0.02)$ & $3.86 \times 10^{-01}$ & $0.08(0.05-0.11)$ & $1.07 \times 10^{-05}$ & $-0.03(-0.06-0.01)$ & $1.63 \times 10^{-01}$ & $0.04(0.00-0.07)$ & $4.66 \times 10^{-02}$ \\
\hline SLDLPLp & $-0.04(-0.08--0.01)$ & $2.86 \times 10^{-02}$ & $0.02(-0.02-0.05)$ & $3.24 \times 10^{-01}$ & $-0.04(-0.07-0.00)$ & $6.11 \times 10^{-02}$ & $0.03(0.00-0.06)$ & $1.30 \times 10^{-01}$ \\
\hline SLDLCp & $0.05(0.02-0.09)$ & $5.15 \times 10^{-03}$ & $-0.04(-0.08--0.01)$ & $1.23 \times 10^{-02}$ & $0.05(0.01-0.08)$ & $1.07 \times 10^{-02}$ & $-0.06(-0.09--0.03)$ & $1.08 \times 10^{-03}$ \\
\hline SLDLCEp & $0.05(0.01-0.08)$ & $1.50 \times 10^{-02}$ & $-0.03(-0.07-0.00)$ & $5.47 \times 10^{-02}$ & $0.04(0.01-0.08)$ & $3.55 \times 10^{-02}$ & $-0.05(-0.08--0.02)$ & $6.87 \times 10^{-03}$ \\
\hline SLDLFCp & $0.01(-0.03-0.04)$ & $7.59 \times 10^{-01}$ & $-0.04(-0.07-0.00)$ & $4.62 \times 10^{-02}$ & $0.01(-0.02-0.05)$ & $5.70 \times 10^{-01}$ & $-0.02(-0.05-0.02)$ & $4.15 \times 10^{-01}$ \\
\hline
\end{tabular}




\begin{tabular}{|c|c|c|c|c|c|c|c|c|}
\hline SLDLTGp & $-0.06(-0.09--0.02)$ & $2.56 \times 10^{-03}$ & $0.08(0.04-0.11)$ & $1.37 \times 10^{-05}$ & $-0.06(-0.09--0.02)$ & $2.69 \times 10^{-03}$ & $0.08(0.05-0.12)$ & $5.15 \times 10^{-06}$ \\
\hline XLHDLPLp & $0.05(0.01-0.08)$ & $1.37 \times 10^{-02}$ & $0.04(0.01-0.07)$ & $2.06 \times 10^{-02}$ & $0.04(0.00-0.07)$ & $6.45 \times 10^{-02}$ & $-0.02(-0.05-0.02)$ & $4.05 \times 10^{-01}$ \\
\hline XLHDLCp & $0.01(-0.02-0.05)$ & $5.76 \times 10^{-01}$ & $0.04(0.00-0.07)$ & $4.67 \times 10^{-02}$ & $0.01(-0.03-0.04)$ & $7.00 \times 10^{-01}$ & $0.02(-0.02-0.05)$ & $3.96 \times 10^{-01}$ \\
\hline XLHDLCEp & $0.01(-0.03-0.04)$ & $8.01 \times 10^{-01}$ & $0.03(-0.01-0.06)$ & $1.28 \times 10^{-01}$ & $0.00(-0.03-0.04)$ & $8.46 \times 10^{-01}$ & $0.02(-0.01-0.05)$ & $3.38 \times 10^{-01}$ \\
\hline XLHDLFCp & $0.03(0.00-0.07)$ & $1.18 \times 10^{-01}$ & $0.07(0.03-0.10)$ & $2.04 \times 10^{-04}$ & $0.02(-0.02-0.05)$ & $3.40 \times 10^{-01}$ & $0.01(-0.02-0.04)$ & $5.59 \times 10^{-01}$ \\
\hline XLHDLTGp & $-0.07(-0.11--0.04)$ & $1.99 \times 10^{-04}$ & $0.04(0.00-0.07)$ & $4.81 \times 10^{-02}$ & $-0.06(-0.09--0.02)$ & $1.79 \times 10^{-03}$ & $0.09(0.05-0.12)$ & $1.20 \times 10^{-06}$ \\
\hline LHDLPLp & $0.02(-0.02-0.05)$ & $3.82 \times 10^{-01}$ & $0.03(0.00-0.06)$ & $1.03 \times 10^{-01}$ & $0.01(-0.03-0.04)$ & $7.00 \times 10^{-01}$ & $-0.01(-0.04-0.03)$ & $6.82 \times 10^{-01}$ \\
\hline LHDLCP & $0.04(0.00-0.07)$ & $4.27 \times 10^{-02}$ & $0.04(0.00-0.07)$ & $3.41 \times 10^{-02}$ & $0.03(-0.01-0.06)$ & $1.88 \times 10^{-01}$ & $-0.02(-0.05-0.01)$ & $3.03 \times 10^{-01}$ \\
\hline LHDLCEp & $0.04(0.00-0.07)$ & $6.58 \times 10^{-02}$ & $0.04(0.00-0.07)$ & $3.70 \times 10^{-02}$ & $0.02(-0.01-0.06)$ & $2.45 \times 10^{-01}$ & $-0.02(-0.05-0.02)$ & $3.59 \times 10^{-01}$ \\
\hline LHDLFCp & $0.07(0.03-0.10)$ & $2.30 \times 10^{-04}$ & $0.04(0.01-0.07)$ & $1.97 \times 10^{-02}$ & $0.05(0.02-0.09)$ & $5.84 \times 10^{-03}$ & $-0.04(-0.07--0.01)$ & $3.13 \times 10^{-02}$ \\
\hline LHDLTGp & $-0.03(-0.07-0.00)$ & $7.17 \times 10^{-02}$ & $0.03(0.00-0.06)$ & $7.38 \times 10^{-02}$ & $-0.04(-0.07-0.00)$ & $7.71 \times 10^{-02}$ & $0.03(0.00-0.06)$ & $1.23 \times 10^{-01}$ \\
\hline MHDLPLp & $-0.07(-0.11--0.03)$ & $2.07 \times 10^{-04}$ & $0.03(0.00-0.06)$ & $8.98 \times 10^{-02}$ & $-0.07(-0.10--0.03)$ & $2.97 \times 10^{-04}$ & $0.04(0.01-0.08)$ & $2.65 \times 10^{-02}$ \\
\hline MHDLCp & $0.12(0.08-0.15)$ & $2.62 \times 10^{-10}$ & $-0.01(-0.05-0.02)$ & $4.17 \times 10^{-01}$ & $0.10(0.07-0.14)$ & $1.66 \times 10^{-08}$ & $-0.08(-0.11--0.04)$ & $1.58 \times 10^{-05}$ \\
\hline MHDLCEp & $0.10(0.07-0.14)$ & $5.35 \times 10^{-08}$ & $-0.04(-0.07--0.01)$ & $1.86 \times 10^{-02}$ & $0.10(0.06-0.13)$ & $3.94 \times 10^{-07}$ & $-0.08(-0.11--0.04)$ & $1.66 \times 10^{-05}$ \\
\hline MHDLFCp & $0.12(0.08-0.15)$ & $1.82 \times 10^{-10}$ & $0.07(0.03-0.10)$ & $1.74 \times 10^{-04}$ & $0.09(0.06-0.13)$ & $1.20 \times 10^{-07}$ & $-0.05(-0.08--0.02)$ & $4.34 \times 10^{-03}$ \\
\hline MHDLTGp & $-0.12(-0.16--0.09)$ & $5.67 \times 10^{-11}$ & $0.02(-0.02-0.05)$ & $3.78 \times 10^{-01}$ & $-0.11(-0.14--0.07)$ & $4.81 \times 10^{-09}$ & $0.09(0.05-0.12)$ & $5.98 \times 10^{-07}$ \\
\hline SHDLPLp & $-0.07(-0.11--0.04)$ & $7.21 \times 10^{-05}$ & $0.07(0.03-0.10)$ & $2.68 \times 10^{-04}$ & $-0.07(-0.11--0.04)$ & $2.29 \times 10^{-04}$ & $0.07(0.04-0.11)$ & $8.62 \times 10^{-05}$ \\
\hline SHDLCp & $0.10(0.06-0.13)$ & $3.18 \times 10^{-07}$ & $-0.07(-0.10--0.04)$ & $1.64 \times 10^{-04}$ & $0.09(0.05-0.12)$ & $4.50 \times 10^{-06}$ & $-0.10(-0.13--0.07)$ & $1.70 \times 10^{-08}$ \\
\hline SHDLCEp & $0.09(0.06-0.13)$ & $1.23 \times 10^{-06}$ & $-0.07(-0.10--0.03)$ & $1.87 \times 10^{-04}$ & $0.08(0.05-0.12)$ & $1.32 \times 10^{-05}$ & $-0.10(-0.13--0.06)$ & $5.06 \times 10^{-08}$ \\
\hline SHDLFCp & $-0.03(-0.07-0.00)$ & $7.73 \times 10^{-02}$ & $0.08(0.05-0.11)$ & $6.97 \times 10^{-06}$ & $-0.04(-0.07-0.00)$ & $6.45 \times 10^{-02}$ & $0.07(0.04-0.11)$ & $6.32 \times 10^{-05}$ \\
\hline SHDLTGp & $-0.11(-0.15--0.08)$ & $2.84 \times 10^{-09}$ & $0.01(-0.02-0.05)$ & $3.97 \times 10^{-01}$ & $-0.10(-0.13--0.06)$ & $1.07 \times 10^{-07}$ & $0.08(0.05-0.12)$ & $1.64 \times 10^{-06}$ \\
\hline VLDLD & $-0.14(-0.18--0.11)$ & $2.65 \times 10^{-13}$ & $0.03(-0.01-0.06)$ & $1.31 \times 10^{-01}$ & $-0.13(-0.16--0.09)$ & $1.48 \times 10^{-11}$ & $0.12(0.08-0.15)$ & $7.76 \times 10^{-12}$ \\
\hline LDLD & $-0.02(-0.05-0.02)$ & $4.40 \times 10^{-01}$ & $0.05(0.02-0.09)$ & $3.58 \times 10^{-03}$ & $-0.01(-0.05-0.02)$ & $4.61 \times 10^{-01}$ & $0.00(-0.03-0.04)$ & $9.28 \times 10^{-01}$ \\
\hline HDLD & $0.12(0.09-0.16)$ & $5.67 \times 10^{-11}$ & $0.10(0.07-0.13)$ & $1.98 \times 10^{-08}$ & $0.09(0.06-0.12)$ & $1.16 \times 10^{-08}$ & $-0.04(-0.07--0.01)$ & $1.25 \times 10^{-02}$ \\
\hline SerumC & $0.04(0.01-0.08)$ & $2.95 \times 10^{-02}$ & $0.08(0.05-0.12)$ & $3.58 \times 10^{-06}$ & $0.03(-0.01-0.06)$ & $1.67 \times 10^{-01}$ & $0.03(-0.01-0.06)$ & $1.88 \times 10^{-01}$ \\
\hline VLDLC & $-0.11(-0.14--0.07)$ & $1.58 \times 10^{-08}$ & $0.05(0.01-0.08)$ & $7.88 \times 10^{-03}$ & $-0.10(-0.13--0.06)$ & $2.17 \times 10^{-07}$ & $0.10(0.07-0.13)$ & $1.04 \times 10^{-08}$ \\
\hline RemnantC & $-0.06(-0.10--0.03)$ & $1.33 \times 10^{-03}$ & $0.06(0.03-0.09)$ & $1.12 \times 10^{-03}$ & $-0.06(-0.09--0.02)$ & $2.22 \times 10^{-03}$ & $0.08(0.05-0.11)$ & $1.25 \times 10^{-05}$ \\
\hline LDLC & $0.03(0.00-0.07)$ & $7.46 \times 10^{-02}$ & $0.03(0.00-0.06)$ & $8.81 \times 10^{-02}$ & $0.03(-0.01-0.06)$ & $1.92 \times 10^{-01}$ & $0.00(-0.03-0.04)$ & $8.32 \times 10^{-01}$ \\
\hline HDLC & $0.13(0.10-0.17)$ & $4.46 \times 10^{-12}$ & $0.10(0.06-0.13)$ & $3.61 \times 10^{-08}$ & $0.10(0.07-0.13)$ & $1.48 \times 10^{-09}$ & $-0.04(-0.07--0.01)$ & $1.15 \times 10^{-02}$ \\
\hline HDL2C & $0.13(0.10-0.17)$ & $5.86 \times 10^{-12}$ & $0.10(0.06-0.13)$ & $4.32 \times 10^{-08}$ & $0.10(0.07-0.13)$ & $1.98 \times 10^{-09}$ & $-0.04(-0.07--0.01)$ & $8.60 \times 10^{-03}$ \\
\hline HDL3C & $0.13(0.09-0.16)$ & $2.95 \times 10^{-11}$ & $0.09(0.06-0.13)$ & $1.12 \times 10^{-07}$ & $0.10(0.06-0.13)$ & $5.63 \times 10^{-08}$ & $-0.02(-0.05-0.01)$ & $2.15 \times 10^{-01}$ \\
\hline EstC & $0.05(0.01-0.08)$ & $1.05 \times 10^{-02}$ & $0.08(0.05-0.11)$ & $5.58 \times 10^{-06}$ & $0.03(0.00-0.07)$ & $8.10 \times 10^{-02}$ & $0.02(-0.01-0.06)$ & $2.04 \times 10^{-01}$ \\
\hline FreeC & $0.02(-0.01-0.06)$ & $2.19 \times 10^{-01}$ & $0.09(0.05-0.12)$ & $1.47 \times 10^{-06}$ & $0.01(-0.03-0.04)$ & $6.58 \times 10^{-01}$ & $0.03(-0.01-0.06)$ & $1.66 \times 10^{-01}$ \\
\hline SerumTG & $-0.12(-0.16--0.09)$ & $4.05 \times 10^{-11}$ & $0.06(0.02-0.09)$ & $1.54 \times 10^{-03}$ & $-0.12(-0.15--0.08)$ & $8.36 \times 10^{-10}$ & $0.12(0.09-0.15)$ & $6.81 \times 10^{-12}$ \\
\hline VLDLTG & $-0.13(-0.16--0.09)$ & $1.12 \times 10^{-11}$ & $0.04(0.01-0.08)$ & $1.60 \times 10^{-02}$ & $-0.12(-0.15--0.08)$ & $4.48 \times 10^{-10}$ & $0.12(0.09-0.15)$ & $4.15 \times 10^{-12}$ \\
\hline LDLTG & $-0.01(-0.05-0.02)$ & $5.28 \times 10^{-01}$ & $0.11(0.08-0.14)$ & $5.95 \times 10^{-10}$ & $-0.03(-0.06-0.01)$ & $1.55 \times 10^{-01}$ & $0.06(0.03-0.10)$ & $5.50 \times 10^{-04}$ \\
\hline HDLTG & $-0.08(-0.12--0.05)$ & $1.99 \times 10^{-05}$ & $0.12(0.09-0.15)$ & $3.56 \times 10^{-11}$ & $-0.08(-0.12--0.05)$ & $9.47 \times 10^{-06}$ & $0.11(0.08-0.14)$ & $7.69 \times 10^{-10}$ \\
\hline DAG & $-0.10(-0.14--0.06)$ & $4.71 \times 10^{-07}$ & $0.02(-0.01-0.06)$ & $2.77 \times 10^{-01}$ & $-0.10(-0.14--0.06)$ & $1.69 \times 10^{-06}$ & $0.05(0.02-0.09)$ & $9.85 \times 10^{-03}$ \\
\hline
\end{tabular}




\begin{tabular}{|c|c|c|c|c|c|c|c|c|}
\hline DAGTG & $-0.04(-0.08-0.00)$ & $4.53 \times 10^{-02}$ & $-0.02(-0.05-0.02)$ & $3.84 \times 10^{-01}$ & $-0.04(-0.08-0.00)$ & $4.34 \times 10^{-02}$ & $-0.01(-0.05-0.02)$ & $5.25 \times 10^{-01}$ \\
\hline TotPG & $0.01(-0.02-0.05)$ & $5.89 \times 10^{-01}$ & $0.14(0.10-0.17)$ & $1.38 \times 10-14$ & $-0.01(-0.04-0.03)$ & $7.55 \times 10^{-01}$ & $0.06(0.03-0.10)$ & $3.82 \times 10^{-04}$ \\
\hline TGPG & $-0.14(-0.18--0.11)$ & $3.70 \times 10^{-13}$ & $0.02(-0.01-0.05)$ & $2.83 \times 10^{-01}$ & $-0.13(-0.16--0.09)$ & $1.48 \times 10^{-11}$ & $0.11(0.08-0.14)$ & $1.37 \times 10^{-10}$ \\
\hline PC & $0.02(-0.02-0.05)$ & $3.87 \times 10^{-01}$ & $0.14(0.11-0.17)$ & $9.98 \times 10^{-15}$ & $0.00(-0.03-0.04)$ & $9.83 \times 10^{-01}$ & $0.07(0.04-0.10)$ & $7.22 \times 10^{-05}$ \\
\hline SM & $0.03(0.00-0.07)$ & $9.94 \times 10^{-02}$ & $0.10(0.07-0.13)$ & $2.01 \times 10^{-08}$ & $0.01(-0.03-0.04)$ & $7.00 \times 10^{-01}$ & $-0.01(-0.04-0.02)$ & $6.68 \times 10^{-01}$ \\
\hline TotCho & $0.01(-0.03-0.04)$ & $7.94 \times 10^{-01}$ & $0.10(0.07-0.13)$ & $9.97 \times 10^{-09}$ & $-0.01(-0.04-0.03)$ & $7.00 \times 10^{-01}$ & $0.04(0.01-0.07)$ & $3.05 \times 10^{-02}$ \\
\hline ApoA1 & $0.11(0.07-0.14)$ & $1.60 \times 10^{-08}$ & $0.13(0.10-0.17)$ & $6.12 \times 10^{-14}$ & $0.08(0.04-0.11)$ & $1.01 \times 10^{-05}$ & $0.01(-0.02-0.04)$ & $7.42 \times 10^{-01}$ \\
\hline ApoB & $-0.06(-0.09--0.02)$ & $1.71 \times 10^{-03}$ & $0.05(0.02-0.09)$ & $2.54 \times 10^{-03}$ & $-0.06(-0.09--0.02)$ & $3.17 \times 10^{-03}$ & $0.08(0.05-0.12)$ & $6.07 \times 10^{-06}$ \\
\hline ApoBApoA1 & $-0.11(-0.15--0.08)$ & $2.15 \times 10^{-09}$ & $-0.01(-0.05-0.02)$ & $4.30 \times 10^{-01}$ & $-0.09(-0.13--0.06)$ & $2.35 \times 10^{-07}$ & $0.08(0.04-0.11)$ & $8.37 \times 10^{-06}$ \\
\hline TotFA & $-0.06(-0.09--0.02)$ & $3.52 \times 10^{-03}$ & $0.12(0.09-0.15)$ & $1.66 \times 10^{-11}$ & $-0.06(-0.10--0.03)$ & $1.36 \times 10^{-03}$ & $0.11(0.07-0.14)$ & $3.07 \times 10^{-09}$ \\
\hline FALen & $-0.06(-0.09--0.02)$ & $4.35 \times 10^{-03}$ & $0.00(-0.03-0.04)$ & $8.04 \times 10^{-01}$ & $-0.06(-0.09--0.02)$ & $4.40 \times 10^{-03}$ & $0.03(0.00-0.07)$ & $1.29 \times 10^{-01}$ \\
\hline UnSat & $0.10(0.07-0.14)$ & $4.63 \times 10^{-08}$ & $-0.06(-0.09--0.02)$ & $1.96 \times 10^{-03}$ & $0.09(0.05-0.12)$ & $1.76 \times 10^{-06}$ & $-0.10(-0.14--0.07)$ & $6.43 \times 10^{-09}$ \\
\hline DHA & $0.06(0.02-0.09)$ & $3.25 \times 10^{-03}$ & $0.05(0.01-0.08)$ & $9.01 \times 10^{-03}$ & $0.03(-0.01-0.06)$ & $1.35 \times 10^{-01}$ & $0.01(-0.02-0.04)$ & $6.72 \times 10^{-01}$ \\
\hline LA & $-0.04(-0.07-0.00)$ & $6.90 \times 10^{-02}$ & $0.08(0.05-0.11)$ & $9.00 \times 10^{-06}$ & $-0.03(-0.07-0.00)$ & $7.70 \times 10^{-02}$ & $0.05(0.02-0.08)$ & $5.91 \times 10^{-03}$ \\
\hline CLA & $-0.04(-0.08-0.00)$ & $6.39 \times 10^{-02}$ & $0.08(0.05-0.12)$ & $1.25 \times 10^{-05}$ & $-0.05(-0.09--0.01)$ & $1.05 \times 10^{-02}$ & $0.06(0.02-0.09)$ & $2.75 \times 10^{-03}$ \\
\hline FAw3 & $0.05(0.01-0.09)$ & $8.83 \times 10^{-03}$ & $0.07(0.03-0.10)$ & $2.47 \times 10^{-04}$ & $0.02(-0.01-0.06)$ & $2.54 \times 10^{-01}$ & $0.03(0.00-0.06)$ & $1.00 \times 10^{-01}$ \\
\hline FAw6 & $-0.02(-0.06-0.01)$ & $2.15 \times 10^{-01}$ & $0.10(0.06-0.13)$ & $4.16 \times 10^{-08}$ & $-0.03(-0.06-0.01)$ & $1.44 \times 10^{-01}$ & $0.06(0.02-0.09)$ & $2.05 \times 10^{-03}$ \\
\hline PUFA & $-0.01(-0.05-0.02)$ & $5.02 \times 10^{-01}$ & $0.10(0.06-0.13)$ & $4.22 \times 10^{-08}$ & $-0.02(-0.06-0.01)$ & $2.64 \times 10^{-01}$ & $0.05(0.02-0.09)$ & $2.73 \times 10^{-03}$ \\
\hline MUFA & $-0.07(-0.11--0.04)$ & $1.06 \times 10^{-04}$ & $0.10(0.07-0.14)$ & $5.25 \times 10^{-09}$ & $-0.08(-0.11--0.04)$ & $8.91 \times 10^{-05}$ & $0.11(0.08-0.15)$ & $3.28 \times 10^{-10}$ \\
\hline SFA & $-0.06(-0.09--0.02)$ & $1.83 \times 10^{-03}$ & $0.13(0.09-0.16)$ & $2.19 \times 10^{-12}$ & $-0.07(-0.10--0.03)$ & $6.92 \times 10^{-04}$ & $0.12(0.08-0.15)$ & $7.38 \times 10^{-11}$ \\
\hline DHAFA & $0.11(0.08-0.15)$ & $2.30 \times 10^{-09}$ & $-0.02(-0.05-0.02)$ & $3.18 \times 10^{-01}$ & $0.08(0.05-0.12)$ & $8.97 \times 10^{-06}$ & $-0.06(-0.09--0.02)$ & $1.72 \times 10^{-03}$ \\
\hline LAFA & $0.04(0.00-0.07)$ & $6.90 \times 10^{-02}$ & $-0.06(-0.10--0.03)$ & $3.55 \times 10^{-04}$ & $0.05(0.01-0.08)$ & $1.84 \times 10^{-02}$ & $-0.09(-0.12--0.05)$ & $8.64 \times 10^{-07}$ \\
\hline CLAFA & $-0.01(-0.05-0.02)$ & $5.08 \times 10^{-01}$ & $0.05(0.01-0.08)$ & $1.04 \times 10^{-02}$ & $-0.03(-0.07-0.01)$ & $1.63 \times 10^{-01}$ & $0.02(-0.01-0.06)$ & $2.48 \times 10^{-01}$ \\
\hline FAw3FA & $0.13(0.09-0.16)$ & $2.54 \times 10^{-11}$ & $-0.02(-0.05-0.02)$ & $3.25 \times 10^{-01}$ & $0.10(0.06-0.13)$ & $2.70 \times 10^{-07}$ & $-0.05(-0.09--0.02)$ & $3.63 \times 10^{-03}$ \\
\hline FAw6FA & $0.07(0.03-0.10)$ & $2.35 \times 10^{-04}$ & $-0.06(-0.10--0.03)$ & $3.14 \times 10^{-04}$ & $0.07(0.04-0.11)$ & $1.12 \times 10^{-04}$ & $-0.11(-0.15--0.08)$ & $1.85 \times 10^{-10}$ \\
\hline PUFAFA & $0.09(0.06-0.13)$ & $7.87 \times 10^{-07}$ & $-0.07(-0.10--0.03)$ & $2.47 \times 10^{-04}$ & $0.09(0.05-0.12)$ & $2.40 \times 10^{-06}$ & $-0.12(-0.15--0.08)$ & $2.35 \times 10^{-11}$ \\
\hline MUFAFA & $-0.07(-0.11--0.04)$ & $1.40 \times 10^{-04}$ & $0.04(0.00-0.07)$ & $4.14 \times 10^{-02}$ & $-0.07(-0.10--0.03)$ & $3.65 \times 10^{-04}$ & $0.08(0.04-0.11)$ & $1.36 \times 10^{-05}$ \\
\hline SFAFA & $-0.03(-0.07-0.00)$ & $7.46 \times 10^{-02}$ & $0.05(0.02-0.08)$ & $6.65 \times 10^{-03}$ & $-0.03(-0.07-0.00)$ & $8.10 \times 10^{-02}$ & $0.07(0.04-0.10)$ & $1.29 \times 10^{-04}$ \\
\hline Glc & $-0.07(-0.10--0.03)$ & $5.55 \times 10^{-04}$ & $0.04(0.00-0.07)$ & $3.41 \times 10^{-02}$ & $-0.08(-0.12--0.05)$ & $7.44 \times 10^{-06}$ & $0.06(0.03-0.09)$ & $1.09 \times 10^{-03}$ \\
\hline Lac & $-0.12(-0.16--0.09)$ & $8.76 \times 10^{-11}$ & $0.07(0.03-0.10)$ & $1.89 \times 10^{-04}$ & $-0.11(-0.15--0.08)$ & $1.11 \times 10^{-09}$ & $0.12(0.08-0.15)$ & $2.72 \times 10^{-11}$ \\
\hline Cit & $0.04(0.01-0.08)$ & $3.32 \times 10^{-02}$ & $-0.01(-0.04-0.03)$ & $7.51 \times 10^{-01}$ & $0.02(-0.01-0.06)$ & $3.17 \times 10^{-01}$ & $-0.06(-0.09--0.02)$ & $1.61 \times 10^{-03}$ \\
\hline Ala & $-0.06(-0.10--0.03)$ & $8.96 \times 10^{-04}$ & $0.11(0.07-0.14)$ & $1.75 \times 10^{-09}$ & $-0.07(-0.10--0.03)$ & $4.21 \times 10^{-04}$ & $0.11(0.08-0.15)$ & $2.85 \times 10^{-10}$ \\
\hline Gln & $0.04(0.01-0.08)$ & $3.11 \times 10^{-02}$ & $-0.09(-0.12--0.06)$ & $5.66 \times 10^{-07}$ & $0.04(0.00-0.07)$ & $4.79 \times 10^{-02}$ & $-0.06(-0.09--0.03)$ & $1.19 \times 10^{-03}$ \\
\hline $\mathrm{His}$ & $0.01(-0.02-0.05)$ & $5.37 \times 10^{-01}$ & $-0.04(-0.07-0.00)$ & $4.40 \times 10^{-02}$ & $0.02(-0.01-0.06)$ & $2.26 \times 10^{-01}$ & $0.01(-0.02-0.05)$ & $4.45 \times 10^{-01}$ \\
\hline Ile & $-0.15(-0.18--0.11)$ & $2.11 \times 10^{-14}$ & $-0.02(-0.06-0.01)$ & $1.70 \times 10^{-01}$ & $-0.13(-0.16--0.09)$ & $4.81 \times 10-13$ & $0.11(0.08-0.14)$ & $1.18 \times 10^{-11}$ \\
\hline Leu & $-0.12(-0.15--0.08)$ & $1.96 \times 10^{-10}$ & $-0.04(-0.07--0.01)$ & $2.24 \times 10^{-02}$ & $-0.10(-0.13--0.07)$ & $1.44 \times 10^{-09}$ & $0.11(0.08-0.13)$ & $8.31 \times 10-12$ \\
\hline Val & $-0.08(-0.11--0.04)$ & $3.35 \times 10^{-05-}$ & $-0.07(-0.10--0.03)$ & $2.07 \times 10^{-04}$ & $-0.06(-0.09--0.03)$ & $2.05 \times 10^{-04}$ & $0.06(0.03-0.09)$ & $3.82 \times 10^{-04}$ \\
\hline Phe & $-0.10(-0.14--0.07)$ & $6.71 \times 10^{-08}$ & $0.03(0.00-0.06)$ & $1.03 \times 10^{-01}$ & $-0.10(-0.14--0.07)$ & $4.37 \times 10^{-08}$ & $0.08(0.04-0.11)$ & $1.24 \times 10^{-05}$ \\
\hline
\end{tabular}




\begin{tabular}{|c|c|c|c|c|c|c|c|c|}
\hline Tyr & $-0.07(-0.10--0.03)$ & $3.31 \times 10^{-04}$ & $0.03(0.00-0.06)$ & $1.03 \times 10^{-01}$ & $-0.07(-0.11--0.04)$ & $6.00 \times 10^{-05}$ & $0.07(0.04-0.10)$ & $6.87 \times 10^{-05}$ \\
\hline Ace & $0.06(0.03-0.10)$ & $6.68 \times 10^{-04}$ & $-0.09(-0.12--0.06)$ & $4.16 \times 10^{-07}$ & $0.06(0.02-0.09)$ & $3.53 \times 10^{-03}$ & $-0.08(-0.11--0.04)$ & $1.83 \times 10^{-05}$ \\
\hline bOHBut & $0.00(-0.03-0.04)$ & $8.85 \times 10^{-01}$ & $-0.05(-0.08--0.02)$ & $4.12 \times 10^{-03}$ & $-0.01(-0.04-0.03)$ & $7.14 \times 10^{-01}$ & $-0.04(-0.08--0.01)$ & $1.82 \times 10^{-02}$ \\
\hline Crea & $-0.01(-0.05-0.03)$ & $6.21 \times 10^{-01}$ & $-0.10(-0.13--0.07)$ & $8.40 \times 10^{-09}$ & $0.00(-0.03-0.03)$ & $8.59 \times 10^{-01}$ & $0.05(0.02-0.08)$ & $1.19 \times 10^{-03}$ \\
\hline Alb & $0.03(-0.01-0.06)$ & $1.68 \times 10^{-01}$ & $-0.03(-0.06-0.00)$ & $8.81 \times 10^{-02}$ & $0.03(0.00-0.07)$ & $8.10 \times 10^{-02}$ & $0.00(-0.03-0.03)$ & $9.92 \times 10^{-01}$ \\
\hline $\mathrm{Gp}$ & $-0.17(-0.21--0.14)$ & $2.37 \times 10-19$ & $0.09(0.06-0.13)$ & $8.12 \times 10^{-08}$ & $-0.16(-0.20--0.13)$ & $9.17 \times 10-18$ & $0.12(0.08-0.15)$ & $9.90 \times 10^{-11}$ \\
\hline
\end{tabular}

\begin{tabular}{|c|c|c|c|c|c|c|c|c|}
\hline & \multicolumn{4}{|l|}{ Model 2} & \multicolumn{4}{|l|}{ Model 3} \\
\hline & \multicolumn{2}{|c|}{ Overall Depression } & \multicolumn{2}{|c|}{ IMD } & \multicolumn{2}{|c|}{ Overall Depression } & \multicolumn{2}{|c|}{ IMD } \\
\hline & $\beta(95 \% \mathrm{CI})$ & FDR q value & $\beta(95 \% \mathrm{CI})$ & FDR q value & $\beta(95 \% \mathrm{CI})$ & FDR q value & $\beta(95 \% \mathrm{CI})$ & FDR q value \\
\hline XXLVLDLL & $-0.10(-0.13--0.06)$ & $7.90 \times 10^{-07}$ & $0.12(0.09-0.16)$ & $5.42 \times 10^{-12}$ & $-0.07(-0.11-0.04)$ & $4.33 \times 10^{-04}$ & $0.12(0.08-0.15)$ & $4.47 \times 10^{-10}$ \\
\hline XXLVLDLPL & $-0.10(-0.13--0.06)$ & $6.44 \times 10^{-07}$ & $0.13(0.09-0.16)$ & $3.20 \times 10^{-12}$ & $-0.07(-0.11-0.04)$ & $4.33 \times 10^{-04}$ & $0.12(0.08-0.15)$ & $4.47 \times 10^{-10}$ \\
\hline XXLVLDLC & $-0.09(-0.12--0.05)$ & $9.91 \times 10^{-06}$ & $0.12(0.09-0.15)$ & $2.03 \times 10^{-11}$ & $-0.06(-0.10--0.03)$ & $1.85 \times 10^{-03}$ & $0.11(0.08-0.15)$ & $6.74 \times 10^{-10}$ \\
\hline XXLVLDLCE & $-0.08(-0.11--0.04)$ & $7.95 \times 10^{-05}$ & $0.11(0.07-0.14)$ & $3.11 \times 10^{-09}$ & $-0.06(-0.09--0.02)$ & $4.54 \times 10^{-03}$ & $0.10(0.07-0.14)$ & $1.70 \times 10^{-08}$ \\
\hline XXLVLDLFC & $-0.09(-0.13--0.06)$ & $1.06 \times 10^{-06}$ & $0.13(0.10-0.16)$ & $3.03 \times 10^{-12}$ & $-0.07(-0.11--0.04)$ & $5.65 \times 10^{-04}$ & $0.12(0.08-0.15)$ & $4.47 \times 10^{-10}$ \\
\hline XXLVLDLTG & $-0.10(-0.13--0.06)$ & $6.39 \times 10^{-07}$ & $0.12(0.09-0.16)$ & $5.42 \times 10^{-12}$ & $-0.07(-0.11--0.04)$ & $4.18 \times 10^{-04}$ & $0.12(0.08-0.15)$ & $4.47 \times 10^{-10}$ \\
\hline XLVLDLP & $-0.10(-0.13--0.06)$ & $4.52 \times 10^{-07}$ & $0.13(0.09-0.16)$ & $3.03 \times 10^{-12}$ & $-0.07(-0.11--0.04)$ & $4.17 \times 10^{-04}$ & $0.11(0.08-0.15)$ & $4.47 \times 10^{-10}$ \\
\hline XLVLDLL & $-0.10(-0.13--0.06)$ & $2.81 \times 10^{-07}$ & $0.13(0.09-0.16)$ & $3.03 \times 10^{-12}$ & $-0.08(-0.11--0.04)$ & $2.72 \times 10^{-04}$ & $0.12(0.08-0.15)$ & $4.47 \times 10^{-10}$ \\
\hline XLVLDLPL & $-0.10(-0.13--0.06)$ & $6.33 \times 10^{-07}$ & $0.13(0.09-0.16)$ & $3.03 \times 10^{-12}$ & $-0.07(-0.11--0.04)$ & $4.18 \times 10^{-04}$ & $0.12(0.08-0.15)$ & $4.47 \times 10^{-10}$ \\
\hline XLVLDLC & $-0.09(-0.13--0.06)$ & $1.19 \times 10^{-06}$ & $0.12(0.09-0.16)$ & $7.95 \times 10^{-12}$ & $-0.07(-0.11--0.04)$ & $4.94 \times 10^{-04}$ & $0.11(0.08-0.15)$ & $6.74 \times 10^{-10}$ \\
\hline XLVLDLCE & $-0.09(-0.13--0.06)$ & $1.96 \times 10^{-06}$ & $0.12(0.09-0.15)$ & $1.30 \times 10^{-11}$ & $-0.07(-0.11--0.03)$ & $6.38 \times 10^{-04}$ & $0.11(0.08-0.14)$ & $8.34 \times 10^{-10}$ \\
\hline XLVLDLFC & $-0.10(-0.13--0.06)$ & $8.09 \times 10^{-07}$ & $0.13(0.09-0.16)$ & $5.42 \times 10^{-12}$ & $-0.07(-0.11-0.04)$ & $4.42 \times 10^{-04}$ & $0.11(0.08-0.15)$ & $5.07 \times 10^{-10}$ \\
\hline XLVLDLTG & $-0.10(-0.14--0.07)$ & $1.51 \times 10^{-07}$ & $0.13(0.09-0.16)$ & $3.03 \times 10^{-12}$ & $-0.08(-0.11--0.04)$ & $1.69 \times 10^{-04}$ & $0.11(0.08-0.15)$ & $4.47 \times 10^{-10}$ \\
\hline LVLDLP & $-0.10(-0.14--0.07)$ & $1.30 \times 10^{-07}$ & $0.12(0.09-0.16)$ & $6.34 \times 10^{-12}$ & $-0.08(-0.12--0.04)$ & $1.54 \times 10^{-04}$ & $0.11(0.08-0.14)$ & $1.19 \times 10^{-09}$ \\
\hline LVLDLL & $-0.11(-0.14--0.07)$ & $6.22 \times 10^{-08}$ & $0.12(0.09-0.16)$ & $5.42 \times 10^{-12}$ & $-0.08(-0.12--0.05)$ & $1.03 \times 10^{-04}$ & $0.11(0.08-0.14)$ & $9.90 \times 10^{-10}$ \\
\hline LVLDLPL & $-0.10(-0.14--0.07)$ & $1.30 \times 10^{-07}$ & $0.12(0.09-0.16)$ & $6.28 \times 10^{-12}$ & $-0.08(-0.12--0.04)$ & $1.54 \times 10^{-04}$ & $0.11(0.08-0.14)$ & $1.09 \times 10^{-09}$ \\
\hline LVLDLC & $-0.10(-0.14--0.06)$ & $2.45 \times 10^{-07}$ & $0.12(0.09-0.15)$ & $7.95 \times 10^{-12}$ & $-0.08(-0.11--0.04)$ & $1.98 \times 10^{-04}$ & $0.11(0.08-0.14)$ & $9.90 \times 10^{-10}$ \\
\hline LVLDLCE & $-0.10(-0.14--0.07)$ & $1.72 \times 10^{-07}$ & $0.12(0.08-0.15)$ & $8.16 \times 10^{-11}$ & $-0.08(-0.12--0.04)$ & $1.54 \times 10^{-04}$ & $0.10(0.07-0.14)$ & $5.81 \times 10^{-09}$ \\
\hline LVLDLFC & $-0.10(-0.14--0.07)$ & $2.30 \times 10^{-07}$ & $0.13(0.09-0.16)$ & $3.20 \times 10^{-12}$ & $-0.08(-0.11-0.04)$ & $2.59 \times 10^{-04}$ & $0.11(0.08-0.15)$ & $5.56 \times 10^{-10}$ \\
\hline LVLDLTG & $-0.11(-0.14--0.07)$ & $6.22 \times 10^{-08}$ & $0.12(0.09-0.16)$ & $5.42 \times 10^{-12}$ & $-0.08(-0.12--0.05)$ & $1.03 \times 10^{-04}$ & $0.11(0.08-0.14)$ & $1.19 \times 10^{-09}$ \\
\hline MVLDLP & $-0.10(-0.14-0.07)$ & $1.72 \times 10^{-07}$ & $0.11(0.08-0.15)$ & $1.68 \times 10^{-10}$ & $-0.08(-0.11--0.04)$ & $1.65 \times 10^{-04}$ & $0.10(0.07-0.13)$ & $1.85 \times 10^{-08}$ \\
\hline MVLDLL & $-0.10(-0.14--0.07)$ & $1.21 \times 10^{-07}$ & $0.11(0.08-0.15)$ & $9.77 \times 10^{-11}$ & $-0.08(-0.12--0.05)$ & $1.04 \times 10^{-04}$ & $0.10(0.07-0.13)$ & $1.05 \times 10^{-08}$ \\
\hline MVLDLPL & $-0.10(-0.14--0.07)$ & $1.51 \times 10^{-07}$ & $0.11(0.08-0.15)$ & $9.98 \times 10^{-11}$ & $-0.08(-0.12--0.05)$ & $1.48 \times 10^{-04}$ & $0.10(0.07-0.13)$ & $1.05 \times 10^{-08}$ \\
\hline MVLDLC & $-0.10(-0.13--0.06)$ & $4.48 \times 10^{-07}$ & $0.11(0.08-0.14)$ & $3.97 \times 10^{-10}$ & $-0.08(-0.11--0.04)$ & $1.69 \times 10^{-04}$ & $0.10(0.07-0.14)$ & $1.06 \times 10^{-08}$ \\
\hline MVLDLCE & $-0.09(-0.12--0.05)$ & $3.85 \times 10^{-06}$ & $0.10(0.07-0.13)$ & $1.61 \times 10^{-08}$ & $-0.07(-0.11--0.04)$ & $4.18 \times 10^{-04}$ & $0.10(0.06-0.13)$ & $6.55 \times 10^{-08}$ \\
\hline MVLDLFC & $-0.10(-0.14--0.07)$ & $1.72 \times 10^{-07}$ & $0.12(0.09-0.15)$ & $2.03 \times 10^{-11}$ & $-0.08(-0.11--0.04)$ & $1.69 \times 10^{-04}$ & $0.11(0.07-0.14)$ & $2.68 \times 10^{-09}$ \\
\hline MVLDLTG & $-0.10(-0.14--0.07)$ & $1.01 \times 10^{-07}$ & $0.12(0.08-0.15)$ & $3.98 \times 10^{-11}$ & $-0.08(-0.12--0.05)$ & $1.04 \times 10^{-04}$ & $0.10(0.07-0.13)$ & $8.09 \times 10^{-09}$ \\
\hline SVLDLP & $-0.09(-0.13--0.06)$ & $1.96 \times 10^{-06}$ & $0.10(0.06-0.13)$ & $5.00 \times 10^{-08}$ & $-0.07(-0.11--0.04)$ & $4.18 \times 10^{-04}$ & $0.09(0.05-0.12)$ & $8.93 \times 10^{-07}$ \\
\hline
\end{tabular}




\begin{tabular}{|c|c|c|c|c|c|c|c|c|}
\hline SVLDLL & $-0.09(-0.13--0.06)$ & $2.23 \times 10^{-06}$ & $0.10(0.06-0.13)$ & $6.21 \times 10^{-08}$ & $-0.07(-0.11--0.04)$ & $4.18 \times 10^{-04}$ & $0.09(0.05-0.12)$ & $8.45 \times 10^{-07}$ \\
\hline SVLDLPL & $-0.09(-0.13--0.06)$ & $2.23 \times 10^{-06}$ & $0.10(0.06-0.13)$ & $5.00 \times 10^{-08}$ & $-0.07(-0.11-0.04)$ & $4.19 \times 10^{-04}$ & $0.09(0.06-0.12)$ & $8.30 \times 10^{-07}$ \\
\hline SVLDLC & $-0.07(-0.10--0.03)$ & $5.60 \times 10^{-04}$ & $0.08(0.05-0.11)$ & $1.25 \times 10^{-05}$ & $-0.06(-0.09--0.02)$ & $5.35 \times 10^{-03}$ & $0.08(0.05-0.11)$ & $7.86 \times 10^{-06}$ \\
\hline SVLDLCE & $-0.06(-0.09--0.02)$ & $5.14 \times 10^{-03}$ & $0.06(0.03-0.10)$ & $6.17 \times 10^{-04}$ & $-0.05(-0.09--0.01)$ & $1.51 \times 10^{-02}$ & $0.07(0.04-0.10)$ & $1.26 \times 10^{-04}$ \\
\hline SVLDLFC & $-0.08(-0.12--0.05)$ & $1.26 \times 10^{-05}$ & $0.10(0.07-0.13)$ & $3.04 \times 10^{-08}$ & $-0.07(-0.10--0.03)$ & $1.05 \times 10^{-03}$ & $0.09(0.06-0.13)$ & $3.13 \times 10^{-07}$ \\
\hline SVLDLTG & $-0.10(-0.13--0.06)$ & $2.45 \times 10^{-07}$ & $0.10(0.07-0.14)$ & $4.07 \times 10^{-09}$ & $-0.08(-0.11--0.04)$ & $1.81 \times 10^{-04}$ & $0.09(0.06-0.12)$ & $3.56 \times 10^{-07}$ \\
\hline XSVLDLP & $-0.05(-0.08--0.01)$ & $1.88 \times 10^{-02}$ & $0.06(0.03-0.10)$ & $6.51 \times 10^{-04}$ & $-0.04(-0.08--0.01)$ & $3.83 \times 10^{-02}$ & $0.07(0.04-0.10)$ & $8.01 \times 10^{-05}$ \\
\hline XSVLDLL & $-0.04(-0.08-0.00)$ & $4.63 \times 10^{-02}$ & $0.06(0.02-0.09)$ & $2.20 \times 10^{-03}$ & $-0.04(-0.07-0.00)$ & $5.95 \times 10^{-02}$ & $0.07(0.03-0.10)$ & $1.85 \times 10^{-04}$ \\
\hline XSVLDLPL & $-0.02(-0.05-0.02)$ & $4.25 \times 10^{-01}$ & $0.04(0.01-0.07)$ & $3.52 \times 10^{-02}$ & $-0.02(-0.06-0.01)$ & $3.53 \times 10^{-01}$ & $0.06(0.02-0.09)$ & $1.88 \times 10^{-03}$ \\
\hline XSVLDLC & $-0.02(-0.06-0.01)$ & $2.63 \times 10^{-01}$ & $0.03(0.00-0.07)$ & $9.51 \times 10^{-02}$ & $-0.03(-0.06-0.01)$ & $1.82 \times 10^{-01}$ & $0.05(0.01-0.08)$ & $9.10 \times 10^{-03}$ \\
\hline XSVLDLCE & $-0.03(-0.06-0.01)$ & $1.74 \times 10^{-01}$ & $0.03(0.00-0.06)$ & $1.16 \times 10^{-01}$ & $-0.03(-0.07-0.00)$ & $1.12 \times 10^{-01}$ & $0.04(0.01-0.08)$ & $1.33 \times 10^{-02}$ \\
\hline XSVLDLFC & $-0.01(-0.05-0.02)$ & $5.46 \times 10^{-01}$ & $0.04(0.00-0.07)$ & $5.87 \times 10^{-02}$ & $-0.02(-0.05-0.02)$ & $4.74 \times 10^{-01}$ & $0.05(0.02-0.08)$ & $4.40 \times 10^{-03}$ \\
\hline XSVLDLTG & $-0.08(-0.12--0.05)$ & $1.49 \times 10^{-05}$ & $0.10(0.06-0.13)$ & $5.29 \times 10^{-08}$ & $-0.06(-0.10--0.03)$ & $1.73 \times 10^{-03}$ & $0.09(0.05-0.12)$ & $9.55 \times 10^{-07}$ \\
\hline IDLP & $0.00(-0.03-0.04)$ & $9.00 \times 10^{-01}$ & $0.03(-0.01-0.06)$ & $1.43 \times 10^{-01}$ & $0.00(-0.04-0.03)$ & $8.67 \times 10^{-01}$ & $0.05(0.02-0.08)$ & $6.50 \times 10^{-03}$ \\
\hline IDLL & $0.01(-0.03-0.04)$ & $6.84 \times 10^{-01}$ & $0.02(-0.01-0.06)$ & $2.61 \times 10^{-01}$ & $0.00(-0.03-0.03)$ & $9.69 \times 10^{-01}$ & $0.04(0.01-0.07)$ & $1.23 \times 10^{-02}$ \\
\hline IDLPL & $0.02(-0.02-0.05)$ & $3.92 \times 10^{-01}$ & $0.01(-0.02-0.05)$ & $5.04 \times 10^{-01}$ & $0.01(-0.03-0.04)$ & $7.78 \times 10^{-01}$ & $0.04(0.00-0.07)$ & $4.31 \times 10^{-02}$ \\
\hline IDLC & $0.01(-0.02-0.05)$ & $5.92 \times 10^{-01}$ & $0.02(-0.01-0.06)$ & $2.58 \times 10^{-01}$ & $0.00(-0.03-0.03)$ & $9.69 \times 10^{-01}$ & $0.04(0.01-0.08)$ & $1.07 \times 10^{-02}$ \\
\hline IDLCE & $0.00(-0.03-0.04)$ & $9.38 \times 10^{-01}$ & $0.03(0.00-0.07)$ & $8.76 \times 10^{-02}$ & $-0.01(-0.04-0.03)$ & $7.73 \times 10^{-01}$ & $0.05(0.02-0.08)$ & $2.27 \times 10^{-03}$ \\
\hline IDLFC & $0.04(0.00-0.07)$ & $8.01 \times 10^{-02}$ & $0.00(-0.04-0.03)$ & $8.24 \times 10^{-01}$ & $0.02(-0.01-0.05)$ & $3.38 \times 10^{-01}$ & $0.02(-0.01-0.05)$ & $2.55 \times 10^{-01}$ \\
\hline IDLTG & $-0.05(-0.09--0.02)$ & $5.93 \times 10^{-03}$ & $0.08(0.05-0.11)$ & $1.30 \times 10^{-05}$ & $-0.04(-0.08--0.01)$ & $4.19 \times 10^{-02}$ & $0.08(0.05-0.11)$ & $1.23 \times 10^{-05}$ \\
\hline LLDLP & $0.01(-0.02-0.05)$ & $5.79 \times 10^{-01}$ & $0.02(-0.01-0.06)$ & $2.20 \times 10^{-01}$ & $0.00(-0.03-0.04)$ & $8.77 \times 10^{-01}$ & $0.04(0.01-0.08)$ & $1.16 \times 10^{-02}$ \\
\hline LLDLL & $0.02(-0.02-0.05)$ & $4.29 \times 10^{-01}$ & $0.02(-0.01-0.05)$ & $3.18 \times 10^{-01}$ & $0.01(-0.03-0.04)$ & $7.92 \times 10^{-01}$ & $0.04(0.01-0.07)$ & $1.75 \times 10^{-02}$ \\
\hline LLDLPL & $0.01(-0.02-0.05)$ & $5.28 \times 10^{-01}$ & $0.02(-0.01-0.06)$ & $2.59 \times 10^{-01}$ & $0.00(-0.03-0.04)$ & $8.77 \times 10^{-01}$ & $0.04(0.01-0.08)$ & $1.33 \times 10^{-02}$ \\
\hline LLDLC & $0.02(-0.02-0.06)$ & $3.49 \times 10^{-01}$ & $0.01(-0.02-0.05)$ & $4.92 \times 10^{-01}$ & $0.01(-0.03-0.04)$ & $7.22 \times 10^{-01}$ & $0.04(0.00-0.07)$ & $4.10 \times 10^{-02}$ \\
\hline LLDLCE & $0.01(-0.02-0.05)$ & $5.24 \times 10^{-01}$ & $0.02(-0.01-0.05)$ & $3.05 \times 10^{-01}$ & $0.00(-0.03-0.04)$ & $8.77 \times 10^{-01}$ & $0.04(0.01-0.07)$ & $1.75 \times 10^{-02}$ \\
\hline LLDLFC & $0.04(0.00-0.07)$ & $6.78 \times 10^{-02}$ & $-0.01(-0.04-0.03)$ & $7.55 \times 10^{-01}$ & $0.02(-0.01-0.06)$ & $3.00 \times 10^{-01}$ & $0.02(-0.01-0.05)$ & $3.10 \times 10^{-01}$ \\
\hline LLDLTG & $-0.03(-0.06-0.01)$ & $1.91 \times 10^{-01}$ & $0.06(0.03-0.10)$ & $4.75 \times 10^{-04}$ & $-0.02(-0.06-0.01)$ & $3.44 \times 10^{-01}$ & $0.07(0.04-0.10)$ & $1.01 \times 10^{-04}$ \\
\hline MLDLP & $0.01(-0.02-0.05)$ & $5.39 \times 10^{-01}$ & $0.02(-0.01-0.06)$ & $2.79 \times 10^{-01}$ & $0.01(-0.03-0.04)$ & $8.01 \times 10^{-01}$ & $0.04(0.01-0.07)$ & $2.20 \times 10^{-02}$ \\
\hline MLDLL & $0.02(-0.02-0.05)$ & $4.60 \times 10^{-01}$ & $0.02(-0.02-0.05)$ & $3.37 \times 10^{-01}$ & $0.01(-0.03-0.04)$ & $7.73 \times 10^{-01}$ & $0.04(0.01-0.07)$ & $2.67 \times 10^{-02}$ \\
\hline MLDLPL & $-0.01(-0.04-0.03)$ & $8.07 \times 10^{-01}$ & $0.04(0.01-0.08)$ & $2.62 \times 10^{-02}$ & $-0.01(-0.04-0.03)$ & $6.97 \times 10^{-01}$ & $0.06(0.03-0.09)$ & $8.93 \times 10^{-04}$ \\
\hline MLDLC & $0.02(-0.01-0.06)$ & $2.77 \times 10^{-01}$ & $0.01(-0.03-0.04)$ & $6.72 \times 10^{-01}$ & $0.01(-0.02-0.05)$ & $5.95 \times 10^{-01}$ & $0.03(0.00-0.06)$ & $9.33 \times 10^{-02}$ \\
\hline MLDLCE & $0.02(-0.01-0.06)$ & $2.77 \times 10^{-01}$ & $0.01(-0.03-0.04)$ & $7.19 \times 10^{-01}$ & $0.01(-0.02-0.05)$ & $5.95 \times 10^{-01}$ & $0.03(0.00-0.06)$ & $1.08 \times 10^{-01}$ \\
\hline MLDLFC & $0.02(-0.01-0.06)$ & $2.85 \times 10^{-01}$ & $0.01(-0.02-0.05)$ & $4.76 \times 10^{-01}$ & $0.01(-0.02-0.05)$ & $5.61 \times 10^{-01}$ & $0.03(0.00-0.07)$ & $5.33 \times 10^{-02}$ \\
\hline MLDLTG & $-0.02(-0.05-0.02)$ & $4.08 \times 10^{-01}$ & $0.06(0.02-0.09)$ & $1.79 \times 10^{-03}$ & $-0.01(-0.05-0.02)$ & $6.18 \times 10^{-01}$ & $0.06(0.03-0.10)$ & $3.87 \times 10^{-04}$ \\
\hline SLDLP & $0.02(-0.02-0.05)$ & $4.35 \times 10^{-01}$ & $0.02(-0.01-0.06)$ & $2.55 \times 10^{-01}$ & $0.01(-0.03-0.04)$ & $6.97 \times 10^{-01}$ & $0.04(0.01-0.07)$ & $1.97 \times 10^{-02}$ \\
\hline SLDLL & $0.02(-0.02-0.06)$ & $3.50 \times 10^{-01}$ & $0.02(-0.01-0.05)$ & $3.20 \times 10^{-01}$ & $0.01(-0.02-0.05)$ & $6.39 \times 10^{-01}$ & $0.04(0.01-0.07)$ & $2.63 \times 10^{-02}$ \\
\hline SLDLPL & $0.00(-0.03-0.04)$ & $8.28 \times 10^{-01}$ & $0.04(0.01-0.07)$ & $3.07 \times 10^{-02}$ & $0.00(-0.04-0.03)$ & $9.80 \times 10^{-01}$ & $0.06(0.02-0.09)$ & $1.22 \times 10^{-03}$ \\
\hline SLDLC & $0.03(-0.01-0.07)$ & $1.64 \times 10^{-01}$ & $0.00(-0.03-0.04)$ & $8.53 \times 10^{-01}$ & $0.02(-0.02-0.05)$ & $4.37 \times 10^{-01}$ & $0.03(-0.01-0.06)$ & $1.59 \times 10^{-01}$ \\
\hline
\end{tabular}




\begin{tabular}{|c|c|c|c|c|c|c|c|c|}
\hline SLDLCE & $0.03(-0.01-0.07)$ & $1.55 \times 10^{-01}$ & $0.00(-0.03-0.03)$ & $9.77 \times 10^{-01}$ & $0.02(-0.02-0.05)$ & $4.32 \times 10^{-01}$ & $0.02(-0.01-0.05)$ & $2.17 \times 10^{-01}$ \\
\hline SLDLFC & $0.02(-0.01-0.06)$ & $2.64 \times 10^{-01}$ & $0.02(-0.02-0.05)$ & $4.62 \times 10^{-01}$ & $0.01(-0.02-0.05)$ & $5.14 \times 10^{-01}$ & $0.03(0.00-0.07)$ & $5.49 \times 10^{-02}$ \\
\hline SLDLTG & $-0.06(-0.09--0.02)$ & $4.23 \times 10^{-03}$ & $0.10(0.06-0.13)$ & $6.88 \times 10^{-08}$ & $-0.04(-0.08--0.01)$ & $3.94 \times 10^{-02}$ & $0.10(0.06-0.13)$ & $1.06 \times 10^{-07}$ \\
\hline XLHDLP & $0.06(0.02-0.09)$ & $1.23 \times 10^{-03}$ & $-0.01(-0.04-0.02)$ & $4.31 \times 10^{-01}$ & $0.04(0.01-0.07)$ & $2.22 \times 10^{-02}$ & $0.00(-0.03-0.03)$ & $8.42 \times 10^{-01}$ \\
\hline XLHDLL & $0.06(0.02-0.09)$ & $1.26 \times 10^{-03}$ & $-0.02(-0.05-0.01)$ & $3.40 \times 10^{-01}$ & $0.04(0.01-0.07)$ & $2.39 \times 10^{-02}$ & $0.00(-0.03-0.03)$ & $9.24 \times 10^{-01}$ \\
\hline XLHDLPL & $0.06(0.03-0.09)$ & $1.78 \times 10^{-04}$ & $-0.03(-0.06-0.00)$ & $8.01 \times 10^{-02}$ & $0.05(0.02-0.08)$ & $6.63 \times 10^{-03}$ & $-0.01(-0.04-0.02)$ & $4.36 \times 10^{-01}$ \\
\hline XLHDLC & $0.05(0.02-0.08)$ & $5.68 \times 10^{-03}$ & $-0.01(-0.04-0.02)$ & $6.30 \times 10^{-01}$ & $0.04(0.00-0.07)$ & $5.67 \times 10^{-02}$ & $0.01(-0.02-0.04)$ & $5.31 \times 10^{-01}$ \\
\hline XLHDLCE & $0.05(0.02-0.08)$ & $6.95 \times 10^{-03}$ & $-0.01(-0.04-0.02)$ & $6.92 \times 10^{-01}$ & $0.03(0.00-0.07)$ & $6.60 \times 10^{-02}$ & $0.01(-0.02-0.04)$ & $4.46 \times 10^{-01}$ \\
\hline XLHDLFC & $0.05(0.02-0.08)$ & $3.59 \times 10^{-03}$ & $-0.01(-0.04-0.02)$ & $6.30 \times 10^{-01}$ & $0.04(0.01-0.07)$ & $3.75 \times 10^{-02}$ & $0.01(-0.02-0.04)$ & $6.30 \times 10^{-01}$ \\
\hline XLHDLTG & $-0.03(-0.07-0.01)$ & $1.52 \times 10^{-01}$ & $0.08(0.05-0.12)$ & $3.56 \times 10^{-06}$ & $-0.03(-0.06-0.01)$ & $1.86 \times 10^{-01}$ & $0.09(0.06-0.13)$ & $1.45 \times 10^{-07}$ \\
\hline LHDLP & $0.06(0.03-0.09)$ & $3.19 \times 10^{-04}$ & $-0.02(-0.05-0.01)$ & $2.25 \times 10^{-01}$ & $0.05(0.02-0.08)$ & $8.27 \times 10^{-03}$ & $-0.01(-0.04-0.02)$ & $6.13 \times 10^{-01}$ \\
\hline LHDLL & $0.06(0.03-0.09)$ & $3.05 \times 10^{-04}$ & $-0.03(-0.06-0.00)$ & $1.18 \times 10^{-01}$ & $0.05(0.02-0.08)$ & $8.66 \times 10^{-03}$ & $-0.01(-0.04-0.02)$ & $4.13 \times 10^{-01}$ \\
\hline LHDLPL & $0.06(0.03-0.09)$ & $6.80 \times 10^{-04}$ & $-0.02(-0.05-0.01)$ & $1.80 \times 10^{-01}$ & $0.04(0.01-0.07)$ & $1.51 \times 10^{-02}$ & $-0.01(-0.04-0.02)$ & $5.28 \times 10^{-01}$ \\
\hline LHDLC & $0.07(0.03-0.10)$ & $9.15 \times 10^{-05}$ & $-0.03(-0.06-0.00)$ & $8.65 \times 10^{-02}$ & $0.05(0.02-0.08)$ & $3.23 \times 10^{-03}$ & $-0.02(-0.04-0.01)$ & $3.37 \times 10^{-01}$ \\
\hline LHDLCE & $0.06(0.03-0.10)$ & $1.16 \times 10^{-04}$ & $-0.03(-0.06-0.00)$ & $1.07 \times 10^{-01}$ & $0.05(0.02-0.08)$ & $3.97 \times 10^{-03}$ & $-0.01(-0.04-0.01)$ & $3.90 \times 10^{-01}$ \\
\hline LHDLFC & $0.07(0.04-0.10)$ & $5.81 \times 10^{-05}$ & $-0.03(-0.06-0.00)$ & $8.41 \times 10^{-02}$ & $0.05(0.02-0.09)$ & $2.11 \times 10^{-03}$ & $-0.02(-0.05-0.01)$ & $3.29 \times 10^{-01}$ \\
\hline LHDLTG & $0.04(0.00-0.07)$ & $4.63 \times 10^{-02}$ & $0.02(-0.01-0.05)$ & $3.75 \times 10^{-01}$ & $0.03(-0.01-0.06)$ & $1.83 \times 10^{-01}$ & $0.03(0.00-0.06)$ & $7.61 \times 10^{-02}$ \\
\hline MHDLP & $0.02(-0.01-0.05)$ & $2.43 \times 10^{-01}$ & $0.02(-0.01-0.05)$ & $2.81 \times 10^{-01}$ & $0.02(-0.01-0.05)$ & $3.44 \times 10^{-01}$ & $0.02(-0.01-0.05)$ & $2.29 \times 10^{-01}$ \\
\hline MHDLL & $0.02(-0.01-0.05)$ & $3.47 \times 10^{-01}$ & $0.03(0.00-0.06)$ & $1.31 \times 10^{-01}$ & $0.01(-0.02-0.05)$ & $4.81 \times 10^{-01}$ & $0.03(0.00-0.06)$ & $1.04 \times 10^{-01}$ \\
\hline MHDLPL & $0.02(-0.01-0.05)$ & $2.38 \times 10^{-01}$ & $0.02(-0.01-0.05)$ & $2.81 \times 10^{-01}$ & $0.02(-0.01-0.05)$ & $3.44 \times 10^{-01}$ & $0.02(-0.01-0.05)$ & $2.17 \times 10^{-01}$ \\
\hline MHDLC & $0.03(0.00-0.07)$ & $6.18 \times 10^{-02}$ & $0.01(-0.02-0.04)$ & $6.87 \times 10^{-01}$ & $0.03(0.00-0.06)$ & $1.60 \times 10^{-01}$ & $0.01(-0.02-0.04)$ & $5.56 \times 10^{-01}$ \\
\hline MHDLCE & $0.03(0.00-0.07)$ & $6.54 \times 10^{-02}$ & $0.01(-0.02-0.04)$ & $6.87 \times 10^{-01}$ & $0.03(-0.01-0.06)$ & $1.64 \times 10^{-01}$ & $0.01(-0.02-0.04)$ & $5.68 \times 10^{-01}$ \\
\hline MHDLFC & $0.03(0.00-0.07)$ & $5.67 \times 10^{-02}$ & $0.01(-0.02-0.04)$ & $7.23 \times 10^{-01}$ & $0.03(0.00-0.06)$ & $1.57 \times 10^{-01}$ & $0.01(-0.02-0.04)$ & $5.41 \times 10^{-01}$ \\
\hline MHDLTG & $-0.09(-0.13--0.05)$ & $4.00 \times 10^{-06}$ & $0.10(0.07-0.14)$ & $1.98 \times 10^{-08}$ & $-0.07(-0.11-0.04)$ & $4.94 \times 10^{-04}$ & $0.09(0.06-0.13)$ & $5.74 \times 10^{-07}$ \\
\hline SHDLP & $-0.01(-0.04-0.03)$ & $8.24 \times 10^{-01}$ & $0.03(0.00-0.06)$ & $1.06 \times 10^{-01}$ & $0.00(-0.03-0.04)$ & $9.69 \times 10^{-01}$ & $0.02(-0.01-0.06)$ & $2.14 \times 10^{-01}$ \\
\hline SHDLL & $0.00(-0.03-0.03)$ & $9.95 \times 10^{-01}$ & $0.03(-0.01-0.06)$ & $1.80 \times 10^{-01}$ & $0.00(-0.03-0.04)$ & $8.78 \times 10^{-01}$ & $0.02(-0.01-0.05)$ & $2.97 \times 10^{-01}$ \\
\hline SHDLPL & $-0.04(-0.07-0.00)$ & $6.86 \times 10^{-02}$ & $0.06(0.03-0.09)$ & $6.18 \times 10^{-04}$ & $-0.02(-0.06-0.01)$ & $2.94 \times 10^{-01}$ & $0.04(0.01-0.08)$ & $1.06 \times 10^{-02}$ \\
\hline SHDLC & $0.05(0.01-0.08)$ & $1.99 \times 10^{-02}$ & $-0.04(-0.07-0.00)$ & $5.35 \times 10^{-02}$ & $0.03(0.00-0.07)$ & $1.27 \times 10^{-01}$ & $-0.03(-0.06-0.01)$ & $1.45 \times 10^{-01}$ \\
\hline SHDLCE & $0.05(0.02-0.09)$ & $5.70 \times 10^{-03}$ & $-0.05(-0.08--0.01)$ & $1.46 \times 10^{-02}$ & $0.04(0.00-0.07)$ & $6.36 \times 10^{-02}$ & $-0.03(-0.07-0.00)$ & $7.22 \times 10^{-02}$ \\
\hline SHDLFC & $-0.01(-0.05-0.02)$ & $5.39 \times 10^{-01}$ & $0.05(0.02-0.08)$ & $4.36 \times 10^{-03}$ & $0.00(-0.04-0.03)$ & $9.30 \times 10^{-01}$ & $0.04(0.01-0.07)$ & $3.19 \times 10^{-02}$ \\
\hline SHDLTG & $-0.10(-0.13--0.06)$ & $6.44 \times 10^{-07}$ & $0.10(0.06-0.13)$ & $3.88 \times 10^{-08}$ & $-0.07(-0.11--0.04)$ & $4.18 \times 10^{-04}$ & $0.08(0.05-0.11)$ & $4.47 \times 10^{-06}$ \\
\hline XXLVLDLPLp & $-0.05(-0.09--0.01)$ & $1.18 \times 10^{-02}$ & $0.07(0.03-0.10)$ & $2.77 \times 10^{-04}$ & $-0.04(-0.08--0.01)$ & $4.60 \times 10^{-02}$ & $0.07(0.03-0.10)$ & $2.10 \times 10^{-04}$ \\
\hline XXLVLDLCp & $-0.05(-0.08--0.01)$ & $1.80 \times 10^{-02}$ & $0.07(0.04-0.11)$ & $6.84 \times 10^{-05}$ & $-0.04(-0.08-0.00)$ & $5.90 \times 10^{-02}$ & $0.08(0.04-0.11)$ & $3.29 \times 10^{-05}$ \\
\hline XXLVLDLCEp & $-0.03(-0.07-0.00)$ & $9.88 \times 10^{-02}$ & $0.07(0.04-0.11)$ & $1.07 \times 10^{-04}$ & $-0.03(-0.06-0.01)$ & $1.86 \times 10^{-01}$ & $0.08(0.04-0.11)$ & $1.88 \times 10^{-05}$ \\
\hline XXLVLDLFCp & $-0.06(-0.10--0.03)$ & $1.68 \times 10^{-03}$ & $0.08(0.05-0.11)$ & $1.42 \times 10^{-05}$ & $-0.05(-0.09--0.02)$ & $1.25 \times 10^{-02}$ & $0.08(0.04-0.11)$ & $2.09 \times 10^{-05}$ \\
\hline XXLVLDLTGp & $-0.04(-0.08--0.01)$ & $2.89 \times 10^{-02}$ & $0.05(0.02-0.09)$ & $4.36 \times 10^{-03}$ & $-0.04(-0.07-0.00)$ & $8.00 \times 10^{-02}$ & $0.06(0.02-0.09)$ & $2.86 \times 10^{-03}$ \\
\hline XLVLDLPLp & $-0.06(-0.09--0.02)$ & $3.72 \times 10^{-03}$ & $0.08(0.05-0.12)$ & $4.84 \times 10^{-06}$ & $-0.05(-0.09--0.01)$ & $1.70 \times 10^{-02}$ & $0.08(0.05-0.12)$ & $7.97 \times 10^{-06}$ \\
\hline XLVLDLCp & $-0.05(-0.09--0.02)$ & $9.24 \times 10^{-03}$ & $0.08(0.05-0.11)$ & $8.57 \times 10^{-06}$ & $-0.04(-0.08--0.01)$ & $3.43 \times 10^{-02}$ & $0.08(0.05-0.11)$ & $8.78 \times 10^{-06}$ \\
\hline
\end{tabular}




\begin{tabular}{|c|c|c|c|c|c|c|c|c|}
\hline XLVLDLCEp & $-0.04(-0.08--0.01)$ & $2.62 \times 10^{-02}$ & $0.07(0.04-0.11)$ & $4.70 \times 10^{-05}$ & $-0.04(-0.07-0.00)$ & $6.89 \times 10^{-02}$ & $0.08(0.04-0.11)$ & $3.26 \times 10^{-05}$ \\
\hline XLVLDLFCp & $-0.06(-0.10--0.03)$ & $1.20 \times 10^{-03}$ & $0.09(0.06-0.12)$ & $7.21 \times 10^{-07}$ & $-0.05(-0.09--0.02)$ & $8.66 \times 10^{-03}$ & $0.09(0.05-0.12)$ & $1.20 \times 10^{-06}$ \\
\hline XLVLDLTGp & $-0.05(-0.09--0.01)$ & $1.19 \times 10^{-02}$ & $0.07(0.04-0.11)$ & $9.60 \times 10^{-05}$ & $-0.04(-0.08--0.01)$ & $3.86 \times 10^{-02}$ & $0.07(0.04-0.10)$ & $1.65 \times 10^{-04}$ \\
\hline LVLDLPLp & $-0.05(-0.09--0.02)$ & $9.07 \times 10^{-03}$ & $0.05(0.02-0.08)$ & $7.16 \times 10^{-03}$ & $-0.05(-0.08--0.01)$ & $2.60 \times 10^{-02}$ & $0.05(0.01-0.08)$ & $1.40 \times 10^{-02}$ \\
\hline LVLDLCp & $-0.06(-0.10--0.03)$ & $1.11 \times 10^{-03}$ & $0.06(0.03-0.10)$ & $6.39 \times 10^{-04}$ & $-0.06(-0.09--0.02)$ & $6.12 \times 10^{-03}$ & $0.06(0.03-0.09)$ & $1.42 \times 10^{-03}$ \\
\hline LVLDLCEp & $-0.05(-0.09--0.01)$ & $1.18 \times 10^{-02}$ & $0.05(0.01-0.08)$ & $1.47 \times 10^{-02}$ & $-0.05(-0.08--0.01)$ & $2.61 \times 10^{-02}$ & $0.05(0.01-0.08)$ & $1.37 \times 10^{-02}$ \\
\hline LVLDLFCp & $-0.08(-0.12--0.05)$ & $3.28 \times 10^{-05}$ & $0.08(0.05-0.12)$ & $4.38 \times 10^{-06}$ & $-0.07(-0.11--0.03)$ & $8.14 \times 10^{-04}$ & $0.08(0.04-0.11)$ & $3.27 \times 10^{-05}$ \\
\hline LVLDLTGp & $-0.05(-0.09--0.02)$ & $9.30 \times 10^{-03}$ & $0.05(0.01-0.08)$ & $1.50 \times 10^{-02}$ & $-0.05(-0.08--0.01)$ & $2.76 \times 10^{-02}$ & $0.04(0.01-0.07)$ & $3.19 \times 10^{-02}$ \\
\hline MVLDLPLp & $0.09(0.05-0.12)$ & $2.41 \times 10^{-06}$ & $-0.08(-0.11-0.04)$ & $7.73 \times 10^{-06}$ & $0.07(0.04-0.10)$ & $4.33 \times 10^{-04}$ & $-0.06(-0.09--0.03)$ & $3.81 \times 10^{-04}$ \\
\hline MVLDLCp & $0.00(-0.04-0.03)$ & $9.76 \times 10^{-01}$ & $0.02(-0.01-0.05)$ & $3.27 \times 10^{-01}$ & $-0.01(-0.04-0.03)$ & $7.39 \times 10^{-01}$ & $0.04(0.00-0.07)$ & $4.29 \times 10^{-02}$ \\
\hline MVLDLCEp & $-0.01(-0.04-0.03)$ & $7.74 \times 10^{-01}$ & $0.01(-0.02-0.05)$ & $4.71 \times 10^{-01}$ & $-0.02(-0.05-0.02)$ & $4.75 \times 10^{-01}$ & $0.03(0.00-0.06)$ & $1.07 \times 10^{-01}$ \\
\hline MVLDLFCp & $-0.08(-0.11--0.04)$ & $5.61 \times 10^{-05}$ & $0.10(0.06-0.13)$ & $5.00 \times 10^{-08}$ & $-0.06(-0.10--0.03)$ & $2.25 \times 10^{-03}$ & $0.09(0.05-0.12)$ & $1.07 \times 10^{-06}$ \\
\hline MVLDLTGp & $-0.03(-0.06-0.00)$ & $1.32 \times 10^{-01}$ & $0.00(-0.03-0.03)$ & $9.77 \times 10^{-01}$ & $-0.02(-0.05-0.01)$ & $3.79 \times 10^{-01}$ & $-0.02(-0.05-0.01)$ & $2.37 \times 10^{-01}$ \\
\hline SVLDLPLp & $0.06(0.03-0.10)$ & $5.38 \times 10^{-04}$ & $-0.07(-0.10--0.04)$ & $6.59 \times 10^{-05}$ & $0.06(0.02-0.09)$ & $5.53 \times 10^{-03}$ & $-0.07(-0.10--0.04)$ & $1.15 \times 10^{-04}$ \\
\hline SVLDLCp & $0.03(-0.01-0.07)$ & $1.47 \times 10^{-01}$ & $-0.02(-0.05-0.02)$ & $3.43 \times 10^{-01}$ & $0.02(-0.02-0.05)$ & $4.94 \times 10^{-01}$ & $0.00(-0.03-0.04)$ & $8.65 \times 10^{-01}$ \\
\hline SVLDLCEp & $0.00(-0.03-0.04)$ & $8.31 \times 10^{-01}$ & $0.00(-0.03-0.04)$ & $9.60 \times 10^{-01}$ & $-0.01(-0.04-0.03)$ & $7.88 \times 10^{-01}$ & $0.02(-0.01-0.05)$ & $3.23 \times 10^{-01}$ \\
\hline SVLDLFCp & $0.07(0.03-0.10)$ & $2.43 \times 10^{-04}$ & $-0.03(-0.06-0.01)$ & $1.61 \times 10^{-01}$ & $0.06(0.02-0.09)$ & $3.07 \times 10^{-03}$ & $-0.02(-0.05-0.02)$ & $4.01 \times 10^{-01}$ \\
\hline SVLDLTGp & $-0.07(-0.11--0.04)$ & $1.13 \times 10^{-04}$ & $0.06(0.02-0.09)$ & $1.43 \times 10^{-03}$ & $-0.05(-0.09--0.02)$ & $5.27 \times 10^{-03}$ & $0.03(0.00-0.06)$ & $5.65 \times 10^{-02}$ \\
\hline XSVLDLPLp & $0.08(0.05-0.11)$ & $1.43 \times 10^{-05}$ & $-0.06(-0.09--0.03)$ & $5.40 \times 10^{-04}$ & $0.06(0.03-0.09)$ & $2.02 \times 10^{-03}$ & $-0.04(-0.07--0.01)$ & $2.09 \times 10^{-02}$ \\
\hline XSVLDLCp & $0.02(-0.01-0.06)$ & $3.14 \times 10^{-01}$ & $-0.04(-0.07-0.00)$ & $5.72 \times 10^{-02}$ & $0.00(-0.03-0.04)$ & $8.68 \times 10^{-01}$ & $-0.02(-0.05-0.02)$ & $3.76 \times 10^{-01}$ \\
\hline XSVLDLCEp & $-0.01(-0.05-0.03)$ & $6.56 \times 10^{-01}$ & $-0.01(-0.05-0.02)$ & $4.93 \times 10^{-01}$ & $-0.02(-0.06-0.01)$ & $2.77 \times 10^{-01}$ & $0.00(-0.03-0.03)$ & $9.24 \times 10^{-01}$ \\
\hline XSVLDLFCp & $0.09(0.06-0.13)$ & $2.00 \times 10^{-06}$ & $-0.08(-0.12--0.05)$ & $6.17 \times 10^{-06}$ & $0.07(0.03-0.10)$ & $6.74 \times 10^{-04}$ & $-0.06(-0.09--0.03)$ & $1.04 \times 10^{-03}$ \\
\hline XSVLDLTGp & $-0.06(-0.10--0.03)$ & $1.21 \times 10^{-03}$ & $0.06(0.03-0.10)$ & $3.27 \times 10^{-04}$ & $-0.04(-0.08--0.01)$ & $2.50 \times 10^{-02}$ & $0.04(0.01-0.08)$ & $1.40 \times 10^{-02}$ \\
\hline IDLPLp & $0.06(0.02-0.09)$ & $4.82 \times 10^{-03}$ & $-0.10(-0.13--0.06)$ & $6.88 \times 10^{-08}$ & $0.05(0.01-0.08)$ & $2.94 \times 10^{-02}$ & $-0.10(-0.13--0.07)$ & $3.23 \times 10^{-08}$ \\
\hline IDLCp & $0.02(-0.02-0.05)$ & $3.96 \times 10^{-01}$ & $-0.01(-0.05-0.02)$ & $4.84 \times 10^{-01}$ & $0.00(-0.03-0.04)$ & $9.69 \times 10^{-01}$ & $0.01(-0.02-0.04)$ & $6.03 \times 10^{-01}$ \\
\hline IDLCEp & $-0.02(-0.06-0.01)$ & $3.13 \times 10^{-01}$ & $0.04(0.00-0.07)$ & $5.72 \times 10^{-02}$ & $-0.03(-0.06-0.01)$ & $2.35 \times 10^{-01}$ & $0.05(0.02-0.08)$ & $4.86 \times 10^{-03}$ \\
\hline IDLFCp & $0.09(0.05-0.12)$ & $3.00 \times 10^{-06}$ & $-0.10(-0.14--0.07)$ & $3.75 \times 10^{-09}$ & $0.06(0.03-0.10)$ & $1.14 \times 10^{-03}$ & $-0.08(-0.11--0.05)$ & $3.31 \times 10^{-06}$ \\
\hline IDLTGp & $-0.05(-0.08--0.01)$ & $2.10 \times 10^{-02}$ & $0.06(0.02-0.09)$ & $1.72 \times 10^{-03}$ & $-0.03(-0.06-0.01)$ & $1.82 \times 10^{-01}$ & $0.04(0.00-0.07)$ & $4.24 \times 10^{-02}$ \\
\hline LLDLPLp & $-0.02(-0.06-0.02)$ & $3.34 \times 10^{-01}$ & $0.00(-0.03-0.04)$ & $9.62 \times 10^{-01}$ & $-0.01(-0.04-0.03)$ & $7.23 \times 10^{-01}$ & $-0.02(-0.05-0.01)$ & $2.17 \times 10^{-01}$ \\
\hline LLDLCp & $0.03(0.00-0.07)$ & $1.00 \times 10^{-01}$ & $-0.04(-0.07-0.00)$ & $5.89 \times 10^{-02}$ & $0.02(-0.02-0.05)$ & $4.98 \times 10^{-01}$ & $-0.01(-0.04-0.02)$ & $5.11 \times 10^{-01}$ \\
\hline LLDLCEp & $0.00(-0.04-0.03)$ & $9.21 \times 10^{-01}$ & $0.01(-0.02-0.05)$ & $4.92 \times 10^{-01}$ & $-0.01(-0.05-0.02)$ & $5.53 \times 10^{-01}$ & $0.03(0.00-0.07)$ & $5.90 \times 10^{-02}$ \\
\hline LLDLFCp & $0.08(0.04-0.11)$ & $8.24 \times 10^{-05}$ & $-0.12(-0.15--0.09)$ & $2.03 \times 10^{-11}$ & $0.05(0.02-0.09)$ & $9.16 \times 10^{-03}$ & $-0.11(-0.14--0.08)$ & $2.36 \times 10^{-09}$ \\
\hline LLDLTGp & $-0.04(-0.08-0.00)$ & $4.54 \times 10^{-02}$ & $0.05(0.02-0.09)$ & $4.70 \times 10^{-03}$ & $-0.02(-0.06-0.01)$ & $2.98 \times 10^{-01}$ & $0.03(0.00-0.07)$ & $6.67 \times 10^{-02}$ \\
\hline MLDLPLp & $-0.05(-0.09--0.02)$ & $1.07 \times 10^{-02}$ & $0.04(0.00-0.07)$ & $5.87 \times 10^{-02}$ & $-0.03(-0.07-0.00)$ & $8.50 \times 10^{-02}$ & $0.01(-0.02-0.04)$ & $5.48 \times 10^{-01}$ \\
\hline MLDLCp & $0.04(0.00-0.07)$ & $6.18 \times 10^{-02}$ & $-0.04(-0.08--0.01)$ & $2.28 \times 10^{-02}$ & $0.02(-0.01-0.06)$ & $3.00 \times 10^{-01}$ & $-0.02(-0.05-0.01)$ & $2.55 \times 10^{-01}$ \\
\hline MLDLCEp & $0.03(0.00-0.07)$ & $1.02 \times 10^{-01}$ & $-0.03(-0.07-0.00)$ & $1.17 \times 10^{-01}$ & $0.02(-0.02-0.05)$ & $4.14 \times 10^{-01}$ & $-0.01(-0.04-0.03)$ & $7.00 \times 10^{-01}$ \\
\hline MLDLFCp & $0.00(-0.03-0.04)$ & $8.67 \times 10^{-01}$ & $-0.02(-0.06-0.01)$ & $2.79 \times 10^{-01}$ & $0.01(-0.02-0.05)$ & $6.24 \times 10^{-01}$ & $-0.04(-0.07--0.01)$ & $2.53 \times 10^{-02}$ \\
\hline MLDLTGp & $-0.03(-0.07-0.00)$ & $1.07 \times 10^{-01}$ & $0.04(0.00-0.07)$ & $4.15 \times 10^{-02}$ & $-0.02(-0.05-0.02)$ & $4.37 \times 10^{-01}$ & $0.02(-0.01-0.06)$ & $2.29 \times 10^{-01}$ \\
\hline
\end{tabular}




\begin{tabular}{|c|c|c|c|c|c|c|c|c|}
\hline SLDLPLp & $-0.04(-0.07-0.00)$ & $6.18 \times 10^{-02}$ & $0.03(0.00-0.06)$ & $1.32 \times 10^{-01}$ & $-0.02(-0.06-0.01)$ & $2.77 \times 10^{-01}$ & $0.00(-0.03-0.04)$ & $7.90 \times 10^{-01}$ \\
\hline SLDLCp & $0.05(0.01-0.08)$ & $1.61 \times 10^{-02}$ & $-0.06(-0.10--0.03)$ & $1.19 \times 10^{-03}$ & $0.03(0.00-0.06)$ & $1.51 \times 10^{-01}$ & $-0.04(-0.07-0.00)$ & $4.17 \times 10^{-02}$ \\
\hline SLDLCEp & $0.04(0.00-0.08)$ & $4.63 \times 10^{-02}$ & $-0.05(-0.09--0.02)$ & $5.86 \times 10^{-03}$ & $0.02(-0.01-0.06)$ & $3.00 \times 10^{-01}$ & $-0.03(-0.06-0.00)$ & $1.29 \times 10^{-01}$ \\
\hline SLDLFCp & $0.01(-0.03-0.04)$ & $6.85 \times 10^{-01}$ & $-0.01(-0.05-0.02)$ & $5.24 \times 10^{-01}$ & $0.02(-0.02-0.05)$ & $4.75 \times 10^{-01}$ & $-0.03(-0.06-0.00)$ & $1.04 \times 10^{-01}$ \\
\hline SLDLTGp & $-0.06(-0.09--0.02)$ & $4.19 \times 10^{-03}$ & $0.08(0.05-0.12)$ & $9.34 \times 10^{-06}$ & $-0.04(-0.07-0.00)$ & $7.55 \times 10^{-02}$ & $0.06(0.03-0.10)$ & $5.93 \times 10^{-04}$ \\
\hline XLHDLPLp & $0.03(-0.01-0.06)$ & $2.09 \times 10^{-01}$ & $-0.01(-0.05-0.02)$ & $5.04 \times 10^{-01}$ & $0.01(-0.03-0.04)$ & $7.10 \times 10^{-01}$ & $0.00(-0.03-0.03)$ & $9.46 \times 10^{-01}$ \\
\hline XLHDLCp & $0.01(-0.03-0.04)$ & $8.28 \times 10^{-01}$ & $0.02(-0.02-0.05)$ & $3.43 \times 10^{-01}$ & $-0.01(-0.05-0.03)$ & $7.05 \times 10^{-01}$ & $0.03(0.00-0.06)$ & $1.08 \times 10^{-01}$ \\
\hline XLHDLCEp & $0.00(-0.03-0.04)$ & $9.03 \times 10^{-01}$ & $0.02(-0.01-0.05)$ & $3.05 \times 10^{-01}$ & $-0.01(-0.05-0.02)$ & $6.39 \times 10^{-01}$ & $0.03(0.00-0.07)$ & $9.24 \times 10^{-02}$ \\
\hline XLHDLFCp & $0.01(-0.02-0.05)$ & $6.15 \times 10^{-01}$ & $0.01(-0.02-0.05)$ & $4.76 \times 10^{-01}$ & $0.00(-0.04-0.03)$ & $8.78 \times 10^{-01}$ & $0.03(-0.01-0.06)$ & $1.59 \times 10^{-01}$ \\
\hline XLHDLTGp & $-0.05(-0.09--0.01)$ & $1.21 \times 10^{-02}$ & $0.09(0.05-0.12)$ & $2.66 \times 10^{-06}$ & $-0.05(-0.08--0.01)$ & $2.35 \times 10^{-02}$ & $0.09(0.05-0.12)$ & $1.79 \times 10^{-06}$ \\
\hline LHDLPLp & $0.00(-0.04-0.03)$ & $8.51 \times 10^{-01}$ & $0.00(-0.04-0.03)$ & $8.68 \times 10^{-01}$ & $-0.02(-0.05-0.02)$ & $4.61 \times 10^{-01}$ & $0.00(-0.03-0.03)$ & $9.57 \times 10^{-01}$ \\
\hline LHDLCp & $0.01(-0.02-0.05)$ & $5.86 \times 10^{-01}$ & $-0.01(-0.05-0.02)$ & $4.71 \times 10^{-01}$ & $0.00(-0.04-0.03)$ & $8.99 \times 10^{-01}$ & $-0.01(-0.04-0.03)$ & $6.84 \times 10^{-01}$ \\
\hline LHDLCEp & $0.01(-0.03-0.04)$ & $6.71 \times 10^{-01}$ & $-0.01(-0.05-0.02)$ & $5.18 \times 10^{-01}$ & $-0.01(-0.04-0.03)$ & $8.39 \times 10^{-01}$ & $-0.01(-0.04-0.03)$ & $7.53 \times 10^{-01}$ \\
\hline LHDLFCp & $0.03(0.00-0.07)$ & $8.99 \times 10^{-02}$ & $-0.03(-0.07-0.00)$ & $7.20 \times 10^{-02}$ & $0.02(-0.02-0.05)$ & $4.43 \times 10^{-01}$ & $-0.02(-0.06-0.01)$ & $1.97 \times 10^{-01}$ \\
\hline LHDLTGp & $-0.03(-0.07-0.00)$ & $9.90 \times 10^{-02}$ & $0.03(0.00-0.07)$ & $9.59 \times 10^{-02}$ & $-0.04(-0.08--0.01)$ & $4.93 \times 10^{-02}$ & $0.04(0.00-0.07)$ & $5.33 \times 10^{-02}$ \\
\hline MHDLPLp & $-0.05(-0.09--0.01)$ & $1.07 \times 10^{-02}$ & $0.04(0.01-0.07)$ & $3.34 \times 10^{-02}$ & $-0.04(-0.08--0.01)$ & $3.86 \times 10^{-02}$ & $0.04(0.00-0.07)$ & $4.14 \times 10^{-02}$ \\
\hline MHDLCp & $0.08(0.05-0.12)$ & $2.28 \times 10^{-05}$ & $-0.07(-0.10--0.04)$ & $8.40 \times 10^{-05}$ & $0.07(0.03-0.10)$ & $1.22 \times 10^{-03}$ & $-0.06(-0.10--0.03)$ & $4.69 \times 10^{-04}$ \\
\hline MHDLCEp & $0.08(0.04-0.11)$ & $8.18 \times 10^{-05}$ & $-0.07(-0.11--0.04)$ & $6.68 \times 10^{-05}$ & $0.06(0.03-0.10)$ & $2.25 \times 10^{-03}$ & $-0.07(-0.10--0.03)$ & $2.40 \times 10^{-04}$ \\
\hline MHDLFCp & $0.07(0.03-0.10)$ & $1.95 \times 10^{-04}$ & $-0.04(-0.07--0.01)$ & $1.54 \times 10^{-02}$ & $0.05(0.02-0.08)$ & $8.66 \times 10^{-03}$ & $-0.03(-0.06-0.00)$ & $7.56 \times 10^{-02}$ \\
\hline MHDLTGp & $-0.09(-0.13--0.06)$ & $2.00 \times 10^{-06}$ & $0.08(0.05-0.11)$ & $5.75 \times 10^{-06}$ & $-0.08(-0.11--0.04)$ & $2.59 \times 10^{-04}$ & $0.07(0.04-0.10)$ & $8.37 \times 10^{-05}$ \\
\hline SHDLPLp & $-0.07(-0.10--0.03)$ & $5.22 \times 10^{-04}$ & $0.07(0.03-0.10)$ & $2.02 \times 10^{-04}$ & $-0.05(-0.09--0.01)$ & $1.36 \times 10^{-02}$ & $0.05(0.02-0.08)$ & $7.63 \times 10^{-03}$ \\
\hline SHDLCp & $0.08(0.04-0.11)$ & $8.24 \times 10^{-05}$ & $-0.10(-0.13--0.06)$ & $8.61 \times 10^{-08}$ & $0.05(0.02-0.09)$ & $8.76 \times 10^{-03}$ & $-0.08(-0.11--0.04)$ & $2.10 \times 10^{-05}$ \\
\hline SHDLCEp & $0.07(0.04-0.11)$ & $1.56 \times 10^{-04}$ & $-0.09(-0.13--0.06)$ & $1.97 \times 10^{-07}$ & $0.05(0.02-0.09)$ & $1.25 \times 10^{-02}$ & $-0.07(-0.11--0.04)$ & $3.77 \times 10^{-05}$ \\
\hline SHDLFCp & $-0.04(-0.08--0.01)$ & $3.85 \times 10^{-02}$ & $0.07(0.04-0.11)$ & $4.85 \times 10^{-05}$ & $-0.02(-0.06-0.01)$ & $3.00 \times 10^{-01}$ & $0.05(0.02-0.09)$ & $2.39 \times 10^{-03}$ \\
\hline SHDLTGp & $-0.08(-0.12--0.05)$ & $2.12 \times 10^{-05}$ & $0.08(0.05-0.11)$ & $8.57 \times 10^{-06}$ & $-0.06(-0.10--0.03)$ & $1.85 \times 10^{-03}$ & $0.07(0.03-0.10)$ & $1.85 \times 10^{-04}$ \\
\hline VLDLD & $-0.11(-0.15--0.08)$ & $8.82 \times 10^{-09}$ & $0.11(0.08-0.14)$ & $1.35 \times 10^{-10}$ & $-0.09(-0.12--0.05)$ & $2.64 \times 10^{-05}$ & $0.09(0.06-0.12)$ & $1.43 \times 10^{-07}$ \\
\hline LDLD & $-0.01(-0.04-0.03)$ & $7.21 \times 10^{-01}$ & $0.00(-0.03-0.04)$ & $8.70 \times 10^{-01}$ & $-0.01(-0.05-0.03)$ & $6.92 \times 10^{-01}$ & $0.01(-0.03-0.04)$ & $7.00 \times 10^{-01}$ \\
\hline HDLD & $0.07(0.04-0.10)$ & $1.49 \times 10^{-05}$ & $-0.03(-0.06-0.00)$ & $4.36 \times 10^{-02}$ & $0.06(0.03-0.09)$ & $1.06 \times 10^{-03}$ & $-0.02(-0.04-0.01)$ & $3.17 \times 10^{-01}$ \\
\hline SerumC & $0.02(-0.02-0.05)$ & $3.49 \times 10^{-01}$ & $0.03(-0.01-0.06)$ & $1.61 \times 10^{-01}$ & $0.01(-0.02-0.04)$ & $6.67 \times 10^{-01}$ & $0.05(0.02-0.08)$ & $4.69 \times 10^{-03}$ \\
\hline VLDLC & $-0.08(-0.12--0.05)$ & $2.26 \times 10^{-05}$ & $0.10(0.06-0.13)$ & $1.04 \times 10^{-07}$ & $-0.07(-0.10--0.03)$ & $8.17 \times 10^{-04}$ & $0.09(0.06-0.13)$ & $2.10 \times 10^{-07}$ \\
\hline RemnantC & $-0.05(-0.09--0.01)$ & $1.30 \times 10^{-02}$ & $0.07(0.04-0.11)$ & $4.70 \times 10^{-05}$ & $-0.05(-0.08--0.01)$ & $2.69 \times 10^{-02}$ & $0.08(0.05-0.12)$ & $2.41 \times 10^{-06}$ \\
\hline LDLC & $0.02(-0.01-0.06)$ & $2.64 \times 10^{-01}$ & $0.00(-0.03-0.04)$ & $8.16 \times 10^{-01}$ & $0.01(-0.02-0.05)$ & $6.18 \times 10^{-01}$ & $0.03(0.00-0.06)$ & $1.24 \times 10^{-01}$ \\
\hline HDLC & $0.08(0.04-0.11)$ & $8.82 \times 10^{-06}$ & $-0.03(-0.06-0.00)$ & $4.24 \times 10^{-02}$ & $0.06(0.03-0.09)$ & $7.80 \times 10^{-04}$ & $-0.02(-0.05-0.01)$ & $2.44 \times 10^{-01}$ \\
\hline HDL2C & $0.07(0.04-0.10)$ & $1.23 \times 10^{-05}$ & $-0.03(-0.06--0.01)$ & $3.22 \times 10^{-02}$ & $0.06(0.03-0.09)$ & $9.39 \times 10^{-04}$ & $-0.02(-0.05-0.01)$ & $2.01 \times 10^{-01}$ \\
\hline HDL3C & $0.07(0.04-0.10)$ & $5.42 \times 10^{-05}$ & $-0.01(-0.04-0.02)$ & $4.71 \times 10^{-01}$ & $0.06(0.03-0.09)$ & $9.39 \times 10^{-04}$ & $0.00(-0.03-0.03)$ & $9.52 \times 10^{-01}$ \\
\hline EstC & $0.02(-0.01-0.06)$ & $2.36 \times 10^{-01}$ & $0.03(-0.01-0.06)$ & $1.74 \times 10^{-01}$ & $0.01(-0.02-0.05)$ & $5.06 \times 10^{-01}$ & $0.05(0.02-0.08)$ & $5.81 \times 10^{-03}$ \\
\hline FreeC & $0.01(-0.03-0.04)$ & $7.96 \times 10^{-01}$ & $0.03(-0.01-0.06)$ & $1.43 \times 10^{-01}$ & $0.00(-0.04-0.03)$ & $9.10 \times 10^{-01}$ & $0.05(0.02-0.08)$ & $4.69 \times 10^{-03}$ \\
\hline SerumTG & $-0.10(-0.14--0.07)$ & $1.52 \times 10^{-07}$ & $0.12(0.08-0.15)$ & $8.16 \times 10^{-11}$ & $-0.08(-0.12--0.05)$ & $1.48 \times 10^{-04}$ & $0.10(0.07-0.14)$ & $9.38 \times 10^{-09}$ \\
\hline
\end{tabular}




\begin{tabular}{|c|c|c|c|c|c|c|c|c|}
\hline VLDLTG & $-0.10(-0.14--0.07)$ & $1.21 \times 10^{-07}$ & $0.11(0.08-0.15)$ & $6.39 \times 10^{-11}$ & $-0.08(-0.12--0.05)$ & $1.16 \times 10^{-04}$ & $0.10(0.07-0.13)$ & $1.05 \times 10^{-08}$ \\
\hline LDLTG & $-0.03(-0.07-0.00)$ & $1.11 \times 10^{-01}$ & $0.06(0.03-0.10)$ & $4.05 \times 10^{-04}$ & $-0.02(-0.06-0.01)$ & $2.77 \times 10^{-01}$ & $0.07(0.04-0.10)$ & $1.26 \times 10^{-04}$ \\
\hline HDLTG & $-0.08(-0.11-0.04)$ & $5.61 \times 10^{-05}$ & $0.11(0.07-0.14)$ & $2.99 \times 10^{-09}$ & $-0.06(-0.10--0.03)$ & $3.00 \times 10^{-03}$ & $0.10(0.07-0.14)$ & $3.23 \times 10^{-08}$ \\
\hline DAG & $-0.09(-0.13--0.05)$ & $1.54 \times 10^{-05}$ & $0.05(0.01-0.09)$ & $1.29 \times 10^{-02}$ & $-0.08(-0.12--0.04)$ & $6.50 \times 10^{-04}$ & $0.04(0.00-0.08)$ & $4.75 \times 10^{-02}$ \\
\hline DAGTG & $-0.04(-0.08-0.00)$ & $5.43 \times 10^{-02}$ & $-0.01(-0.05-0.02)$ & $5.24 \times 10^{-01}$ & $-0.04(-0.08-0.00)$ & $9.90 \times 10^{-02}$ & $-0.02(-0.05-0.02)$ & $4.11 \times 10^{-01}$ \\
\hline TotPG & $-0.02(-0.05-0.02)$ & $3.50 \times 10^{-01}$ & $0.07(0.04-0.10)$ & $9.80 \times 10^{-05}$ & $-0.02(-0.05-0.02)$ & $4.75 \times 10^{-01}$ & $0.07(0.04-0.11)$ & $1.52 \times 10^{-05}$ \\
\hline TGPG & $-0.11(-0.14--0.07)$ & $3.14 \times 10^{-08}$ & $0.11(0.07-0.14)$ & $1.10 \times 10^{-09}$ & $-0.08(-0.12--0.05)$ & $9.26 \times 10^{-05}$ & $0.09(0.05-0.12)$ & $6.92 \times 10^{-07}$ \\
\hline PC & $-0.01(-0.05-0.02)$ & $6.13 \times 10^{-01}$ & $0.07(0.04-0.11)$ & $3.11 \times 10^{-05}$ & $-0.01(-0.04-0.03)$ & $7.23 \times 10^{-01}$ & $0.08(0.05-0.11)$ & $2.29 \times 10^{-06}$ \\
\hline SM & $0.00(-0.04-0.03)$ & $9.43 \times 10^{-01}$ & $-0.01(-0.04-0.03)$ & $7.72 \times 10^{-01}$ & $-0.01(-0.04-0.02)$ & $5.95 \times 10^{-01}$ & $0.01(-0.02-0.04)$ & $6.03 \times 10^{-01}$ \\
\hline TotCho & $-0.02(-0.05-0.02)$ & $4.41 \times 10^{-01}$ & $0.04(0.01-0.07)$ & $3.17 \times 10^{-02}$ & $-0.01(-0.05-0.02)$ & $5.07 \times 10^{-01}$ & $0.05(0.01-0.08)$ & $1.04 \times 10^{-02}$ \\
\hline ApoA1 & $0.05(0.02-0.08)$ & $3.21 \times 10^{-03}$ & $0.01(-0.02-0.04)$ & $4.76 \times 10^{-01}$ & $0.04(0.01-0.07)$ & $2.15 \times 10^{-02}$ & $0.03(0.00-0.06)$ & $8.98 \times 10^{-02}$ \\
\hline ApoB & $-0.05(-0.08--0.01)$ & $1.55 \times 10^{-02}$ & $0.08(0.04-0.11)$ & $2.18 \times 10^{-05}$ & $-0.04(-0.08--0.01)$ & $3.86 \times 10^{-02}$ & $0.09(0.05-0.12)$ & $1.61 \times 10^{-06}$ \\
\hline ApoBApoA1 & $-0.07(-0.11--0.04)$ & $1.05 \times 10^{-04}$ & $0.07(0.04-0.10)$ & $6.67 \times 10^{-05}$ & $-0.06(-0.10--0.03)$ & $1.54 \times 10^{-03}$ & $0.07(0.04-0.10)$ & $6.22 \times 10^{-05}$ \\
\hline TotFA & $-0.06(-0.10--0.02)$ & $2.23 \times 10^{-03}$ & $0.11(0.07-0.14)$ & $4.38 \times 10^{-09}$ & $-0.05(-0.08--0.01)$ & $1.95 \times 10^{-02}$ & $0.11(0.07-0.14)$ & $5.43 \times 10^{-09}$ \\
\hline FALen & $-0.06(-0.10--0.02)$ & $6.64 \times 10^{-03}$ & $0.04(0.00-0.07)$ & $7.08 \times 10^{-02}$ & $-0.04(-0.08-0.00)$ & $5.95 \times 10^{-02}$ & $0.01(-0.02-0.05)$ & $4.56 \times 10^{-01}$ \\
\hline UnSat & $0.08(0.04-0.12)$ & $4.14 \times 10^{-05}$ & $-0.10(-0.13--0.06)$ & $6.88 \times 10^{-08}$ & $0.06(0.03-0.10)$ & $2.11 \times 10^{-03}$ & $-0.09(-0.13--0.06)$ & $4.06 \times 10^{-07}$ \\
\hline DHA & $0.02(-0.02-0.05)$ & $3.64 \times 10^{-01}$ & $0.01(-0.02-0.05)$ & $4.85 \times 10^{-01}$ & $0.02(-0.02-0.05)$ & $4.74 \times 10^{-01}$ & $0.02(-0.02-0.05)$ & $4.07 \times 10^{-01}$ \\
\hline LA & $-0.02(-0.06-0.01)$ & $2.64 \times 10^{-01}$ & $0.05(0.01-0.08)$ & $1.50 \times 10^{-02}$ & $-0.03(-0.06-0.00)$ & $1.50 \times 10^{-01}$ & $0.06(0.03-0.09)$ & $5.61 \times 10^{-04}$ \\
\hline CLA & $-0.06(-0.09--0.02)$ & $9.19 \times 10^{-03}$ & $0.06(0.02-0.10)$ & $2.11 \times 10^{-03}$ & $-0.05(-0.09--0.01)$ & $2.50 \times 10^{-02}$ & $0.06(0.02-0.09)$ & $3.04 \times 10^{-03}$ \\
\hline FAw3 & $0.01(-0.03-0.04)$ & $6.84 \times 10^{-01}$ & $0.04(0.00-0.07)$ & $5.90 \times 10^{-02}$ & $0.01(-0.03-0.05)$ & $6.67 \times 10^{-01}$ & $0.04(0.01-0.07)$ & $3.55 \times 10^{-02}$ \\
\hline FAw6 & $-0.02(-0.06-0.01)$ & $2.57 \times 10^{-01}$ & $0.05(0.02-0.09)$ & $3.57 \times 10^{-03}$ & $-0.03(-0.06-0.01)$ & $2.25 \times 10^{-01}$ & $0.07(0.03-0.10)$ & $2.57 \times 10^{-04}$ \\
\hline PUFA & $-0.02(-0.06-0.02)$ & $3.49 \times 10^{-01}$ & $0.05(0.02-0.09)$ & $4.00 \times 10^{-03}$ & $-0.02(-0.06-0.01)$ & $3.31 \times 10^{-01}$ & $0.06(0.03-0.10)$ & $3.52 \times 10^{-04}$ \\
\hline MUFA & $-0.08(-0.11--0.04)$ & $8.18 \times 10^{-05}$ & $0.11(0.08-0.15)$ & $1.51 \times 10^{-10}$ & $-0.06(-0.09--0.02)$ & $5.27 \times 10^{-03}$ & $0.11(0.07-0.14)$ & $3.65 \times 10^{-09}$ \\
\hline SFA & $-0.06(-0.10--0.03)$ & $1.23 \times 10^{-03}$ & $0.12(0.08-0.15)$ & $1.78 \times 10^{-10}$ & $-0.05(-0.09--0.01)$ & $1.74 \times 10^{-02}$ & $0.11(0.08-0.15)$ & $6.69 \times 10^{-10}$ \\
\hline DHAFA & $0.07(0.04-0.11)$ & $2.66 \times 10^{-04}$ & $-0.05(-0.08--0.02)$ & $6.32 \times 10^{-03}$ & $0.06(0.02-0.09)$ & $4.02 \times 10^{-03}$ & $-0.05(-0.08--0.01)$ & $1.14 \times 10^{-02}$ \\
\hline LAFA & $0.06(0.03-0.10)$ & $1.12 \times 10^{-03}$ & $-0.09(-0.13--0.06)$ & $5.00 \times 10^{-08}$ & $0.03(0.00-0.06)$ & $1.11 \times 10^{-01}$ & $-0.07(-0.10--0.04)$ & $2.39 \times 10^{-05}$ \\
\hline CLAFA & $-0.03(-0.07-0.01)$ & $1.38 \times 10^{-01}$ & $0.03(-0.01-0.06)$ & $2.25 \times 10^{-01}$ & $-0.03(-0.07-0.01)$ & $1.82 \times 10^{-01}$ & $0.02(-0.01-0.06)$ & $2.32 \times 10^{-01}$ \\
\hline FAw3FA & $0.08(0.04-0.11)$ & $7.23 \times 10^{-05}$ & $-0.05(-0.08--0.01)$ & $1.18 \times 10^{-02}$ & $0.07(0.03-0.10)$ & $1.14 \times 10^{-03}$ & $-0.04(-0.07--0.01)$ & $2.67 \times 10^{-02}$ \\
\hline FAw6FA & $0.08(0.04-0.11)$ & $2.30 \times 10^{-05}$ & $-0.11(-0.15--0.08)$ & $4.03 \times 10^{-11}$ & $0.05(0.02-0.08)$ & $9.16 \times 10^{-03}$ & $-0.09(-0.13--0.06)$ & $3.23 \times 10^{-08}$ \\
\hline PUFAFA & $0.09(0.06-0.12)$ & $1.96 \times 10^{-06}$ & $-0.12(-0.15--0.09)$ & $1.30 \times 10^{-11}$ & $0.06(0.03-0.10)$ & $1.86 \times 10^{-03}$ & $-0.10(-0.13--0.07)$ & $1.21 \times 10^{-08}$ \\
\hline MUFAFA & $-0.07(-0.11--0.04)$ & $1.14 \times 10^{-04}$ & $0.08(0.05-0.11)$ & $4.03 \times 10^{-06}$ & $-0.05(-0.09--0.02)$ & $1.21 \times 10^{-02}$ & $0.06(0.03-0.10)$ & $2.46 \times 10^{-04}$ \\
\hline SFAFA & $-0.03(-0.07-0.00)$ & $1.01 \times 10^{-01}$ & $0.06(0.03-0.10)$ & $4.86 \times 10^{-04}$ & $-0.02(-0.06-0.01)$ & $3.00 \times 10^{-01}$ & $0.06(0.02-0.09)$ & $1.67 \times 10^{-03}$ \\
\hline Glc & $-0.08(-0.12--0.05)$ & $2.16 \times 10^{-05}$ & $0.06(0.02-0.09)$ & $1.39 \times 10^{-03}$ & $-0.06(-0.10--0.03)$ & $1.29 \times 10^{-03}$ & $0.04(0.00-0.07)$ & $4.14 \times 10^{-02}$ \\
\hline Lac & $-0.11(-0.14--0.07)$ & $5.70 \times 10^{-08}$ & $0.11(0.08-0.14)$ & $7.09 \times 10^{-10}$ & $-0.10(-0.13--0.06)$ & $9.42 \times 10^{-06}$ & $0.09(0.06-0.13)$ & $1.43 \times 10^{-07}$ \\
\hline Cit & $0.01(-0.03-0.04)$ & $7.77 \times 10^{-01}$ & $-0.06(-0.09--0.03)$ & $8.97 \times 10^{-04}$ & $0.00(-0.03-0.04)$ & $8.77 \times 10^{-01}$ & $-0.06(-0.09--0.03)$ & $9.88 \times 10^{-04}$ \\
\hline Ala & $-0.07(-0.11--0.03)$ & $4.37 \times 10^{-04}$ & $0.11(0.07-0.14)$ & $2.36 \times 10^{-09}$ & $-0.06(-0.09--0.02)$ & $8.27 \times 10^{-03}$ & $0.10(0.06-0.13)$ & $1.95 \times 10^{-07}$ \\
\hline Gln & $0.04(0.01-0.08)$ & $4.06 \times 10^{-02}$ & $-0.06(-0.09--0.03)$ & $1.19 \times 10^{-03}$ & $0.03(0.00-0.07)$ & $1.19 \times 10^{-01}$ & $-0.05(-0.09--0.02)$ & $4.69 \times 10^{-03}$ \\
\hline His & $0.02(-0.01-0.06)$ & $2.84 \times 10^{-01}$ & $0.01(-0.02-0.05)$ & $4.71 \times 10^{-01}$ & $0.02(-0.02-0.06)$ & $3.80 \times 10^{-01}$ & $0.02(-0.01-0.05)$ & $3.10 \times 10^{-01}$ \\
\hline
\end{tabular}




\begin{tabular}{|c|c|c|c|c|c|c|c|c|}
\hline Ile & $-0.11(-0.14-0.08)$ & $1.80 \times 10^{-09}$ & $0.10(0.07-0.13)$ & $2.14 \times 10^{-10}$ & $-0.09(-0.12--0.06)$ & $5.15 \times 10^{-06}$ & $0.09(0.06-0.12)$ & $1.01 \times 10^{-07}$ \\
\hline Leu & $-0.09(-0.12--0.06)$ & $1.67 \times 10^{-07}$ & $0.10(0.07-0.13)$ & $6.39 \times 10^{-11}$ & $-0.07(-0.11-0.04)$ & $1.03 \times 10^{-04}$ & $0.09(0.06-0.12)$ & $2.44 \times 10^{-08}$ \\
\hline Val & $-0.05(-0.08--0.02)$ & $2.79 \times 10^{-03}$ & $0.05(0.02-0.08)$ & $1.33 \times 10^{-03}$ & $-0.05(-0.08--0.02)$ & $8.76 \times 10^{-03}$ & $0.04(0.01-0.07)$ & $9.36 \times 10^{-03}$ \\
\hline Phe & $-0.08(-0.12--0.05)$ & $1.10 \times 10^{-05}$ & $0.07(0.03-0.10)$ & $2.20 \times 10^{-04}$ & $-0.07(-0.11-0.04)$ & $4.33 \times 10^{-04}$ & $0.06(0.02-0.09)$ & $2.30 \times 10^{-03}$ \\
\hline Tyr & $-0.07(-0.10--0.03)$ & $4.16 \times 10^{-04}$ & $0.06(0.03-0.09)$ & $1.12 \times 10^{-03}$ & $-0.06(-0.10--0.02)$ & $3.23 \times 10^{-03}$ & $0.05(0.02-0.08)$ & $4.94 \times 10^{-03}$ \\
\hline Ace & $0.05(0.02-0.09)$ & $6.64 \times 10^{-03}$ & $-0.07(-0.10--0.04)$ & $1.34 \times 10^{-04}$ & $0.05(0.01-0.08)$ & $2.55 \times 10^{-02}$ & $-0.06(-0.09--0.03)$ & $1.05 \times 10^{-03}$ \\
\hline bOHBut & $-0.02(-0.05-0.02)$ & $4.49 \times 10^{-01}$ & $-0.04(-0.07-0.00)$ & $5.46 \times 10^{-02}$ & $-0.02(-0.05-0.02)$ & $4.64 \times 10^{-01}$ & $-0.04(-0.07--0.01)$ & $3.50 \times 10^{-02}$ \\
\hline Crea & $0.00(-0.03-0.03)$ & $8.97 \times 10^{-01}$ & $0.05(0.02-0.08)$ & $2.42 \times 10^{-03}$ & $0.01(-0.03-0.04)$ & $7.92 \times 10^{-01}$ & $0.05(0.02-0.08)$ & $2.86 \times 10^{-03}$ \\
\hline Alb & $0.01(-0.02-0.05)$ & $5.28 \times 10^{-01}$ & $0.00(-0.03-0.04)$ & $9.39 \times 10^{-01}$ & $0.00(-0.03-0.04)$ & $9.30 \times 10^{-01}$ & $0.00(-0.03-0.04)$ & $9.24 \times 10^{-01}$ \\
\hline $\mathrm{Gp}$ & $-0.15(-0.18--0.11)$ & $4.01 \times 10^{-14}$ & $0.11(0.08-0.14)$ & $7.39 \times 10^{-10}$ & $-0.12(-0.16--0.09)$ & $3.81 \times 10^{-09}$ & $0.09(0.06-0.12)$ & $4.89 \times 10^{-07}$ \\
\hline
\end{tabular}

Supplemental table 3. The linear regression analysis of the association between the sum score of the symptoms extracted from the metabolitesymptom clustering step and the cardiometabolic endpoints.

\begin{tabular}{|c|c|c|c|c|c|c|c|c|c|}
\hline & & \multicolumn{2}{|c|}{ Crude } & \multicolumn{2}{|c|}{ Model 1} & \multicolumn{2}{|c|}{ Model 2} & \multicolumn{2}{|c|}{ Model 3} \\
\hline & & $\begin{array}{c}\text { Overall } \\
\text { Depression }\end{array}$ & IMD & $\begin{array}{c}\text { Overall } \\
\text { Depression }\end{array}$ & IMD & $\begin{array}{c}\text { Overall } \\
\text { Depression }\end{array}$ & IMD & $\begin{array}{c}\text { Overall } \\
\text { Depression }\end{array}$ & IMD \\
\hline $\begin{array}{l}\text { Cardiometabolic } \\
\text { endpoints }\end{array}$ & SD & $\beta(95 \% \mathrm{CI})$ & $\beta(95 \% \mathrm{CI})$ & $\beta(95 \% \mathrm{CI})$ & $\beta(95 \% \mathrm{CI})$ & $\beta(95 \% \mathrm{CI})$ & $\beta(95 \% \mathrm{CI})$ & $\beta(95 \% \mathrm{CI})$ & $\beta(95 \% \mathrm{CI})$ \\
\hline BMI $\left(\mathrm{kg} / \mathrm{m}^{2}\right)$ & 4.43 & $\begin{array}{c}-0.17 \\
(-0.20--0.13)\end{array}$ & $\begin{array}{c}0.13 \\
(0.09-0.16)\end{array}$ & $\begin{array}{c}-0.16 \\
(-0.19--0.12)\end{array}$ & $\begin{array}{c}0.11 \\
(0.08-0.15)\end{array}$ & $\begin{array}{c}-0.15 \\
(-0.19--0.12)\end{array}$ & $\begin{array}{c}0.11 \\
(0.07-0.14)\end{array}$ & $\begin{array}{c}-0.13 \\
(-0.17--0.09)\end{array}$ & $\begin{array}{c}0.10 \\
(0.06-0.13)\end{array}$ \\
\hline $\begin{array}{c}\text { Total body fat } \\
(\%)\end{array}$ & 8.62 & $\begin{array}{c}-0.08 \\
(-0.12--0.05)\end{array}$ & $\begin{array}{c}0.30 \\
(0.27-0.33)\end{array}$ & $\begin{array}{c}-0.11 \\
(-0.13--0.09)\end{array}$ & $\begin{array}{c}0.09 \\
(0.06-0.11)\end{array}$ & $\begin{array}{c}-0.11 \\
(-0.13--0.09)\end{array}$ & $\begin{array}{c}0.08 \\
(0.06-0.11)\end{array}$ & $\begin{array}{c}-0.09 \\
(-0.12--0.07)\end{array}$ & $\begin{array}{c}0.07 \\
(0.05-0.10)\end{array}$ \\
\hline
\end{tabular}




\begin{tabular}{|c|c|c|c|c|c|c|c|c|c|}
\hline $\begin{array}{c}\text { Waist } \\
\text { circumference } \\
(\mathrm{cm})\end{array}$ & 13.34 & $\begin{array}{c}-0.17 \\
(-0.20--0.13)\end{array}$ & $\begin{array}{c}0.04 \\
(0.01-0.07)\end{array}$ & $\begin{array}{c}-0.16 \\
(-0.19--0.12)\end{array}$ & $\begin{array}{c}0.12 \\
(0.09-0.15)\end{array}$ & $\begin{array}{c}-0.15 \\
(-0.18--0.12)\end{array}$ & $\begin{array}{c}0.11 \\
(0.08-0.15)\end{array}$ & $\begin{array}{c}-0.13 \\
(-0.16--0.09)\end{array}$ & $\begin{array}{c}0.10 \\
(0.07-0.13)\end{array}$ \\
\hline $\begin{array}{l}\text { Visceral adipose } \\
\text { tissue }\left(\mathrm{cm}^{2}\right)^{*}\end{array}$ & 13.34 & $\begin{array}{c}-0.17 \\
(-0.23--0.11)\end{array}$ & $\begin{array}{c}0.02 \\
(-0.03-0.08)\end{array}$ & $\begin{array}{c}-0.15 \\
(-0.20--0.10)\end{array}$ & $\begin{array}{c}0.11 \\
(0.06-0.16)\end{array}$ & $\begin{array}{c}-0.14 \\
(-0.20--0.09)\end{array}$ & $\begin{array}{c}0.09 \\
(0.04-0.14)\end{array}$ & $\begin{array}{c}-0.12 \\
(-0.18--0.07)\end{array}$ & $\begin{array}{c}0.07 \\
(0.02-0.12)\end{array}$ \\
\hline $\begin{array}{l}\text { Fasting glucose } \\
\quad(\mathrm{mmol} / \mathrm{L})\end{array}$ & 0.96 & $\begin{array}{c}-0.07 \\
(-0.10--0.03)\end{array}$ & $\begin{array}{c}0.06 \\
(0.03-0.10)\end{array}$ & $\begin{array}{c}-0.08 \\
(-0.11--0.04)\end{array}$ & $\begin{array}{c}0.08 \\
(0.05-0.11)\end{array}$ & $\begin{array}{c}-0.07 \\
(-0.11--0.04)\end{array}$ & $\begin{array}{c}0.08 \\
(0.05-0.11)\end{array}$ & $\begin{array}{c}-0.05 \\
(-0.09--0.02)\end{array}$ & $\begin{array}{c}0.06 \\
(0.03-0.09)\end{array}$ \\
\hline HOMA-1B & 67.52 & $\begin{array}{c}-0.11 \\
(-0.14--0.07)\end{array}$ & $\begin{array}{c}0.06 \\
(0.03-0.10)\end{array}$ & $\begin{array}{c}-0.09 \\
(-0.13--0.06)\end{array}$ & $\begin{array}{c}0.08 \\
(0.05-0.12)\end{array}$ & $\begin{array}{c}-0.08 \\
(-0.12--0.05)\end{array}$ & $\begin{array}{c}0.08 \\
(0.04-0.11)\end{array}$ & $\begin{array}{c}-0.08 \\
(-0.12--0.05)\end{array}$ & $\begin{array}{c}0.07 \\
(0.04-0.11)\end{array}$ \\
\hline HOMA-IR & 0.96 & $\begin{array}{c}-0.10 \\
(-0.14--0.07)\end{array}$ & $\begin{array}{c}0.08 \\
(0.05-0.11)\end{array}$ & $\begin{array}{c}-0.10 \\
(-0.14--0.07)\end{array}$ & $\begin{array}{c}0.10 \\
(0.06-0.13)\end{array}$ & $\begin{array}{c}-0.10 \\
(-0.13--0.06)\end{array}$ & $\begin{array}{c}0.09 \\
(0.06-0.13)\end{array}$ & $\begin{array}{c}-0.08 \\
(-0.12--0.04)\end{array}$ & $\begin{array}{c}0.08 \\
(0.05-0.12)\end{array}$ \\
\hline HbAlc (\%) & 0.46 & $\begin{array}{c}-0.10 \\
(-0.13--0.06)\end{array}$ & $\begin{array}{c}0.09 \\
(0.06-0.13)\end{array}$ & $\begin{array}{c}-0.11 \\
(-0.15--0.08)\end{array}$ & $\begin{array}{c}0.09 \\
(0.05-0.12)\end{array}$ & $\begin{array}{c}-0.09 \\
(-0.13--0.06)\end{array}$ & $\begin{array}{c}0.09 \\
(0.05-0.12)\end{array}$ & $\begin{array}{c}-0.08 \\
(-0.11--0.04)\end{array}$ & $\begin{array}{c}0.07 \\
(0.04-0.10)\end{array}$ \\
\hline $\begin{array}{l}\text { Total cholesterol } \\
\qquad(\mathrm{mmol} / \mathrm{L})\end{array}$ & 1.05 & $\begin{array}{c}0.02 \\
(-0.02-0.05)\end{array}$ & $\begin{array}{c}0.08 \\
(0.05-0.11)\end{array}$ & $\begin{array}{c}0.00 \\
(-0.03-0.04)\end{array}$ & $\begin{array}{c}0.04 \\
(0.01-0.07)\end{array}$ & $\begin{array}{c}0.00 \\
(-0.04-0.03)\end{array}$ & $\begin{array}{c}0.04 \\
(0.00-0.07)\end{array}$ & $\begin{array}{c}-0.01 \\
(-0.04-0.03)\end{array}$ & $\begin{array}{c}0.06 \\
(0.03-0.09)\end{array}$ \\
\hline $\begin{array}{l}\text { HDL-cholesterol } \\
\qquad(\mathrm{mmol} / \mathrm{L})\end{array}$ & 0.46 & $\begin{array}{c}0.13 \\
(0.10-0.17)\end{array}$ & $\begin{array}{c}0.09 \\
(0.06-0.13)\end{array}$ & $\begin{array}{c}0.10 \\
(0.07-0.13)\end{array}$ & $\begin{array}{c}-0.04 \\
(-0.07--0.01)\end{array}$ & $\begin{array}{c}0.07 \\
(0.04-0.10)\end{array}$ & $\begin{array}{c}-0.03 \\
(-0.06-0.00)\end{array}$ & $\begin{array}{c}0.06 \\
(0.03-0.09)\end{array}$ & $\begin{array}{c}-0.02 \\
(-0.05-0.01)\end{array}$ \\
\hline $\begin{array}{l}\text { Triglycerides } \\
(\mathrm{mmol} / \mathrm{L})\end{array}$ & 0.84 & $\begin{array}{c}-0.13 \\
(-0.17--0.10)\end{array}$ & $\begin{array}{c}0.06 \\
(0.03-0.10)\end{array}$ & $\begin{array}{c}-0.12 \\
(-0.16--0.09)\end{array}$ & $\begin{array}{c}0.12 \\
(0.09-0.15)\end{array}$ & $\begin{array}{c}-0.11 \\
(-0.14--0.07)\end{array}$ & $\begin{array}{c}0.12 \\
(0.08-0.15)\end{array}$ & $\begin{array}{c}-0.09 \\
(-0.12--0.05)\end{array}$ & $\begin{array}{c}0.11 \\
(0.07-0.14)\end{array}$ \\
\hline $\begin{array}{l}\text { LDL-cholesterol } \\
\qquad(\mathrm{mmol} / \mathrm{L})\end{array}$ & 0.96 & $\begin{array}{c}0.02 \\
(-0.01-0.06)\end{array}$ & $\begin{array}{c}0.02 \\
(-0.01-0.05)\end{array}$ & $\begin{array}{c}0.02 \\
(-0.02-0.05)\end{array}$ & $\begin{array}{c}0.00 \\
(-0.03-0.04)\end{array}$ & $\begin{array}{c}0.02 \\
(-0.02-0.05)\end{array}$ & $\begin{array}{c}0.00 \\
(-0.03-0.04)\end{array}$ & $\begin{array}{c}0.01 \\
(-0.03-0.04)\end{array}$ & $\begin{array}{c}0.02 \\
(-0.01-0.06)\end{array}$ \\
\hline
\end{tabular}


Number of individuals with data for BMI: 6572, Total body fat: 6541, Waist circumference: 6566, Visceral adipose tissue: 1869, Fasting glucose: 6554,

HOMA-1B: 6541, HOMA-IR: 6545, HbA1c: 6543, Total cholesterol: 6562, HDL-cholesterol: 6561, Triglycerides: 6561, LDL-cholesterol: 6560. Model 1:

adjusted for age, sex, and education. Model 2 adjusted for, age, sex, education, smoking, alcohol consumption, caloric intake, and physical activity. Model 3

adjusted for, age, sex, education, smoking, alcohol consumption, caloric intake, physical activity, lipid lowering drugs, and. antidepressants. 